
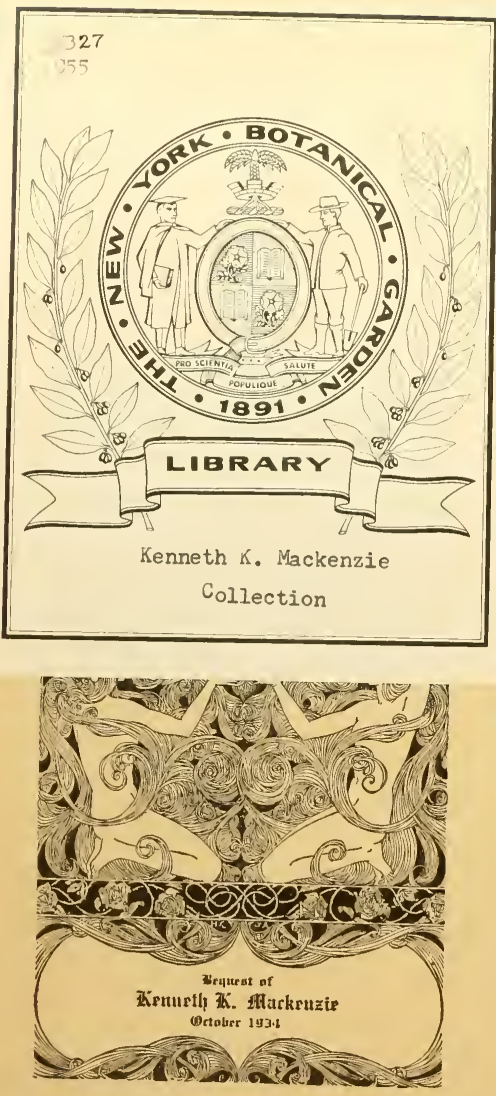


\section{SERTULUII ORENTALE}

SEIV

RECENSIO PLAVTARL II OLYHPO BITIYYICO, IN AgRo BYLANTINO

ET II LLENICO

NONNULLISQUE ALIIS ORIENTIS REGIONIBLS

ANNIS $1849-1850$

\section{JOSEPHO CLEIENTI}

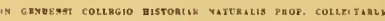

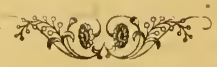

TAURIM I

EI OFICINA REGIA

1855. 
QK $3=$

a $=5$

Memorie della Reale Accademia delle Scienzr SERIE II. TOM. XVI

10693 


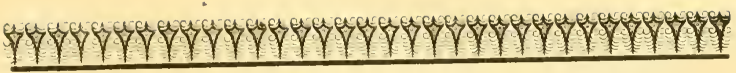

P I A E A T I O

Estate 1849 Anconam oppidum, Austriacis eo ingruentibus, invite salutans, Corcyram insulam primum, deinde Graeciam, Thraciam, nonnullasque Asiae minoris regiones adivi. Ob Patriae conculcatae moerorem, profunde vehementerque animo fractus, studiis gravioribus impar, in hac mea peregrinatione colligendis stirpibus minus notis vel earum regionum rarioribus operam dedi.

Corcyrae litora omnia, ejusdemque montem altiorem Pandokratora nuncupatum, pluries investigavi.

Athenis deinde menses septem commoratus, planitiem paene universam, Piraeei et Phalerei litora nec non montes Parnis, Pentilicum et $\mathrm{Hy}$ mettum septentrionalem meridionalemque perlustravi.

Eodeu anno 1850 , a vere exeunte in aestatem, Byzantii suburbia, terrasque remotiores Pontum Euxinum pertingentes, oram Bosphori orientalen 
vel Bosphorum ultra Scutarianam ditionem ad Cianliciae usque verticem, Katikioi (Chalcedonia) ct Phanaraki litora, cunctis fere diebus, rimatus sum.

Quae omnia citra ultraque Bosphorum loca admodum argillosa, platanis aliquot giganteis, quac fontes diligunt et exornant, exceptis, sterilitate el vastatione miserrimis afliguntur!

Augusto mense ejnsdem anni Brussam asiaticam petii; et primum hujusce regionis colles occidentales ad pagum Demerdesch apricos et calidissimos, accurate investigavi. Deinde Olympum bithynicum conscendi ct in regione abietum superiore occidentali-meridionali, et speciatim in tugurio Domini Fazchesn, veluti in centro, ex quo loca pervaria singillatim perquirere minus arduum erat, per dies sexdecim commoratus sum.

Juga olympica a N. E. ad S. O. longe progrediuntur et in ipsam Brussam (ivitatem, sex circiter miliariis a mare dissitam, pedem ad meridien immittunt. E latere S. E. sublationibus calcareis immanibus, stirpibus pretiosis superbientibus, mons conformatur. Ab latere opposito, idest N. O., rupes praeruptae, inferne graniticae, licet igneae, deteguntur; in qnarum fragmentis dirutis et in convallibus coacervatis, rarissimae stirpes etian hospitantur.

Ab excursionibus olympicis Byzantium redii, locaque illa omnia, vertente antunno, rursum perlustravi. Brevi vero rerum orientalium satietate affectus, morun turpitudinem, ignaviam, inscitiam, miserian incolarum fastidiens, laboribus, molestiisque innumeris defatigatus, Genuam, nti ad incolumitatis arcam cito me transtuli.

Opusculi jam tunc promissi editionem ad hanc usque diem protrahere coactus sum, sive ob supellectilis ad definiendas stirpes defectum, sive ob aerumnas exilii; sed botanicos momenta hujusmodi aequo animo aestimaturos, veniamque morae, invito animo protractae, mili daturos esse confido.

Gratias quamplurimas et toto ex corde ago clarissimis Borssier, DE Yotaris, $G_{A y}, S_{A V}, S_{p A C H}, W_{E B b}$, qui consilio et opera sive in plantis denominandis, sive in herbariis celeberrimis perlibenter mili patefaciendis, me in temni labore adjuvermnt. Eq. W Еввıо autem multa alia officia, praesertim in flora olympica exsiccata divulganda, inagnanime mihi praebuit. Prof. SAvius in Trifoliorum novis speciebus dignoscendis praestantem operam amicissime contulit. Et Prof. De Notarisius collectionem universam, nec non illustrationes quas offero, summa doctrina ac amicitia excudendas curavit. 
Nec brevitatis amore, nec multo minus ingrati animi canssa, ea omnia quae, summa liberalitate, vel perrara in me amicitia, nonnulli humanissimi viri mihi in meo itinere impertiti sunt, obliviscar.

Et primum Doctorem Brallam corcyrensem, qui meam in insula receptionem, tunc, pro eventibus adversis, arduam, summa alacritate explanavit, et deinde epistolas intimas ad iter per Graeciam prosequendum dedit, grato animo recordor. Praeclarae et nobilissimae Familiae Principis Suzi, Metaxa, et Maurocordato meum domicilium atheniense, exquisita urbanitate, sedatum dulceque fecerunt; et Dominus Orphaxidius, nunc rei herbariae in illa Universitate Professor, in excursionibus semper mihi dux et comes carissimus fuit. Byzantii Dynastes Teccus, Sardiniae Regni apud Osmanidos Minister praestantissimus benevolenter patrocinio suo mihi adfuit. Eq. Gaspar Fossatı Architectus valentissimus et Familia ejus perexcellens animum mihi dederunt, meque domum apud se insigni liberalitate receperunt, nec non officia permulta in pervariis negotiis mihi praestiterunt. Idem dicam de Severino Leoso medico eximio, qui amicissimus et perbenevolus semper mihi fuit. Brussae Dominus Falchesıus me ospitio excepit et iter meum olympicum, plurimis facile reddidit.

De Osmanidis et aliis gentibus diversis Byzantii, sicut in bulga incomposita, commorantibus, quid dicam?? Dignitario Scheff-Ked-Bey, Magno Cancellario Norioyn-Bey, quorum benevolentia et animi liberalitas non dubiae fuere, honorem et grati añini significationem tribuo. Indigam populi partem etiam commemoro, quae, quamvis ignara et desidiosa, integra tamen et bona servatur.

Addo: hoc in meo Sertulo de plantis etiam hand novis adnotatiunculis magis abundare quam deficere praetuli; ex eo quod in re herbaria hodierna, ob diagnosium insufficientiam, absque speciminum autenticorum comparatione, nulla fere stirps certe denominari potest! Idcirco botanicos obsecro, non solum ut meas analyses benigno animo accipere velint; sed etiam ut et ipsi magis magisque in speciebus novis describendis accuratiores fieri studeant.

Quarumdam specierum nomina in herbario exsiccato evulgata rejicere coactus sum, eaque in hoc opusculo brevitatis gratia omissa sunt; unicuique, caeterum, obvium erit immutationes quae hic sunt dignoscere, synonimaque exacte conferre. 


\section{R I N N C L I A C E A E}

Avenoxe APENiNa L. Sp. 762.

Hab. Ad radices montis Pentilici atheniensis legi vere 1850.

0hs. A stirpe italica tantum laciniis foliorun oblongo-nbtusiusculis subintegerrimis, nec lanceolatis inciso-dentatis, recedit.

Avemone hortensis L. Sp. 761 .

Hab. Crescit ad margines agrorum planitiei athenieusis et floret vere ohs. Segmenta foliorum valde ludibunda observavi.

A Nemone coronaria L. Sp. 760 .

Hab. Iisdem in locis cum praecedente legi vere.

0ls. Segmenta foliorum rarius dentato-mucronata plerumque obtusiuscula sunt.

Prope Piraeum ath. A. coronariae varietatem performosam, floribus maximis intense coccineis, legi etiam primo vere.

\section{Clematis flammula L.}

Ilah. Atticae, ad Kiephyssum flumen.

\section{Ceratocephales falcatus Pers.}

Hab. Abunde erescit in arvis circa Athenas, ubi legi vere et apstate incipiente.

Ols. Magnitudine varius, pedunculos etiam fructificantes interdum abbreviatos, in anthesi niveo-lanatos, fert.

\section{Ficaria calthaefolia Riche.}

Hab. Atticae; locis humentibus.

Ficaria ranciceloides Moench.

Hab. In herbidis byzantinis.

Ranunculus Camozzianus mihi.

R. caule unifloro erecto, subtortuoso, leviter striato piloso, basi fibris erectis vestito; foliis radicalibis pinnatisectis, segmentis cuneato- 
incisis, laciniis lanceolato-linearibus integerrimis dentatisve; caulinis duobus tribus sensim sessilibus lineari-incisis; sepalis laxiusculis patentilus pilosis, apicem versus nudis; toro piloso; petalis amplis luteo-croceis, obovato-cuneatis, integerrimis; carpellis mndis semiovato-rotundatis, stylis subcircinnato-uncinatis.

R. dissectus Aur.н.! ad specimina Ancheriana in herb. Mus. Paris. non M. B. - R. dissectus $\beta$. glabrescens Borss.! ad specimina PINARD! in herb. W

Hah. Legi in loco humente in regione alpina Olympi bith., ubi cum Stellaria cerastoide promiscue crescit et floret Augusto mense.

Rinencules aguathis $S_{p}$. varietas.

Hall. Legi semel in aquis stagnantibus prope Byzantium, aestate.

0ls. Folia emersa vix 3 -loba, lobis vix et irregulariter lobulatis : immersa saepius trichotoma.

Riandelus ophoglossifolius Vilz.

llab. Legi cum praecedenti eodem tempore.

\section{Idonis iestivalis L.}

Hab. In arvis Atticae.

Nigella divaricata Beaupré.

llab. Una vice mili occurrit in collibus Demerdesch ditionis Brussianae. Solo glareoso et calcareo delectatur. Floret Julio et Augusto.

\section{DELPHINICM JUXCEM DC.}

Ilab. Legi aestate in insula Corcyra, ubi laete viget et ex coespilibus compactis ramos numerosissimos vimineos edit.

Delphisicm peregrixum All.

Hab. Legi in collibus Brussianis aestate decedente. A stirpe Dalmatica haud diversum. 


\section{B E R B E R I D E AE.}

LeoNTice Leontopetalum W.

Hab. Frequenter occurrit primo vere in arvis circa Athenas.

Berberis Cretici L.

Hab. In Monte Parnis.

\section{$P A P A V E R A C E A E$.}

Papaver Piloscm Sibth. et Sy. DC. Syst. 2. p. 8o.

Hab. In Olympo bith. una tantum vice reperi ïsdem in locis ubi primum id detexit el. Siвthorp, seriusque Aucherus. Augusto vertente.

0bs. Stirps venusta, in locis apricis robusta, villoso-argentea, in umbrosis gracillima calvescens : variat insuper petalis aurantiacis, stigmate 6-8-radiato, nec semper 6-radiato, pilis rigidis fere strigosis, nec simpliciter pilosum.

\section{Papayer Riloeas L.}

Hab. In arvis byzantinis sterilibus tota aestate.

0bs. Hujusce speciei varietas tantum perpusilla, etiam statura sesquipollicaris mili circa Byzantium occurrit. Ei sunt folia varie incisa; laciniis seta longiuscula praeditis, flores pro planta grandiusculi, pedunculi filiformes.

\section{Hypecoum litorale Wulf.}

Hab. In sabuletis prope Phalereum athen. legi primo vere.

0bs. Plerumque perpusillum et arena mobili suffocatum.

\section{HypeCoum grandflorum L.}

Hab. In arvis circa Athenas ubique frequentissimum occurrit primo vere. 


\section{F U II A R I A C E AE.}

\section{Fluaria macrocarpa Boiss.!}

Hab. In cultis collinis humilioribus ad radices montis Cabetis athen. primissimo vere cum sequenti specie promiscue crescit et floret.

0bs. A $F$. micrantha non solum fructibus plus minusve grandioribus, sed forma foliorum, glaucedine, facieque propria apte distinguitur.

\section{Femaria micranthi Lagasc.}

Hab. Cum praecedenti ut diximus.

0bs. Variat subinde pusilla, simplex, subindeque elatior et valde ramosa, sed semper floribus minimis et pinnis foliorum minutissime sectis praedita.

\section{R U C I F E R AE.}

\section{Matthola noxtaxa Boiss.!}

Hab. Legi Augusto in declivitatibus alpinis Olympi bith., orientem versus.

0bs. Fruticulus ramis tortuosis, decumbentibus. Flores petalis linearioblongis, apice contortis, sordide purpurascentibns ornantur. Siliquae maturae subglabratae, compressae, stigmate trilobo sessili terminatae, ultra decimetrum longae, ramos longitudine aequantes vel superantes, juniores ut folia niveo-lanatae. Cum speciminibus herb. Mus. Paris. ab Avcherio in Cappadocia lectis sufficienter quadrat, sed petala utriusque comparare non contingit.

\section{Cheiranthes Jacomelu mihi.}

Hab. Legi in pratis saxosis planitiei alpinae Olympi bith. latere N. E. Augusto mense, fructu plene maturo.

Radix perennis, longissima, descendens. Rami, ortu hypogeo, plures, radiciformes, repentes, parte exserta foliorum petiolis arefactis duris restiti; deinde confertim adsurgentes erecti, simplices, sublignosi, angulosostriati, pilis bipartitis adpressis haud crebris ad flores usque scabridi. 
Folia inferiora faseiculato-congesta, vix carnosula, angustissince ef obserse lanceolato-linearia, vel linearia anguste spathulata in petiolum longum basi dilatatum carnosulnm attenuata, obtusiuscula, pilis bipartitis arcte adpressis scabriuscula; superiora sensim rariora lineari-conformia suburinervato-carinata. Flores .......? Pedunculi fructus solitarii, m. o, o I remoti, sparsi ebracteati, erecto-patentes, m. o, oo6 ad m. 0,008 longi. Torus conspicuus, cicatrice exteriori luteola. Siliqua matura m. o, of ad m. 0,08 longa exacte complanata in. 0,003 circiter lata, utrinque sensim angustata, pilis ut caules et folia adpressis subscabrida; valvis nervo prominente diremtis, inferne in dissepimenti conjunctione parce callosis. Stylus persistens m. o, oo5-0, oo6 longit. aequans, inferne more siliquae pilosulus plus minusve purpuraseens, superne lntescens; stigmatis lobi parvi erecto vel complanato-patentes. Semina breviter alata! Cotyledonesaccumbentes!

0bs. A Ch. Cheiri toto coelo distinctus; mulli ex speciminibus orientalibus in herb. Mus. Paris. et Wевви a me collatis similis.

\section{Arabis hirsuta L.}

Arabis Thaliana L.

Ilal). Ad Bosphorum.

\section{Arabis dr.tbaeformis Bolss.! non 4. Boissieri Griseb.}

llab. Declivitatibus saxosis nivi perpetnae proximis in Olyıno bith. delectatur: Floret Aug. mens.

0bs. Surculi sunt abbreviati erectiusculi, nec elongati repentes ut in A. Boissieri Fl. rumel.; folia ovata spathulata, nec elliptica; corolla calyce triplo, nec duplo longior.

Stirps stolonibus multiplicibus abbreviatis remotis, caulibus fitiforinibus nudis, rigidis, lucentibus facie singulari et distincta.

\section{Arajis alpiva olmapica Glem, - A. Thyrsoidea Sibtu.}

Hab. In regione alpina Olympi bith. legi Augusto.

Obs. Habitu, foliorum margine arguto denticulatorum forua, indumento Arabidi alpinae persimilis; differt tamen statura humiliore, valvulis fructus nervo prominente exaratis, seminibus, in fructu saltem immaturo, vix membranaceo-marginatis. 
CARdaine misstes L.

Ilib. Atticae et Byzantii.

Mulcolnia incrassata DC.

Ilab. Ad litora maris prope Piraeum ath. vere floret.

obs. Folia inferiora haud mucronata; pili simplices non stellati. Tota planta in locis sterilibus et siccis contructa, rigida; et contra in locis umbrosis vel humentibus elatior, foliis, caulibus elongatis, floribusque gracillimis.

\section{SISYMRRICM ORIENTALE L.}

Ilab. Ad muros in ipsa urbe Byzantii tota aestate occurrit et floret.

\section{Sistabricm polyceratiun $\mathbf{L}$.}

Hab. Crescit ad vias in ipsa Scutari asiatica et floret tota aestate.

Raphanes Lavdia Morett.

llab. Circa Byzantium.

\section{Brassica eruca L.}

Hal. Circa Athenas. Planta 2-3 pollicaris, caule simplici.

Erysinum rLPestre DC. Syst. 2. 494. - Cheiranthus olympicus Sıвтн. ex DC.

Ilab. In Olympi bith. pratis alpinis editioribus N. E. prospicientibus mense Augusto legi.

Obs. Planta mea eadem ac homonyma in herbariis celeberr. W ЕввII asservata; sed foliis saepius runcinato-dentatis, potius quam denticulatis, petalorum lamina ungue multo breviore, a descriptionibus $\mathrm{C}_{\text {Axdoller }}$ et GrisebachII (Fl. rum. I. p. 26r.) nonnihil recedit.

\section{Erysimen cuspidateỵ DC.}

llab. Specimina bipedalia et ultra inter saepes prope Brussam fructificantia legi Augusto mense.

\section{Aurinia orientalis Griseb.}

Hab. In monte Cabeto ath. 
Alyssum tortcosum W. $K$. pumilum Clem.

Hab. In saxosis editioribus Olympi bith. legi Augusto mense.

0bs. Differt a specie caulibus a basi ramosis, tortuosis, pollicem longitudine vix excedentibus, racemis simplicibus, filamenta omnia appendiculata!

Species forte distincta, sed deficientibus siliculis maturis plura addere nequeo.

Alyssum erosulum Genn. et Pestal. ined.

A. pube stellata incanum; caulibus adscendentibus lignoso-suffiruticosis; ramis simplicibus erectis; sterilium abbreviatorum foliis densis spathulatis vel obverse lanceolato-ellipticis basi angustatis, fertilium angustioribus; racemis floriferis brevibus, fructiferis demum elongatis; petalis sepalis varie ovatis deciduisque sesquilongioribus, dorso pube stellata serius subevanescenti incanis, margine crenulato-dentatis; filanentis irregulariter alato-unidentatis vel subbidentatis; siliculis junioribus rotundatis pedicellis stylisque superne glabrescentibus brevioribus, maturis rotundato-oblongis emarginatis convexo-planis illos subaequantibus; seminibus minutis, exalatis, nigris.

Ila). Ipse legi in Olympi bithynici regione alpina humiliori. Pfstaıozza in Asiae Minoris Adalia prope Berebet-Day.

0ls. A. Wulfenianum Bевкн. differt ab erosulo, cui valde affine, praesertim siliculis glabratis-stylo duplo brevioribus, filamentis ala biden-

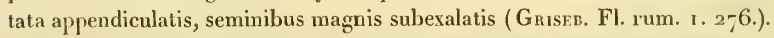
A. Wulfenianum $\beta$. suffiruticosum Borss. I. c. differt caulibus repentibus, filamentis majoribus edentatis, aliisque speciei notis supra comparatis. Tomentum stellatum in $A$. erosulo omnes partes, staminibus stylorumque superiori parte exceptis, obtegit. Semina in unoquoque loculo dno; e latere valvae convexae maturescentia, e latere opposito sterilia. Specimina Pestalotiana magis quam Olympica adnotantur lignosa, contracta, et incana.

Neesli. paniculita Desv.

Iab. Atticae.

Clypeola Joxthlaspi L.

Hah. In agro atheniensi legi aestate. 
Clypeola glabra Borss. Ann. Scient, naturell. XVII. p. 173. IV ALPERs Repertor. 1. $p$. I 46.

Ilab. In iisdem locis ac praecedens nec rara.

0bs. Siliculae emarginatae, in centro elevatae, perfectae glabrae, duo millimetra cum dimidio diametro vix excedentia. Herbula pusilla, a basi ramosa, vix bipollicaris, ramis filiformibus varie flexuoso-ascendentibus; tota in caulibus, foliis, calycibusque pilis stellatis adpressis confertis vestita.

\section{Bunias Erccago L.}

Hab. Atticae.

\section{Draba muralis W.}

Hab. Ad aggeres prope Bosphorum vulgatissima primo vere.

0bs. Tota planta pilis subtrifido-stellatis scabra; siliculis lineari-ellipticis pedunculisque iis longioribus glabris; foliis sessilibus cordatis, nec amplexicaulibus ut in Pers. Synops.

\section{Draba verya $L$.}

Hab. In Attica et ad Bosphorum vulgatissima.

\section{Draba olympica Sibth.}

Ilab. Legi in saxosis calcareis regionis alpinae Olympi bith. ubi copiose crescit et floret. Julio, Augusto.

0bs. Planta nostra cum speciminibus herbar. Webb11, a Borssiero in Olympo bith. lectis, ad unguem convenit; sed a diagnosi Flor. rumel. divergit partibus omnibus piloso-scabris, nec scapis pube molle velutinis, siliculis pubescentibus.

\section{Teesdalia Lepidium R. Br.}

Hab. Reperi in collibus constantinopolitanis ubi et Avcren legit secundum Bolssier. Floret primissimo vere.

Thlaspi CAMPESTRE L.

Hab. Ad aggeres circa Byzantium. 
ThLANP PEROLIATYy L.

Tillaspi Bursa L.

Hal. Atticae et Byzantii.

freris vava Ale.:

Ilab. Ad nives deliqnescentes in declivitatibus Olympii bith., substrato calcareo; floret Augusto mense.

obs. Folia in nostra, quae cum speciminibus jampridem a Borssienio in Olympo ipso lectis, aliisque in herbariis cl. Wеввн extantibus omnino convenit, integerrima, inferiora earundem spathulata, superiora obverse oblonga ciliolata observantur.

\section{LEPIDIU M SPINOSUM L.}

Hab. Legi Julio mense in pascuis collinis constantinopolitanis.

0ls. Planta antheseos tempore gracillima, fructifera autem robusta, alienae prorsus faciei. Siliculae perfectae oblongae ad basim callosobigibbae, apice ex alis oblongis obtusinsculis, sinn divergenti distinctis, emarginatae.

Huic affine Lep. cormutum a Buхваим prope S. Stephanum ad Byzantium lectum, ex Fl. rumel. 1. p. 284., mihi haud visum.

\section{Senebiera Cononopis Pers.}

Ilab. In collibus byzantinis.

\section{Eunomia Chlorifolia DC.!}

Hab. In Olympi bith. calcarcis alpinis, nbi et Siвthorpıos, florentem et fructificantem reperi Augusto mense.

0bs. Cum speciminibus antenticis herb. Webbiani mea comparata exacte quadrant.

Sepala oblonga, obtusa, atropurpurescentia; petala obovala, breviter unguiculata calyce plus quam duplo longiora, albo-carnea, venis plus minusve sature purpureis exarata.

\section{HURRIETIK DELTOHEA DC.}

0bs. Diagnosis hujusce speciei, ex speciminibus in Olympi bithynici valle Gögderè provenientibus a cl. Grisebachio (Fl. rum. 2. p. 208.) conscripta, in plantam nostram in regione ejusdem montis sublimiore 
collectam exacte non quadrat; idcirco ad pleniorem speciei quammaxime versatilis historiam pauca quae ipsenet observavi silentio praeterire nequeo.

Folia sunt spathulata vel obovato-elliptica, obtusiuscula, in petiolum brevem attenuata, denticulo uno vel paucis olssolete notata, saepius integra, nec spathulata acuta 3-5-dentata ( Fl. rumel.). Pedioli longitudine varia, nec calyces subaequantes. Staminum longiorum ala uno latere infra apicem filamenti abrupte truncata altero sensim desinens, breviorum dens lineari-lanceolatus obtusiusculus erectus, nec staminum longiorum ula (totaliter?) abrupte truncata, brevior'um dens acuminatus. Siliculae juniores stylo breviores, maturae illo longiores, nec semper parum breviores. Semina oblique ovata, nec tantum ovalia, cui striato-rugulosa secundum uostra specimina addendum.

Tota planta scabriuscula, pilis plus minus stellato-ramosis, in siliculis densis, reliquis partibus rarioribus.

Hutcinssia procunbeNs DC.

Hab. Abunde provenit in arvis humentibus prope Phalereum atheniense, vere.

In iisdem locis occurrit subsimplex, erecta, pusilla, vel palmaris et ultra, ramosissima, ramis implexis.

Carrichtera Vellae DC.

Hab. Hane pulcherrimam speciem prope Piraeun atheniense in ruderatis hortorum uno loco legi. Floret Martio mense.

\section{I S T I N E AE.}

\section{Cistus laurifolius $\mathrm{L}$.}

Hab. In Olympi bith. regione fagi hand frequens reperitur.

\section{Cistus villosus $L$.}

Hab. In declivitatibus apricis ejusdem montis crescit. Legi quoque in insula Corcyra ubi folia magis rotundata, spissiora, magisque reticulatonervosa observantur. 
Cistes salvifolies microphylles Clem.

IIab. Legi in atheniensi Monte-Pentilico. Ramosissimus, foliis minutissimis subglabratis.

Helianthendi pilosum Benth.

Hab. In Olympo.

\section{F R A N K E N I A C E AE.}

FrankeNia intsuta W.

Ilab. Ad litora maris prope Kalamaki ultra isthmum Corinthi copiose crescit. Rami numerosissimi, radiciformes, sub solo intricati. Legi aestate.

\section{I O L A R I E A E.}

Viola gracilis Sibth. et Sy.

Hab. Legi in Olympo bith. Augusto mense infra saxa nives perpeiuas ambientia.

0bs. Planta pusilla, floribus maximis luteis ornata.

Viola tricolor olympica Griseb. Fl. rum. i. p, 237.

Hab. In sylvulis abietinis inferioribus Olympi bith. Floret Augusto mense.

ViOLA SILYestris LancK.

Hab. Legi vere in agro byzantino.

\section{R E S E D A C E A E.}

RESEDA LUTEA L.

Hab. Prope Phanaraki ultra Scutarim.

\section{R O S E A C E AE.}

\section{Parjassia palustris L. var. nudicaulis Clen.} Augusto.

Ilab. Crescit rara in pratis alpinis humidioribus Olympi bith. Lègi

0bs. Caules aphyllos et staturam minorem quam species praebet. 


\section{S I L E N E A E.}

Grpsopilla olympica Boiss.! Diagn. 8. 55.

Hab. Legi Augusto in cacuminibus alpinis inferioribus Olympi bith. $0 b s$. Calycis 5-angularis squamuloso-furfuracei dentes rubentes, subacuminati, margine scariosi, tubo membranaceo duplo breviores. Petala purpureo-coerulea, obverse lincari-lanceolata, antice rotundata, lamina in unguem gradatim attenuata. Styli duo. Stamina decem, una cum petalis carpophori apice inserta. Ovarium oblongum obtnsum. Reliqua ut in Bolssierı Diagn. I. c.

\section{Tunica olympica Boiss. !}

Hab. Legi una vice in declivitatibus argilloso-calcareis ab aquis exaratis regionis subalpinae Olympi bith. Floret Augusto.

0ls. Planta gracilis uni raro bispithamea, floribus paniculatis solitariis, calycibus exacte obconicis, nervaturis quinque validis praeditis. Gipsophilarum faciem omnino ostendit.

Tunica orfandesiana mihi.

T. caulibus basi lignescentibus, ramisque primariis irregularibus, nodosis, tortuosis, implexis; ramis annotinis simplicibus alterneve superne ramosis, rigidiusculis, obtuse quadrangulis, glabris; foliis inferioribus approximatis, subfasciculatis, carnosulis, margine serrulato aculeolatis, obtusiusculis, ramorum annotinorum connatis abbreviatis fere squamaeformibus, in sicco, nervo excepto, omnino scariosis, plus minusve acuminato-mucronatis; florum fasciculis terminalibus solitariis vel subracemoso-paniculatis; bracteis ovatis, interioribus magis magisque latis, omnibus nervo valido carinato-mucronatis, reliqua parte scariosis; pediolis obconico-incrassatis, sesquimillimetrum longis; calycibus 5-fidis scariosis, laciniis obtusiusculis dorso 3 -nerviis; petalis obverse lineari-lanceolatis stamina aequantibus subexsertis, lamina in unguem sensim attenuata; capsulis oblongis inclusis, valvis maturitate superne truncatis; seminibus orbiculato-membranaceis.

Ilab. Ad rupium calcarium fissuras in summo cacumine Montis Parnis atheniensis, comite cl. Profess. Orphanides, novembr. 1849, cum fructibus perfecte maturis legi. 
Folia sesquimillim. lata, 12-16. millim. Iongitudine meticutia. Faselculi flormm capituliformes obconici, bracteis firtu maturescente stranineopallescentibus. Tota planta spithamam vix altitudine superal. Folia semper carnosula et mollia nore salsolarum servantur. Caules autem arefactione fragilissimi fiunt. Petala persistentia ex sicco purpurascentia et concolora judicanda.

0bs. Tunicue dianthoidi F. et M. affinis. Ab ea differt praecipue capitulis majoribus; floribus numerosioribus compositis, bracteis latioribus, minus tenuiter scariosis; caulibus robustioribus; foliis carnosulis latioribus, margine serrulato-aculeolatis.

Dianthus humgarices Pers, ex Fl, rumel.

Hib. Crescit haud frequens in pascuis alpinis Olympi bitlı. et floret Augusto.

0bs. Planta gracilis; petalorum lamina maxima, magis yuam in V. plumario profundissime crispato-lacera, arefactione contracta.

\section{Dianthus pallens Sibth.}

D. pereunis, glaucescens; caulilus caespitosis, adscendentibus erectisve, glabris, simplicibus subindeve alterne dichotomis, ramisque unifloris; foliis nervosis, margine cartilagineo denticulato-scabriusculis, linearibus, acutis, flaccidis, internodio brevioribus, vaginis latitudinem folii aequantibus, radicalibus latiusculis; bracteis 4-8., interioribus obovatis ex apice obtusissimo breviter acuminatis, margine scariosis, exterioribus angustioribus, calyce profunde 5-dentato, tenuiter striato, elongato, a basi in anthesi scusim angustato, quadruplo bervioribus; petalorun lamina cuneata! profunde obtuseque dentata excisave, glabra, intus alba, extus sordide purpureo-virente; seminibus badiis depressis, subdiscoideo-peltatis, vertice umbilicatis, undulatis.

Dianthus leptophyllus Wıцу. Enum. 1. p. 468? - Griseb. FI. rumel. 1. p. 191 .

Dianthus pallens URvis.. Enun. 302.

Dianthus pomeridianus Friv. ex Griseb.

Hab. Species passim obvia in insula Corcyra, in Graecia, agro constantinopolitano atque in Asiae minoris regionibus occidentali-borealibus, ad vias collinas, in aggeribus apricis etc. Floret aestate.

Flores aperiuntar vespere, clanduntur mane hora perquam mutabili. 
Petala in alternatione somni et vigiliae plus minusve convoluta observantur.

0bs. Cl. Grisebach (J. c.) Dianthum pallentem Sm. et Unvillei, D. pomeridianum Frivaldski uno nomine D. leptopetali Wuld complectitur. De identilate $D$. leptopetali, qui a pomeridiano bracteis ovatis acutis brevissimis, petalis lanceolatis, foliis subulatis prae aliis distingueretur, deficientibus mihi speciminibus speciei Willdenowianae $\mathrm{cmm}$ cl. Florae rumelicae Anctore haud certabo; sed cum eo $D$. pallentem et pomeridianum unam eandemque constitnere speciem minus dubito, ejusdemque sententiam, observationibus a memetipso in ilinere meo ab insula Corcyra per agrum hellenicum et rumelicum et in $\Lambda$ siam minorem circa hanc plantam peractis confirmare gaudeo.

Dianthus pallens late per orientem patens, sistit speciem quamunaxime mutabilem, tum hora qua flores vigilant, a vespere nempe ad diluculum varia, cum statura a spithama ad pedem et uitra, vel caulibus simplicibus ramosisve, vel forma et numero bractearum in iisdem caespitibus varia, vel petalis plus minusve dentatis, vel demum foliorum latitudine.

Ipse immo, lusibus hujusce speciei perspectis, quae tamen moribus et moerore, ut ita dicain, faciei facile a congeneribus dignoscitur, nonnullas alias Dianthorum orientalium species a nuperioribus descriptas huic subscribendas esse autumo.

\section{Dianthus pubescens Sir.}

Hab. Legi vere decedente in cultis collinis prope Bosphorum.

0bs. Dianthus pubescens fasciculatus Griseb. Fl. rumel. r. p. 190, in Macedonia australi proveniens, differt a specie, a BoIssıerio etiam prope Byzantium observata : foliis constanter 3-nerviis nec 3-5-nerviis, vaginis folii latitudinem $2-3$-plove superantibus, calyce glabro et superne scabriuseulo, bracteis ealycem dimidium aequantibus.

Dianthus deltoides Macedoniae incola differt a nostro foliis obtusiusculis nec acutis, bracteis breviter nec longe aristatis tubo duplo nec quadruplo brevioribus, lamina ovato-oblonga nec cuneato-rombea.

Di.ixthus leccophaeus, macropetalon C.em. PI. olymp. exs.

D. caulibus caespitosis repentibus; ramis unifloris adscendentibus; foliis 3-multinerviis abbreviatis, rigidis subpungentibus, inferioribus subim- 
bricatis, margine scabriusculis, caulinis glabris, vagina brevi; bracteis quatuor, interioribus ovatis, exterioribus angustioribus, calycis striati apice constricti tertiam partem aequantibus; petalorum lamina irregulariter dentata, extus viridi-purpurascenti.

Hab. In Olympi bith. declivitatibus alpinis legi Augusto mense.

0bs. Dianthus leucophaeus Sw. (Griseb. Fl. rumel. r. p. rg3.) ex speciminibus olympicis, in ditissimo herbario celeb. WEвви observatis, recedit a varietate nostra bracteis omnibus late ovatis, calycem dimidium aequantibus, petalis minoribus eorundemque lamina 3-crenata.

\section{Dunthus veletinus Guss.}

6. contractus CLEm. : compacte caespitosus, caulibus dimorphis, abbreviatis, brevissimisque monocephalis, vel elongatis polycephalis.

Hab. Utraque varietas $\alpha$. $\beta$. primo vere et aestate in cultis collinis prope Byzantium erescit.

Varietas $\alpha$. pro aetate se praebet caulibus indivisis monocephalis, vel ramosis polycephalis.

\section{Dianthes Cibraries mihi.}

D. caulibus basi ramoso-caespitosis, adscendentibus, quadrangulis, plerumque laevibus; foliis inferioribus congestis, linearibus, rigidis, pungentibus, multinerviis; caulinis late linearibus, internodiis multo brevioribus; vaginis dimidiam longitudinem foliorum subaequantibus; cyma fasciculata 4-10-flora, bracteis obovatis ex apice rotundato mucronatosetaceis, scariosis, nervosis, superne validioribus, plus minusve sanguineopurpurascentibus exaratis, dimidium calycem tegentibus, mucrone auctis illum subaequantibus; calycibus glabris, profunde 5-dentatis, dentibus lanceolato-linearibus, acutis, conspicue nervosis, ciliato-puberulis tuboque superne atro-sanguineis; petalorum lamina cuneata, antice dentata, purpurea, basi pallidiori, intus pilosiuscula unguibus triplo breviore.

Hab. Copiose occurrit in convalle quadam alpina Olympi bith. latere S. E. Floret Augusto mense.

0ls. Fasciculatorum sectionis plurimis speciebus in herb. el. Wевви et Mus. Paris. a nobis perpensis Dianth. noster affinis; sed nulli exacte convenit.

Foliis abbreviatis, rigidis, pungentibus, stolonum approximatis fortiterque nervosis praecipue distinguendum est. Pulcherrima stirps ! 
Silexe olympica Boiss. ! Diagn. r. p. 24. Griseb. Fl. rumel. 2. p. 502.

Hab. Copiose provenit in declivitatibus lapidosis alpinis Olympi bith. a nivibus perpetuis non longe in latere N. O.

Rhizoma ligneum, tortuosum, multiceps; ramis contractis, elongatisve stoloniformibus gemmas eoden tempore floriferas homotinasque edentibus. Folia subcarnosula, in petiolum margine membranaceum attenuata, eximie connata, toto margine denticulis ciliformibus, inferne recurvis instructa, caeterum glabra, inferiora conferta linearia, vel anguste oblanceolato-linearia, subinde subfalcato-secunda, raworum floriferornm per paria remota, angustiora, lineari-subulata. Rami floriferi plerumque indivisi, stricti vix spithamei, thyrso paucifloro conferto racemiformi terminati. Bracteae ut folia connata e basi dilatata attenuatae, ovato lanceolatove subulatae, margine membranaceae, ciliatae, disco nervis rubescentibns exaratae. Pedunculi 2-3-flori, bracteas aequantes, pedicellorum intermedio nudo, lateralibus 2 -bracteatis. Calyx obconicus, lucidorubescens, membranaceus, ro-nervius, nervis 5 alternis tenuioribus, limb. 5-dentatus, dentibus triangulari-ovatis, obtusis, margine membranaceis, ciliolatis. Petalorum unguis 3-nervius, ciliatus, calycem subaequans, lamina 2-fida, luteola, viscida. Stamina exserta, filamenta stylique inferne villosa. Capsula maturitate breviter exserta, ovata, nigropunctata (?). Semina ambitu fere toto canaliculata, subundulata, rugosaque, fusco-cinnamomea. Species eximia!

Planta viridis supra medium viscosissima.

\section{Silene falcata $\mathrm{S}_{\mathrm{M}}$.}

Hab. Copiosissime provenit in declivitatibus calcareis meridionalibus regionis alpinae Olympi bith. et floret Augusto.

0/s. In nostris speciminibus omnes plantae partes piloso-glandulosae sunt. Dentes calycini potius lanceolati et margine scarioso ovato-obtusati, quam triangulares denominandi. Petala facie albescentia extus livida, nec concolora ochroleuca. Tandem stamina omnia, nec quinque tantum exserta.

\section{Silene INFLATA Sis.} glaucescens.

Hab. In Olympi bith. reg. alpina. Tota planta laevis plus minusve 
Sileve pendelica Borss. !

Hah. Una vicc inihi occurrit in monte Fentilico atheniensi, primo vere.

Stirps parvula et elegans.

Silexe SERicea All.

Mab. Cum praecelente.

SiLENE SPINESCENS Sy.

Hab. Legi in monte Hymetto atheniensi.

SiLeNe dichotoma Ehrs.

SileNe QHiNQUeVtLNera L.

Hab. In collinis agri constantinopolitani.

\section{Velfza rigida L.}

Hab. In declivitatibus collinis sterilioribus prope Byzantium haud rara occurrit aestate.

\section{A L S I N E AE.}

\section{Spergela pentandra L.}

Hab. Abunde crescit in collibus prope Byzantinm rere et aestate.

\section{spergularia pentagona DC.}

Ilab. In cultis et in sterilibus byzantinis frequenter crescit magnitudine admodum varia. Floret tota aestate.

Alsine juniperina Fenzi, ex Ledeb. Fl. ross. 1. 346 . - Arenaria juniperina L. - Alsine nodosa Vıs. IIl. pl. Graec. et As. min. Atti del Congresso di Torino p. 180. - Arenaria nodosa Bory et Chaub. Exped. Mor. Botan. p. 125.

Hab. In declivitatibus orientalibus regionis alpinae Olympi bith. legi Augusto mense.

0bs. Ab Aren. verna Bartı. differt nervis sepalorum adproximatis, nec duo laterales a medio remotis; petalis ovatis nec lanceolatis; capsulis 
calyce sesqui vel duplo longioribus, nec breviter exsertis; seminibus vis rugulosis, nec muricatis rel rugosis.

Alsinis juniperinae specimina in Olympo bith. a me lecta characteres secquentes ostendunt, quos hic praebere lubet ut a specichus superius memoratis plantae nostrae diversitas clarius innotescat.

A. caule suffrutescente, abbreviato, ramoso, caespitoso, ramis numerosissimis adscendentibus; floriferis elongatis, sterililus internodiis abbreviatis robustioribus, foliis pedunculisque plus minusve glanduloso-pilosis; foliis rigidis acuminatis, subulatis, falcatis, supra canaliculatis, subtus trinerviis (licet bisulcatis), ad genicula nodosa laxe connatis; cymis plerisque bis trifidis fastigiato-corymbosis; pedunculis lateralibus trifloris, pediolis piloso-glandulosis calyce longioribus, intermedio terminali unifloro; calycibus ovatis; sepalis comniventibus ovato-lanceolatis, acuminatocuspidatis, trinerviis, margine cartilagineis; petalis albis calyce tertia parte duplove longioribus, ovatis, obtusis, ungue brevi; capsulis 3-valvibus calycem sesqui vel duplo superantibus, valvulis demum apice liberis ohtusis; seminibus (more selenidum) foveolato-japillosis vel rugosis, margine dorsali dilatato subbialato.

Alsine erthrocephala Bolss.! Diagn. 8. p. $9^{8}$.

Hab. Cum sequenti specie in Olympi bith. regione alpina promiscue crescit et floret.

0bs. Ludit statura interdum pygmaea interdum elatiuscula. Quae ipse legi specimina a Boisseriana quidquam divergunt: sepalis 3-nervato-carinatis reapse bisulcatis, sulcisque intense viridibus, reliqua parte ex albo purpurascentibus; foliis brevilus, robuste ciliatis; caulibus pilis brevissimis glanduloso-siscidulis plus minusve adspersis.

Alsine unrseta Fenzl ex Ledeb. Fl. ross. r. 346 .

Hab. Augusto mense cum praecedente floret loco citato.

0ls. Gracillima elongata; sepalis magis quam in praecedenti lanceolatis, regulariter multinerviis, concoloribus, caulibusque superne hirsutis; hirsutie minuta vix glandulifera; ciliis foliorum rarissimis rel nullis.

Alsine tencifolia $\beta$. viscosi Kоси Syn. p. 125.

$\%$ byzantina Clementi: pusilla ; valde caespitosa, contracta et parce ramosa ; foliis basi membranaceo-dilatatis, connatis; cymis contractis, 
congesto-corymbosis, pediolis vix calycem aequantibus; sepalis distincte Irinerviis, piloso-glandulosis; capsulis exsertis.

Hab. In proximitatibus Byzantii ultra il Gran Campo legi; quo loco crescit etiam var. $\beta$. statura multo proceriore, caulibus gracilibus et magis ramosis; peduncnlis divaricatis solitariis, aut tantum in dichotomiae axilla duobus vel tribus. Insignis !

Arenaria rotendifolia M. B. Ledeb. Fl. ross. 1. 369. - Fl. rumel. 1. p. 203.

Hab. In regione abietis Olympi bithynici ad rivulos. Augusto.

0bs. Bracteae oblongae vel ellipticae parvae, bracteolae lineares, subulatae, canaliculatae, basi ut petioli ciliolatae. Sepala ovata in apicem obtusiusculım, mncronulatumve sensim angustata, nervis, lateralibus praesertim, tenuissimis sub I-nervia, margine albo-membranacea. Petala alba, oblonga, obtusa, in anthesi sepala aequantia. Antherae sub apice filamenti insertae, loculis discretis. Styli 2-5, ut plurimum 3. Capsula matura calycem aequans, late ovata, obtusa, glabra, inferiori parte submembranacea, semi 4-valvis, valvulis chartaceis, integris, bifidisque dehiscens. Semina plurima compressiuscula, subrotundo-reniformia, badia, sub vitro eximie rugulosa, funiculis centralibus, longinsculis, filiformibus fasciculatis adfixa.

De reliquo conf. Fl. rossicam et Fl. rumelicam.

\section{Arevaria serpyllifolia glandllosa Koch.}

0ls. In speciminibus nostris byzantinis pili totius plantae et praecipue sepalorum minulissime glandnliferi et quasi muniliformes adnotantur. Legi in sterilibus acstate. Rотн.

Lepigonum medium Wahlenb. Kocu Syn. I. I21. - Arenaria marina

Lepigonum rebrum Wahlenb. Koch 1. c. - Arenaria rubra $\alpha$. L.

Hab. Abunde crescunt in collibus siccis prope Byzantium. Florent tota aestate.

0bs. Folia in Lepigono rubro linearia vix carnosula submucronulata, cylindraceo-compressa, arcuata. Stipulae scariosae amplexicaules, connataeve. Capsulae calycem subaequantes. Petala dilute purpurascentia. Semina omnia aptera, margine tumido cincta, sub vitro obsolete muriculata, 
Variat glabra, totaque piloso-glandulosa, ramis prostratis adscendentibusve. Formae majores, glanduloso-hirtae, habitu ad arenariam macroryzam accedunt, sed semina in nostra quantum videre licet omnia aptera.

\section{Moenchia maxtica Bartl.}

Ilab. In collibus apricis nltra il Gran Campo di Costantinopoli abunde provenit; nec ulla nota differt a planta in sylva Mantica veronensi primitus lecta. Floret primo vere.

Cerasticm grandiflorim W. K. var. glabratum Boiss. in litt.

Hab. Legi in declivitatibus subalpinis Olympi bith. Aug. mense.

0bs. Tota planta pilis reflexis, basi submembranaceo-furfuraceis scabriuscula.

\section{Cerastium viscosum $\mathrm{L}$.}

IIab. Legi in collibus byzantinis, ubi formam perhumilem praebet.

\section{Cerasticm pilosim Fl. graec.}

IIab. In pascuis sterilibus atheniensibus tota aestate undique provenit.

0bs. Variat statura pygmaea et subspithamea. In planta elatiori pili minus densi sed constanter patentes, candidi, longissimi extant.

\section{Cerastium lanatum Lanck.}

Hab. In monte Parnis ditionis praecedentis autumno incipiente legi.

\section{Cerastium trigrnum Vill. - Stellaria cerastoides L.}

Hab. Legi uno loco humenti in regione alpina Olympi bith. Floret Ang. mense.

0bs. Caules uno latere obiter pubescentes, superne undique pilososubglandulosi. Folia falcata, angustata, potius linearia quam oblongolanceolata. Sepala obtusa ovato-oblonga, inferne trinervia, vix carinata.

\section{Holosteum cmbelatem L.}

\section{Ilab. In Attica.}




\section{I N E A E.}

Livem olympicum Boiss.

Ilab. In regione alpina Olympi bith. huc et illue in herbidis florente occurrit Augusto mense.

0bs. A Lino decolorato (Ic. L. hirsutum Fl. graec. t. 302.) quod in Olympo bith. Sьвтновріus decerpsit, differt: radice perenni nec annua; foliis dorso praecipue regulariter et valde pilosis, nec sparse villosis; cymis interdum 3-floris, nec dichotomis ramis laxe spiciformibus; sepalis ovato-lanceolatis, nec oblongo-lanceolatis; petalis violaceo-azzureis sepalis 4-plo superantibus, nec roseis duplo superantibus.

\section{Linum galdicum L.}

Hab. Circa Byzantium.

\section{A L V A C E A E.}

Althaea rosea Cav.

llab. In aggeribus circa Scutarim asiaticum.

\section{Malva sylvestris L.}

Ilab. In agro byzantino, scutariano et atheniensi formae quamplu- . rimae hujusce speciei obviae sunt.

\section{GOSSYPIUM HeRBaCeum L.}

Hab. In cultis prope Kiephyssum atheniensem sponte.

\section{H Y P E R I G I N E I E.}

Hypericum repens L. et Spach! non aliorum.

Hab. Legi mense Augusti in pascuis dumetosis Olympi bith.

Specimina $H$. repentis Herb. Webbiani et Musaei Parisiensis cuin nostris exacte quadrant. 
IIPERICLA OLYMPICUM L.

llab. Occurrit rarius in solo argilloso-calcareo ab aquis diruto regionis subalpinae Olympi bith. Legi florente Augusto mense.

obs. Corolla calyce triplo longior, pro plantae statura amplissima!

Hupericla sateregifolien Jaub. el Spach. - Griseb. Fl. rumel. 1 . 1. 223.

Hab. In Olympi bith. regione alpina hand frequens. Floret Augusto.

\section{Hipericun Calycinum L.}

Hab. In castanetis umbrosis ad radices Olympi bith. prope Brussan vulgatissimum. Floret Julio.

\section{Hypericum perforatum L.}

Hab. In collibus circa Byzantiun.

Obs. A forma in Europa centrali nec non in Italia ubique obvia, foliis linearibus angustissimisve deflectens.

\section{HyPERICUM EMPETRIFOLIUM W.}

Hab. In planitie circa Athenas.

\section{HIPERICUM CRISPUM L.}

Hab. Cum praecedente, nec non in arvis prope Phanaraki ultra Katikioi passim.

\section{G E R A N I E AE.}

\section{Geranium molle L.}

Geranium pusillum L.

Hab. Ad vias urbanas et suburbanas Byzantii hae duo species promiscue crescunt, et ab italicis nec characteribus nec facie recedunt. Tota aestate florent.

\section{Erodiun cicutarium L.}

Hab. In agro byzantino, valde mutabile.

Erodium olympicum Boiss. ! Diagn.

E. caulibus basi dense caespitosis, floriferis elongatis, sulcato striatis, 
subflexuosis pilosis: foliis radicalibus congestis, caulinis plerumque quatuor oppositis, omnibus undique piloso-subincanis, pinnatisectis segmentis pinnatifidis, laciniis oblongo-linearibus, obtusiusculis; rachi subdentifera; pedunculis multifloris pedicellisque calyces superantibus glanduloso-pilosis ; floribus polygamis; sepalis inaequalibus oblongo-obtusis breviter mucronatis, pelucido-scariosis, piloso-glandulosis, ciliatis, 3-7-nerviis, nervis sordide purpureis; petalis obovatis, subemarginatis calycem duplo superantibus, pallide roseis incarnatisve; fructu patenter hirsuto, cauda inferiori parte, intus longe barbata, extus tota pilis brevissimis patulis hirta.

Hab. In cacumine Olympi bith. ex quo ad inferiora alpina etiam descendit. Floret Augusto.

0ls. Affine Erodium Sibthorpianum ab hac specie luculenter differt foliis simpliciter pinnatis, pinnis ovatis, acutis; ovario pilis albis adpressis villosissimo, candaque adpresse hirsuta, reliquis omissis.

\section{Z Y G O P H Y L L E A E.}

Tribulus lanuginosus L. sp. 553 ?

Ilab. Circa Athenas. Tota planta villoso-hispidula.

\section{R U T A C E A E.}

Ruta hontana Clus.

Hab. Abunde provenit aestate in declivitatibus glareosis prope Constantinopolim, ubi jam a Siвтновріo collecta.

0bs. Folia radicalia supradecomposita, cetera sensim sensimque simpliciora et pinnata. Petala potius cymbiformia et conformia quam ungue attenuata denominanda.

Ruta divaricata Ten.

llal. In monte Hymetto atheniensi legi aestate.

\section{Peganum Harmala L.}

Hab. Copiose crescit et floret aestate prope Acropolim atheniensem, ubi saepius ramosissimum et lignosum evolvitur. 


\section{R H A II Y E AE.}

Rilaminus oleoides L.

Hab. In monte Parnis athen.

\section{T E R E B I N T H A E AE.}

Pistacia Teredinthus L.

Pistacia Lentiscus L.

Ilab. In Corcyra insula.

Res Cotinus $\mathbf{L}$.

Hab. In monte Pentilico.

\section{P A P I L I O N A C E AE.}

Genista Lydi Boiss.! Diagn. - G. leptophylla Spach var. virescens.

Ilab. In regione Fagi Olympi bith. aestate.

0bs. Quae ipse observavi hujusce speciei individua legumina imperfecta, seminaque fere omnia abortientia mihi obtulerunt.

Genista tinctoria L.

Hab. Circa Scutarim asiaticum.

Genista acanthoclada DC.

Hab. In litore prope Kalamaki ultra Isthmum Corinthi legi aestate.

Calycotone villosa LK.

Hab. Corcyrae et Hymetti atheniensis.

Spartium Juncelin $L$.

Hah. Ad Bosphorum.

Gonocytisus angulatus SPACh! - Genista parviflora DC. - Spartium angulatum L. - Retama angulata Griseb. Fl. rum. I. p. 5.

Hab. Legi Augusto decedente in collibus Demerdesch in ditione Brussensi. 
Arbuscula alteme ranosa, ramis vimineis stratis, ranulis sulcatoangulatis, pedicellis calycihusque pilis minutis adpressis, subsericeis. Folia ternata, foliolis oblongo-ellipticis, acutinsculis, floralia simplicia. Bracteae hracteolacque parvae, lineares, decidnae. Flores in ranulorum extremitate racemosi; pedicelli longitudine calycis, superne incrassati. Calyx cyathiformis subbilabiatus, labio superiore bidentato, dentibus triangulo acutis. sinu lato distinetis, inferiore superiore quidquam longiore sed angustiore, minute tridentato. Vexillum cordato-ovatum carinam retusam subaequans, alas inferne foveolatas excedens. Stamina monadelpha. Antherarum lobuli, sub vitro, pilis minutis penicillati. Stigma exigunm subdiscoideum, e sicco, vix a stylo filiformi distinctum. Legnmen immaturum, calycis longitn dinem duylo excedens, elliptico-mrceolatum, pilis minutis appressis, confertis canescens. Corolla laete flava.

0bs. Ex praemissis, speciatim de partibus floris, satis clare elucet, ni nimium fallor, hanc plantam gradum pracbere fere internedium Genistas inter et Retamas celeb. Boıssıer ; idcirco genus Gonocytisus, quod characteribus fructificationis et vegetationis innixum, stirpem nostram aliasque affines colligit, praeferendun esse censeo.

Prostat in ditissimo cl. Wевви herbario sub nomine Genistae parviflorae? Planta canariensis, quae a nostra valde differt ramis omnibus profunde, exquisiteve sulcato alatis.

Crtists cmisotmeus Borss. ! - Cytisus supinus L. FI. rumel.

Hal. In dumetis lapidosis ultra Ciamlicia a Scutari asiatico non longe legi aestate decedente.

Obs. Staturam semper humilem praebet quamvis radix lignosa et robusta sit. Ramuli sesquipalmares, vel palmares, ex radice repente erecti. Calyces villoso-sericei corollis luteis quasi concolores.

Cjtisi chrysothrichi var. gracilem Bosss. ! in Olympo bith. legi regione subalpina. Planta magis elongata, ex aggeribus pendens vel prostrata. Floret Julio et Augusto.

\section{ONonis antiglorum L.}

Ilab. In planitie atheniensi.

\section{Ononis Columae All.}

Hab. In monte Parnis ath. 
Avtiugleis Hermandae L.

Ilab. Crescit in ericetis prope Byzantiun ad ripan Bosphori BujuhDerem versus. Folia sunt potius lineari-elliptica quam lineari-cuneata, ut in diagnose Livn. Calyecs campanulato-cylindrici cum tota planta argenteo-sericei. Floret Junio, Julio.

Medcago marixa L.

Medicago circinnata L.

Medicago orbicularis Ale.

Medicago lupuliva L.

Medicago Gerardi W.

Hab. Omnes plus minusve frequentes reperiuntur in collibus aliisqut locis Byzantinae ditionis.

Trigonella azcrea C. A. Mey.

Hab. Planta venusta quam legi llorentem primo vere ad litura maris prope Piraemn atheniensem.

Trmolium Menegunianum mihi.

T. caule fistuloso; foliolis ovatis vel obovatis; stipulis vagina lata membranaceo-scariosa externe connexis; capitulis minute bracteolatis, post anthesim umbellatim reflexis; lacinïs calycinis lanceolato-triangularibus, cuspidatis tubum subaequantibus; leguminibus dispermis.

Hab. In collibus constantinopolitanis ultra il Gran Campo una vice legi aestate 1850 .

Radix ......? caulis erecto-adscendens ramique numerosi fistulosi, longitudinaliter striati. Foliola basi cuneata, minnte serrata, serraturis a venulis productis cuspidato-subaristatis. Stipulae basi petioli interne adnatae, membrana ampla continua scariosa m. o, o02-3 longa caulem pedunculumque vaginante praeditae; caudiculae dimidiam longitudinem petioli superantes, triangulares; oblongae, acutae, reticulato-nervosae. Pedunculi axillares erecto-patentes, striati, petiolo bracteante triplo quadruplo longiores. Capitula 3o-40-flora bracteolata, floribus pedicellatis, primum erectis deinde reflexis, centralibus abortientibus, in penicillum rectum conniventibus immutatis. Florum fertilium pedicelli teretes, glabri, longitudine varia, externi brevissimi, interiores pedetentim longiores, 
tandem tubum calycinum aequantes vel superantes. Bracleolae ninutae, lanceolato-acuminatae, scariosae. Calycis tubus membranaceo-scariosus, longitudinaliter 10-nervius. Nervi primarii usque ad apicem dentinm decurrunt; minores cm iis alternantes fauce consistunt et in duabus venulis divisi marginem dentium percurrunt et tandem nervo mediano conjunguntur. Dentes calycini lanceolato-subulati, viriduli; superior tubum aequans vexillo plus quam dimidio brevior; intermedii tubo breviores; infimi intermediis minores. Vexillum ovato-obtusum, in anthesi albo-luteolum, tandem avellanaceum, nervoso-striatum. Alae vexillo quarta parte breviores carinam superantes. Legumen glabrum, dorso infra duo semina, quae matura non vidi, emarginatum.

Tota planta glabra, caules et rami primarii m. o, 25 circiter longi.

0bs..T. Micheliano SAri et T. nigrescenti Viv. affinis. Differt a primo stipulis margine externo connexis, licet continuis caulemque vaginantibus; dentibus calycinis lanceolato-triangularibus tubum subaequantibus, nec lineari-setuce is tubo longioribus. A T. nigrescenti differt caulibus ramisque fistulosis, leguminibus dispermis.

\section{Trifolicy Petrisavil mihi.}

T. caulibus solidis mcdullosis; foliolis cuneato-triangularibus, obtusis; stipulis vagina scarioso-membranacea caulem amplectente externe connexis; capitulis densis; floribus bracteolatis, post anthesim omnibus umbellatim reflexis; dentibus calycinis lanceolatis tubum aequantibus, leguminibus dispermis.

Hab. Copiose provenit in collibus constantinopolitanis ultra il Gran Campo et tota aestate floret.

Planta perennis, caespitosa; ramis primariis sparsis, prostratis, arrhizis, medulla farctis, m. 0,08 a m. o, 18 circiter longis, longitudinaliter striatis. Folia longe petiolata; foliolis cuneato obtusis, nervosis, superiori margine ex nervaturis excurrentibus serrato-cuspidatis. Stipulae exteriori latere inter se, interiori cum petioli basi connexae, caulem pedunculumque late vaginantes; caudiculac triangulares, lineari-acurrinatae, nervosae vaginae longitudine. Pedunculi axillares folio $2-4$-longiores, striati, erecto-divergentes, capitulis densis 25-3o-floris terminati. Flores minute bracteolati, pedicellati. Pedioli teretes, praesertim externi abbreviati, post anthesim omnes recurvati. Bracteolae scariosae, ovato-acuminatae, nervo mediano usque ad apicem producto carinatae. Calycis tubus 
campanulato-cylindricus, membranaceo-scariosus pediolo longior, longitudinaliter 10-nervius; limbus 5-dentatus, dentibus lanceolato-acuminatis, margine scarioso-membranaceis; duobus superioribus majoribus, tubum aequantibus, dimidinmque vexillum paullulum superantibus; inferiore minori dimidiam carinam aequante. Nervi calycis quinque majores usque ad apicem dentium decurrunt; quinque minores, ad faucem bifidi denlium reapse trinervium margines percurrunt. Vexillnm sordide albidum, ovato-acuminatum, longitudinaliter plicato-striatum, apice minute denticulatum. Alae vexillo quarta parte breviores, carinam vix superantes. Legumen sessile, dispermum, dorso, infra semina, emarginatum.

0bs. A praecedente specie differt: caulibus medullosis nec fistulosis, capitulis densifloris, forma foliorum et omnino habitu.

A $T$. nigrescente Viv. diff. leguminibus dispermis nec 4 -spermis, dentibus calycinis tubo et dimidio vexillo brevioribus, capitulis magis densis, et tandem omnibus partibus rigidioribus magisque compactis.

Trifolium armenicm $W$. var. pumilum Clem.

llab. Legi in declivitatibus alpinis Olympi bith. latere orientali. Floret Augusto, Septembre.

Caulis humilis semipalmaris adscendens; capituli abbreviati; stipulae saepe aphyllae.

Trifolium striatcm L. var. constantinopolitanum Clem.

Hab. In collibus circa Constantinopolim aestate.

Tota planta villoso-albescens, caulibus abbreviatis, compactis, robustis.

\section{Trifolicm subterranely L.}

Hab. In agro constantinopolitano tres formae insignes hujus speciei distinguuntur :

a.: Pedunculis folio longioribus, seminibus atro-purpureis nec nigris.

Tota planta gracilis et longissime repens, parce pilosa; flores steriles numerosi tenues; dentes calycini valde elongati, pilosissimi.

Crescit in locis humentibus prope aquaednctum ultra il Gran Campo di Pera.

$\beta$. : Pedunculis folio longioribus, seminibus atro-purpureis sicut 
in antecedenti; sed tota planta valde contracta, robusta, villosa. Flores steriles minus graciles quam in $\alpha$.

Crescit in eadem localitate, sed in solo sicciori at calidiori. $\gamma$ : : Calycibus atro-purpureis.

Planta saepissime pusilla, ramulis prostrato-divaricatis, fere truncatis.

I praecedente non longe tloret vere.

\section{Trifolium cNiflorum L.}

Ilab. Laetissime floret primo vere in pascuis collinis prope Ciumlicia ultra Scutarim asiaticum.

0bs. Species pulcra, ab aliis congeneribus habitu onnino diversa. Lx radice longissima perpendiculari caules numerosi in caespitibus parvulis densis contracti. Ager byzantinus, trifoliis uberrimus, etiam sequentia, quae legi, hospitatur:

$T$. constantinopolitanum SERivg, quod $T$. supino simile, forma calycis ab illo distinguitur. Rarissime mili occurrit circa il Gran Campo di Per'a.

$T$. elegans $\mathrm{S}_{\mathrm{Av}}$. In collibus locisque magis insolatis haud rarum.

$T$. filiforme $\mathrm{L}$. In cultis locisque glareosis rarissimum adnotavi.

T. globosum L. et $T$. resupinatum L. Ubique vulgatissima.

$T$. stellatum L. et $T$. Cherleri L. In herbidis promiscue crescunt, praecedentilus rariora.

$T$. scabrum L. et $T$. glomeratum L. Etiam consociata saepissime observavi. Solo steriliori et duro delectantur.

T. fragiferum L. Vulgatissimum in areis, ad vias, locisque argillosocalcareis.

T. procumbens et $\boldsymbol{T}$. arvense $\mathrm{L}$. Locis apricis hac illacque observavi.

Coronilla Emerts L.

Hab. In monte IIymetto.

\section{DoricNiun Rectim Sering.}

Ilab. Crescit in planitie athenieusi hunidiori. Legi fructificanteu prope flumen Kiephyssum, autumno.

0bs. Species a congeneribus habitu valde recedeus, lignosa, elata ; leguminibus numerosis, capitato-fasciculatis instructa. 
Lotus angestissmes L.

Ilab. Legi in collibus siccioribus prope Byzantium. Floret Julio.

0ls. Caules procumbentes; pedunculi breves; dentes calycini linearisubulati, tubum aequantes. Tota planta, praesertim superne, pilis setiformiluus argenteis adspersa.

Jotes corniculates L.

Hab. Ad Kiephyssum flum. Attica.

Psoralea bituminosa L.

$\beta$. pustulata Cuen.

llab. ๔. In insula Corcyra.

ß. Ad litora maris prope Phanarati, ultra Katikioim (Calcedoniam) aestate. Tota planta multo magis quam species ramosa, magisque piloso-argentea, pilis erecto-patulis; foliolis superioribus ovatolanceolatis, nunquam angustato-linearibus. Legumen calycem conspicue excedens, ad pilorum ortum nigro-pustulatum.

Astragales Pressianes Boiss.! n. 9. p. 88.

A. caespitosus, ramosissimus; ramis adscendentibus erectisve; niveoJanatis; foliis patentibus 6-8-jugis in spinam validam abeuntibus; foliolis ellipticis vel obverse lanceolatis, obovatisve, mucronato-spinulosis; pilis canescentibus subadpressis hirtis; stipulis acuminato-triangularibus, dorso connexis, coriaceis, avellanaceis, internodium dimidium aequantibus superantibusve, inferioribus nudis Incidis, superioribns floralibusque sensim albo-lanatis; floribus sessilibus dense capitatis; capitulis terminalibus, compactis, bombycinis, plerunıque cylindricis bipollicaribus; bracteis membranaceis, obverse lineari-lanceolatis, superne barbatis, calyces aequantibus; calycis bombycini dentibus linearibus, apice subincurvis, praeter mucronem villo occultatis, tubum, demum fissilem, aequantibus; corolla pallide ochroleuca, calyce tertio longiore; rexilli lamina basi obsolete auriculata, in unguem subaequalem attenuata; legumine minimo inonospermo.

Ilab. Legi in collibus di Demerdesch Brussianae ditionis. Floret Augusto mense.

0bs. Auctoritate cl. Borssier ad $A$. Prussianum plantam meam refero At in Diagnosibus orient. l. c. folia adnotantur adpressissime hirta, 
stipulae (omnes) albo-tomentosae brevissimae, capitula rotunda magnitudine nucis, bracteae lineari-setaceae, plumosissimae; quibus characteribus $A$. Prussianus a planta nostra nonnihil recedere videtur.

An A. Brussianus loco Prussiani e patria denominandus?

Astragalus angustifolies Lay.

* Ilab. Legi in regione alpina Olympi bith. ubi floret Julio decedente et Augusto.

Obs. Diagnosim hujusce speciei a cl. Grisebacho in Flora rumelicit I. 57. exhibitam, ex speciminibus ex Olympo illatis hisce absolvendam censeo: "Leguminibus ovalibus utrinque acutiusculis, villis adpressis albo-nigricantibus, bilocularibus, loculis 2-4-spermis, seminibus avellanaceis laeviter rugosis. ")

Planta admodum caespitosa; racemi 4-8-flori potius quam 10-flori; ,lentes calycini lineares subulati, nec lanceolati acuminati.

Astragalus mirsutus Vahl.! DC. Prodrom. 2. p. 306 teste Boissier!

A. caulescens, diffusus, procumbens; foliis sub 5-jugis, varie ellipticis, villoso-argenteis; capitulis subglobosis pedunculatis, pedunculis circiter longitudine foliorum, sordide rubentibus, pilosis; floribus luteoochroleucis, calyce duplo longioribus; calycibus pilis discoloribus, albonigricantibus; dentibus tubum, demum fissum, subaequantibus, lanceolato-subulatis; leguminibus ovatis, rostratis, calyce duplo longioribus, villis longis candidissimis tectis; loculis sub 3 -spermis; seminibus compresso-ovoideo-truncatis, olivaceis, nigro-punctatis.

Hab. Crescit in cacuminibus alpinis aridis Olympi bith. et floret Julio decedente.

0bs. Characteres praepositi ex speciminibus I. c. lectis excerpti, ad pleniorem speciei diagnosim hic exhibentur, vel eo magis quod descriptio Candolleana nimis contracta et incompleta mihi videtur.

Affinis A. vesicario DC. et A. Pastelliano Poclın. Caulis ramique abbreviati apice reliquiis foliorum annorum praegressorum emarcidis vestiti, fructiferi pollicem vix longitudine excedentes. Stipulae papiraceae, ciliatae, caeterum glabrae, pro foliorum amplitudine grandes, cum petioli basi inferne connatae. 
Astragalus Sibthorpianus Bolss.!

Hab. Crescit in pascuis saxosis imbre dirntis regionis alpinae superioris Olympi bith. e latere N. O. Legi Augusto mense florentem et fructificantem.

0bs. Species distinctissima ad sectionem Caprinorum Ledeb. pertinens: caule multiplici sub solo repente, nigricante, squamoso; foliis circiter ro-jugis, minutis, piloso-argenteis; floribus subsessilibus, in capitulum ovato-rotundatum aggregatis; bracteis lanceolato-linearibus, calyceın subaequantibus; calycinis dentibus lineari-subulatis tubum subaequantibus; corollis atropurpureo-viridulis ; vexilli lamina ovato-oblonga, alis angustato-oblongis carinam superantibus tertio longiore; leguminibus compressis, semiovatis, mucronatis; seminiluus coinpressis avellanaceis.

\section{Astragalus Spruneri Boiss.}

lial. Legi in viciniis Athenarum circa Stadium. Flores parum numerosi, elongati; calyces nigricantes; corolla magna, sordide luteo-pmrpurascens. Floret vere.

\section{Biserrela Pelecinus L.}

Hab. Floret primo vere in sylvulis apricis prope Bosphorum.

Herba debilis, forma leguminum perelegans.

\section{OrNituopes conpressus L.}

llab. Crescit pusillus et rarus in sylvulis byzantinis Bosphorum secundantibus. Legi aestate incipiente.

\section{Ononrycils Cadmea Boiss.! Diagn.}

llab. In praeruptis alpinis Olympi bith., mense Augusti.

obs. Duplici sub forma 1. c. mihi se obtulit; caulibus nempe simplicibus, elatis, foliis elongatis, foliolis rarioribus oblongo-lancenlatis, vel caulibus decurtatis a basi ramosis, foliis contractis, foliolis abbreviatis. Flores in utraque varietate semper magni, speciosi, ex quo faciem propriam non dimittit.

\section{Oxobrycuis Capet Galli Lam.}

Hab. In agro constantinopolitano hand frequens, aestate. 
IICIA IIIRTA BiL.B.

Ilab. Pusilla et rara occurrit in sylvulis prope Bosphorum, et floret aestate.

Vicia vani Host. - I icia villosa $\beta$. glabrescens Korн? Syn. I. p. 214 .

Hab. In cultis collinis aridioribus prope Byzantium a pecoribus defrasta e radice perenni? Diu repullulat. Legi aestate.

0ls. Folia potius lanceolato-linearia vel linearia quam lanceolata, pilis praesertim marginalibus subpatulis, nec magis quam in specie adpressis ut in Косн I. c.

\section{Vicia lathyroides L.} incipicnte.

Hab. Sylvulis prope Bosphorum raro incolit. Floret vere et aestate

Vicia pseudo cracca Bertol.

Hab. In ejusdem ditionis locis siccioribus passim.

Vicia cassabica L.

Ilab. Legi una vice in regione abietis Olympi bith. Statura elatiori insignis! Color foliorum obscure viridis. Floret a Julio ad Augustum.

\section{LePINCS ANGLSTIFolius L.}

Ilab. In agro byzantino.

\section{$R O S \wedge \mathrm{CE} A \mathrm{E}$.}

Rubes anoencs Portschl.

Hab. Legi aestate in saxosis collinis prope Ciamlicia ultra Scutarim asiaticum, nec a stirpe dalmatica videtur diversus.

ReBUS TONENTOSES W.

Hab. Crescit in regione subalpina Olympi bith. Folia dorso molliter incano-tomentosa, facie omnino glabra et intense viridia. Legi fructificantem Augusto mense. 
RuBUs FRUTICoses L.

llab. In Attica prope Kiessariany.

Potextilla Beccosisa mili.

P. radice lignosa, valida; caulibus adscendentibus robustis; foliis ternatis, foliolis ovatis vel obovato-cuneatis, grosse et obtuse dentatis; corymbo multifloro; petalis obcordatis vel obovatis, calyce tertia parte longioribus; calyciuis laciuiis inaequalibus; receptaculo conoideo-columnari. villoso.

Ilab. Legi in Olympi lith. pratis alpinis lapidosis latere N. E. Floret Augusto decedente et Septembre.

Radix descendens lignosa, prae planta maxima, nigricans, ad collum reliquiis foliorum persistentibus squamata; squamis rufo-nigricantibus. Caules bi-sesquipedales, plurini, adscendentes, fistulosi et robustissimi, obsolete rotundato-angulati, superne striati et dichotomi, pilis tenuibus villoso-pubescentibus. Folia omnia ternata, inferiora longe petiolata. Foliola inferiorum ovata, basi cuneata, vel obovato-cuneata, rariusve taıtum ovata; superiorum magis cuneata; omnia, parte cuneata excepta, grosse et plus minus profunde serrato-dentata, dentibus omnibus obtusissinis rotundatis conformibus; utrinque viridia, demum frequenter lutescentia; dorso nervaturis et margine subaequaliter villosa, facie glabrata. Petioli pubescentes supra canaliculati. Stipulae grandiusculae, basi petioli adnatae, oblongae vel lanceolatae, oblique acuminatae. Cyma subcorymbosa dichotoma, ramis plus minusve elongatis, floribus in ramis approximatis. Pedioli firmi semper axillares, magis quam caules pilosi. Calyces magni etiam pilosi, laciniis ovato-lanceolatis inaequalibus, exterioribus multo minoribus, nervosis vel reticulato-nervosis, in anthesi subacutis dein obtusiusculis. Petala obcordata vel obovata, ca!yce tertia parte longiora, supra luteo-aurea, subtus ochracea. Filamenta glabra. Receptacnlum conoideo-columnare villosum. Nuculae arcuatim striatocostatae.

0bs. Differt a $P$. grandiflora: dentibus foliorum oblongatorum obtusis; calycinis laciniis inaequalibus obtusiusculis, petalis minoribus, receptaculo conoideo-columnare, omnibus partibus rolsustioribus et facie propria. Forma receptaculi et habitı etiam ad Geum vergit. 
POTENTILLA REPTANS L.

Potentilla canescens Bess.

Hab. In agro byzantino prout in superiori Italia vulgatissimae crescunt.

Sibbalda procumbens L.

Ilab. Aegre crescit in Olympi bith. regione alpina.

Rosa rebigivosa L.

Ilah. In collibus byzantinis.

Rosa pigmaea Bieb. var. olympica Clem.

Hab. Legi ad rupes calcareas alpinas Olympi bith. in versante N. E. 0bs. A specie recedit: foliis tomentoso-sericeis, subtus albicantibus. Poterica spinosum L.

Hab. Byzantii, Scutaris et Atticae.

\section{P O M A C E AE.}

Pyrus salicifolia L.

Ilab. Ad radices mont. Parnis atheniensis, ubi foliis oblongo-ellipticis vestitur, quam quae stirpis dalmaticae multo brevioribus magisque glabratis.

Cotoneaster velgaris Linde.

Hab. Corcyrae.

\section{O N A G A R I AE.}

Epilobicm palustre L. et Fl. bith.

Hab. In regione alpina media Olympi bith. ad rivulos crescit Augusto. 0bs. Subpalmaris, gracilis; petalis violaceis sepalis lanceolatis duplo longioribus; fructibus pollicaribus incanis.

Epilobium roseun Siıth. varietas.

Hab. Legi aestate prope Byzantium.

0bs. Statura minori foliisque haud crebre dentatis a specie distinguitur. 


\section{A L L I T R I C H I N E A E.}

Callitriche platycarpa var. marginata Cien.

C. foliis omnibus e basi plus minusve attenuata spathulatis, retusis, triplinerviis; fructum superiorum pedunculis brevibus, inferiorum elongatis; carpidiis per paria parallelis, angulis marginatis.

0bs. Ab omnibus milhi cognitis varietatibus Callitriches platycarpae stagnatilis celeberrimi Kuntzıngu, characteribus exhibitis satis superque differt.

\section{Y T H R A R I A E.}

\section{Lytimun Graefferi Ten.}

Hab. In planitie atheniensi ad ripas Kiephyssi, et in suburbiis byzantinis reperi aestate.

0ls. In utroque loco $L$. Graefferi floribus multo minoribus quam in planta ligustica ornatur.

\section{LrTHRUM SALICARIA L.}

Hab. Byzantii cum praecedente.

Lithrey numularifolum Lois.! - Middendorfia hamulosa Trautw.? Peplis Borysthenica BвRst. ?

Hab. Loco humenti ultra il Gran Campo di Costantinopoli legi una vice Junio mense.

Obs. Folia subsessilia; caules fistulosi flaccidi; tota planta crispula.

\section{P O R T U L A C E A E.}

Montia Fontana var. minor Косн.

Hab. In dumetosis collium humillima et recondita crescit a Byzantio non longe. Floret primissimo vere.

\section{P A R O N Y H I E AE.}

\section{Paronychla argentea Lam.}

Hab. In mont. Parnis et Olympo. 
Herniuria incaxa Lay.

Ilab. Ad pedes Pentilici.

HERNIARIA HIRSUTA L.

Hab. Ad Byzantium et in Olympo.

\section{S C L E R A N T H E A E.}

\section{Scleranthus marginatus Guss.}

Hab. In collibus siccioribus prope Byzantium copiosissime crescit et floret aestate.

\section{Scleranthus annuts L.}

Hab. In Attica et Byzantii.

\section{Minuartia fasciculata Rchmb.}

Hab. In herbidis sterilibus Atticae vulgatissima reperitur tota aestate.

\section{R A S U L A C E A E.}

Crassula Magnoli Ten. - Sedum caespitosum DC.

Hab. Locis rimosis calcareis circa Byzantium reperitur. Floret a vere in aestate.

Obs. Statura variat a centimetro ad sex. Petala sunt lineari-lanceolata, acuta, albo-scariosa, ad costam rubentia. Follicula rigida patentia in stylum brevem persistentem desinentia, costato-striala, costis rubentibus.

Sedum galioides Pourr.

Hab. In Olympo bith.

Cotyledon unbilicus $\mathbf{L}$.

Cotyledon horizontalis Guss. Fl. sic. Syn. i. p. 513.

Hab. In declivitatibus glareosis prope Byzantium.

0bs. Cotyledon horizontalis, in Fl. rumelica omissus, a C. umbilico probe distinguitur racemo densifloro, floribus horizontalibus, corollae profundius quinquefidae segmentis lanceolatis acutissimis. Vidi in har specie folia cordato-reniformia haud peltata. 


\section{$S A X I F R A G A E$.}

SAXifraga mixta Lapeyr. var. olympica Boiss.! herb.

Hab. In Olympi bitll. regione alpina, sed raro, mihi occurrit mense Augusti.

\section{Saxifraga Friderici-Augusti Biasol.}

Hab. In calcareis alpinis Olympi bith. vulgatissima; Julio, Augusto. 0bs. Ei absolute identica, cujus olim perpauca legi specimina in regione Montenegro nuncupata, per Dalmatiae provincias iter faciens.

Saxifraga Rotundifolia $\alpha$ et ò geodes Fl. rum. 1 . p. 336.

Hab. Cum nonnullis aliis formis intermediis in Olympi bith. regione alpina legi Augusto.

\section{U M B E L L I F E R A E.}

\section{ERINGIUM VIRIDE LK.}

Ilab. Circa Athenas.

\section{Ptychotis anmoldes Косн !}

Hab. Copiose provenit in insula Corcyra, et praesertim ad radices mont. Pandokratora. Tota aestate floret.

Bupleurum olyupicun Borss.! Diagn. - B. ranunculoides Sм.? ex Fl. rum. add. 508. - non LinneI.

B. caule a basi ramoso; ramis rigidis, divaricatis prostratisve, primario subinde nullo, teretibus, striatis, glabris; foliis radicalibus subcongestis, rigidis 5-7-nerviis; inferioribus spathulatis vel oblanceolatoovatis in petiolum attenuatis; superioribus obverse lineari-lanceolatis plus minusve angustatis, falcatis; caulinis paucis, sessilibus, lineari-lanceolatis, acutis; umbellarum radiis 5-8 inaequalibus; involucri foliolis inaequalibus, uno duobus majoribus, lanceolatis, acutis, subquinquenerviis; involucelli foliolis quinque conformibus ovato-lanceolatis, acuminato-cuspidatis, margine leviter cartilagineis, subtrinerviis, nervaturis lutescentibus, 
pediolis fructum aequantibus paullo superantibus; diacheniis ovoideooblongis, subulato-costatis.

Caules el totius plantae partes magnitudine ludunt.

llab. In cacumine Olympi bith. legi Augusto.

Bupleurum glumaceum $\mathrm{S}_{\text {H. }}$.

llab. In insula Corcyra legi aestate.

0bs. In collinis proveniens gracillimum, defoliatum; in litoreis crassius et luxurians; in utroque vero characteres florum el fructus omnino iidem.

\section{Bupleuncy glatcum Roxb.}

Hab. In litore prope Kalamaki ultra isthmum Corinthi copiose reperi mense Augusti.

Obs. Nisi statura minore et umbellis contractis ab italico recedit.

\section{Crithuum maritimum $\mathbf{L}$.}

llab. Ad litora Corcyrae.

Oenanthe peucedinifolia L.

Oenantie pimpinellfFola $L$.

Hab. Utraque provenimnt in collibus Byzantinis aestate.

Obs. Harum posterior, foliis magis dissectis, partitionibus tenuioribus. a planta in Italia vulgatiore paulisper divergit.

\section{Scandix Pecten L.}

Hab. In Attica.

\section{Seseli caespitosum Su.}

Ilab. In Olympi bith. herbidis apricis et lapidosis S. E. prospicien tibus uma vice reperi Augusto mense.

\section{Anetium Foeniculum L.}

Illab. Atticae; ad Kiephyssum.

\section{Heracleum humle S. et Su. !}

Ilab. Species in Olympi bith. regione alpina perrara et a congeneribus etiam facie prima fronte distincta. Legi Augusto incipiente. 


\section{Tordylum APULum L.}

Hab. In collibus byzantinis ultra il Gran Campo mihi occurrit haud frequens aestate et autumno.

Torilis nodosa DC.

Hab. Iisdem in locis cum Tordylio frequentius occurrit.

TORilis infesta Bertol.

Hab. Byzantii.

\section{A R A L I A G E A E.}

Hedera poétarum Bert.

Hab. Uno loco mihi occurrit ab Athenis non longe Kiessariany nuncupato. Floret aestate decedente et autumno fructificat.

\section{O R N E A E.}

Cornus mascula L.

Hab. In sepibus byzantinis.

\section{O R A N T A G E AE.}

\section{Viscum AlbuM L.}

Hab. Ad abietem Apollinis in mont. Parnis ath.

\section{G A P R I F O L I A G E A E.}

Lonicera CAPRifolium L. arborea Clem.

Hlab. Crescit ad margines agrorum prope Brussam asiaticam. Floret mense Augusti.

0bs. Capituli omnes ternato-terminales. Truncus arboreus. Rami et dorsum foliorum omnium connatorum pruinosa. Minus quam specie odore grato scatet. An L. etrusca?

$$
\text { S T E L L A T A E. }
$$

Asperula involucrata WAHLb. ex Fl. rumel. 2. p. 167. 
liab. Habui a Domina Josephina Fossats, quae ad radices Olynui bith. in valle del Paradiso mncupata legit vere lecedente.

0bs. Folia caulina rameaque inferiora non raro ad basim videntu. 3-nervia: caeterum cum planta Fl. rumelicae omnibus partibus congruit. Pulcherrima species!

Aspercla nitida Sy. ex Fl. rumel.

Ilab. Frequens in regione alpina et subalpina Olympi bith.

0bs. Valde ludit statura; saepissime uana et fere acaulis, quandoque longe caulescens. Tamen characteres specifici immutabiles nisi excipias folia et corollam, quae in procerioribus simul cum canlibus clongantur.

\section{Aspfrela Crnanchica homophylla Clem.}

"Foliis supremis oppositis, ceterisque quaternis lineari-subulatis: " caule ramisque inferne valde scabris. "

llab. In collibus byzantinis aestate.

\section{Sherardia ARvensis L.}

liab. Circa Byzantium.

Valantia muralis L.

llab. Byzantii, et in Attica.

\section{Cruchanella graeca Boiss.}

llab. In Hymetto meridionali.

Galium longlfolicir Griseb. - G. effiusum Bolss. et Griseb. Asperula longifolia Sıвт. et $\mathrm{S}_{\mathbf{n}}$. Augusto.

llab. In regione Fagi Olympi bith. haud frequens occurrit. Legi

Galium orientale Boiss.! - Galium incumum Sm.! ex Griseb. Fl. rumel. 2. p. $15 \mathrm{~g}$.

Hab. In Olympi bith. regione alpina latere S. E. crescit rarum, et rupium calcarium fissuris delectatur.

0bs. G. sylvestri affine; distinguitur caulibus dense implexo-caespitosis, foliis sex linearibus, angustis, mucronatis, rigidiusculis, nitidis, in sicco dorso, ob nerrum robustum prominentem, 2-sulcatis, livido-fuscis; cymis 
plerumque 2-3-floris, strictis. - Caules ramique perennantes, juniores pilosiusculo-scabridi, demum glabrati: rani juniores et folia livido-fuscescentia.

\section{Galicm setacecm Lam.}

Hab. Legi in monte Hymetto atheniense, aestate.

Galica maricitcm Lanck. - Guss. Fl. sic. Syu. 1. p. 186 . vC. Ic. pl. gall. rar. tab. 24 .

llab. In apricis prope Byzantim.

0bs. Omni numero convenire mihi risum est cum G. divaricati Icone adducta, nec non cum descriptione cl. Gussonn, nisi quod fructus in Icone Candolleana laeves glabrique dipicti sunt, qui in nostro exiute sub lente granulati: pedioli porro non omnes fructus longitudine aequant ut in planta sicula. Ceterum a $G$. setaceo LAuск, a floribundo et tenuissimo Fl. rumelicae, vel fructu granulato vel corollae segmentis muticis differt.

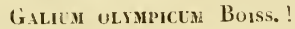

Hab. In Olynupi bith. regionis alpinae declivitatibus calcareis cum Draba olympica, aliisque rarissimis stirjibus abmude crescit et floret Augusto.

0bs. Specimina nostra a descriptione cl. Borssıerı, ex Fl. rumel. characteribus sequentibus quidquam divergunt folia margine admodum revoluta omnino glabra, nec margine scabriuscula; flores axillares terminalesque, nec tantum axillares; laciniae corollinae lanceolato-lineares, obtusinsculae, nec lanceolato-acutae.

\section{Gilien coronitum Siвтн.}

Hab. Huc et illuc in herbidis et inter saxa Olympi bith. regione alpina media reperitur Augusto.

0bs. Folia 3-nervia, nec enervia ut R. et S. 2. p. 219, nec 1-nervia ut in Fl. rumel. traditum est; caules glabri, basi lignescentes ut in R. et s., elongati, prostrato-repentes licet laxi ut in Fl. rumel. 2. p. I63, sed nunquam pilosi.

Galium Mollugo var. - G. Tyrolense II.

Hab. Legi Augusto in regione Fagi Olympi bih. 
Obs. Planta Olympica quae cum speciminibus G. Tyrolensis, in Veronensi provincia lectis, convenit, a G. Mollugine statura minori cauleque recto praeeunte $\mathrm{cl}$. Косн, tantum differre evidenter patet. Cf. Коск Syn. ed. 2. p. 366.

\section{Galium verum $\mathbf{L}$.}

Ilab. Ad Byzantium et in Attica.

Rubia peregrina L.

Hab. In Attica ad Kiephyssum.

\section{A L E R I A N E A E.}

Valeriana Aluiarifolia Vahl. Fl. rumel. 2. p. $17^{2}$.

llab. Species in Olympo bith. perrara. Legi una vice in declivitatibus alpinis orientalibus. Floret Augusto decedente et Septembre.

\section{Fedia echinata Vahl.}

Hab. In Attica.

Valerianella puberula DC. - $\boldsymbol{l}$. microcarpa Betck ex Fl. rumel.

llab. In cultis collinis prope Byzantium crescit admodum mutabilis. Floret vere.

Obs. Dantur specimina semipalmaria gracilia et etiam pollicaria contracta.

\section{I P S A C E AE.}

\section{Dipsacus haciniatus $\mathrm{L}$.}

Ilab. In collibus calidissimis ad Demerdesch prope Brussam asiaticam. Floret Julio, Augusto.

0ls. Folia superiora profunde laciniata, quasi pinnatifida, laciniis serrato-dentatis.

\section{Krautia oRifntalis L.}

Ilab. Legi in collibus Demerdesch a Brussa non longe; aestate. Elata, ramosissima, pene luxurians!! 
Scabiosa vkranica L.

Ilab. Legi in glareosis collinis prope Demerdesch ditionis Brussianae. Floret Julio, Augusto.

0ls. Optime ad specimina herbarii WeBBrr. Caulis basi pilis longis admodum sparsis praeditus, superne glaber. Acheniorum corona pappo triplo brevior.

Scabiosa tencis Sprux. in Boiss. Diagn.

Hab. Legi in insulae Corcyrae declivitatibus collinis haud frequens. Floret Julio.

\section{SCABIOSA MARITIMA L.}

Hab. In agro constantinopolitano valde mutabilis crescit.

\section{Scabiosa Columbaria L.}

Ilab. Cum praecedente. Aestate.

0bs. A typo speciei plerumque recedens caule simplici, spithameo, monocephalo; foliis inferioribus petiolatis, ovatis, serratis. Tota planta villoso-subsericea. Floret aestate.

\section{O M P O S I T AE.}

\section{CICHORACEAE.}

\section{LAPSANA gBandiflora MB.}

Hab. Raro occurrit in regione subalpina Olympi bitb. locis umbrosioribus. Legi Augusto.

0bs. Species plus quam orgyalis et a communi vere distincta.

Sonchus tenerrimus muriculatus Clem. anthodiis, praesertim inferne, muriculatis.

Hab. Prope Piraeum athen. crescit et floret vere.

\section{Cichoriem byzantinum mihi.}

C. perenne? radice caespitosa vel unicanli, caulibus inferne hirtis, sursum scabris, glabrisve, alterne ramosis, ramis patenti-refractis a basi ad apicem incrassatis, fistulosis, plerumque indivisis, apice floriferis; foliis radicalibus rosulatis, plerisque runcinatis, hirtis, floralibus e basi 
ovata acuminatis, vix semi-amplexicaulibus, ab infimis sensim decrescentibus; capitulis in ramorum apice plerumque solitariis, axillaribus 2-3fasciculatis, subsessilibus, subindeque ramulo plus minusve elongato unicapitulifero stipatis; capitulis 3-12-floris; involucri squamis exterioribus adpressis, ovatis, obtusiusculis, margine denticulatis, scabris, glabrisve, interioribus duplo !revioribus; acheniis obconoideis costatis; pappo squamellis membranaceis composito coroniformi, acheniis ipsis quadruplo breviore.

Hab. In agro constantinopolitano, substrato conditionibusque pervariis abunde crescit. Floret a vere in autumnum.

Obs. Planta polymorpha, facie nec non characteribus inter $C$. Endiviam et $C$. divaricatum fere ambigens. Rami, vel si mavis pedunculi axillares quandoque gemini, altero elongato capitulo unico terminato, altero brevissimo capitula $3-4$ gerente; folia oblonga, denticulata; rami flexuosi. In nonnullis speciminibus c contra, caulis dichotome ranosus, folia radicalia runcinata, caulina oblonga, dentata, pedunculi capitulique ut in priore. In plerisque tandem capituli in pedunculo ablsreviato unicus vel plures, pednnculi elongati constanter unicapituliferi, sed longitudine quammaxime varii, una cum caule incurvato-retorti; folia plerumque runcinata, laciniis numerosis, angustis, dissectis, vel oblongis obverse lanceolatis plus minusve irregulariter dentatis. Statura etiam variat a spithama ad orgyam dimidiam usque.

A C. Intybo distinguitur foliolis involucri exterioribus ovatis, adpressis, minute denticulatis interioribus dimidio breviorilus, pappo coroniformi achenio quadruplo tantum breviore.

A $C$. divaricato foliolis involucri exterioribus interiora non aequantibus nec longe ciliatis.

A C. Endivia demum, radice, ut videtur, perenni, foliis floralibus e basi vix semiamplectente attenuatis, nequaquam auriculatis.

HelmiNTHL Feholdes $W$.

Hab. In Attica.

Tolpis umbellata Bertol..

TOlpis altissiala Bertol.

liab. Utramque legi in agro byzantiuo. Florent tota atstate. 
hosiris microcephala Cass.

llab. In praeruptis prope Piraeum atheniense legi vere.

0bs. Statura, scapis brevissimis, capitulis longioribus, vel folia aequantibus, superautibusve, admodum varia.

Hentpvois polyuorpHs DC. - H. rhagadioloides Morus Fl. sard. 2. P 509.

Hah. Crescit ad vias prope Bosphorum et in suburbiis byzantinis. Floret tota aestate.

In saxosis maritimis prope Piraeum athenieuse vere ineunte varieıatem H. hubaeformi TexoRfi respondentenı legi.

Pichis olympica Bolss. Diagn. 4. p. 26.

Ilab. In Olympi bith. pascuis editioribus, Augusto mense, florentem legi.

Picridici velgare Desf.

Hab. In Corcyra et in Attica.

\section{Urospermud picroides Desf.}

Hab. In declivitatibus minoribus montis Pentilici atheniensis haud frequens occurrit ab aestate in autumnum.

Sconzonera pygmaea Sibth. - Griseb. Fl. rumel. 2. p. 264.

$S$. perennis; radice incrassata ad collum squamala, compacte caespiussa, ramis abbreviatis, crassis, squamatis, dense foliosis; foliis supra caespitem recurvatis, adpressis linearibus callo subindistincio obtusatis, basim versus sparse niveo-lanatis; ramis floriferis monocephalis, scapiformibus, basi foliatis, superiora versus folio uno alterove rudimentario squamatis, ceterum glabris, striatis; involucri, ligulis flavis dimidio brevioris, sparse albo-sublanati, squamis subbiseriatis, exterioribus ovatolanceolatis acuninulatis, interioribus oblongis obiusiusculis, margine subcartilagineo plerumque rubescentibus; achenio lineari, valde striato, pappo pluriseriali superne scabro rubescente.

Hah. Crescit in Olympi bith. regione alpina et floret Augusto mense.

obs. Variat in iisdem locis foliis elongatis, erectis, acutiusculis, subglabratis; caespitibus minus densis.

Speciei diagnosim ex exemplaribus collectionis meae concinnavi, co 
praesertim consilio, ut plantae pulcherrimae, non adhuc bene cognitae, characteres melius innotescant.

Podospermum laciniatun DC.

Ilab. In ditione byzantina mire varians.

Podospermun canum Mey.

Var. Olympicum CLem. foliis abbreviatis, regulariter profundiusque pinnatifidis; radice valde incrassata.

Ilab. In Olympi bith. reg. alpin.

Tota planta plus minusve canescens, laciniis anthodialibus basi et marginibus constanter albo-lanatis.

Hypochaeris glarra $\alpha$. Fl. sard. $-H$. minima Cyrill. non Fl. graec.

Ilab. Crescit haud frequens in pratis collinis siccioribus prope Byzantium. Legi vere decedente.

0bs. Folia lanceolato-oblonga, vel etiam ex petiolo angustissime spathulata, minute vel grosse denticulata. Scapus solitarius monocephalus, vel duo tribusve accessoriis serioribus gracilioribusque interdum anctus. Ceterum ab $H$. glabra non differt.

Hypochaeris madicata L.

Ilab. Iisdem locis ac praecedens sed magis frequens.

Taraxacul officinale $\delta$. Taraxacoides Koch.

liab. Numerosa specimina legi primo vere in collibus Ciamlicia ultra Scutarin asiaticum.

0bs. Involucri foliola exteriora erecta, cordato-ovato-acuminata. Achenia sulcata, rostro subsesquibreviora, supra medium tuberculis in dentes sen sim transenutibus muricata.

An T'araxacum laevigatum DC. ?

Taraxacui officinale $\gamma$ alpinum Косн.

llall. In Olympo bith.

Taraxacum Officinale $\varepsilon$. lividum Косн.

Hab. Circa Byzantium. 
Taraxacum gymantuum Lk.

Hab. Legi prope Kiessariany in ditione atheniensi. Floret vere. obs. Foliis hysteranthiis vel synanthiis occurrit.

Barkausia setosa DC. Fl. franc. var. insignis.

llab. Crescit in collibus byzantinis et floret vere.

0bs. Capitulorum structura omnino ad B. setosam accedit, sed facie et statura multo minore distinguitur.

Crepis polymorpha humilis DC. Prodr.

Hab. Ad pedes Pentilici ath.

\section{Chondrilla ramosissina Sibth.}

Hab. Crescit in planitie prope Athenas et floret tota aestate.

obs. Chondrillarum species sane singularis ob foliorum evolutionent imperfectam, ramorum autem maximam.

\section{lactuca Scariola L.}

Hab. In ruderatis Parthenonis.

\section{Zacyntha verrucosa Gaertin.}

Hab. In dumetis et pascuis sterilibus prope Bosphorum hand frequens reperitur aestate.

\section{Pterotheca nemausensis Cass. - Trichocrepis bifida Vis.}

Hab. In byzantinis collibus floret aestate.

0bs. Collata cum speciminibus italicis, dalmaticisque a memetipso lectis, differt tantum statura minore, foliis pedunculisque pubescentilanatis. In reliquis ad unguem convenit.

Hieracium lanatudi Vill. ex Griseb. Fl. rum. 2. p. 27 I.

Hab. Rarissimum ad summitatem rupium calcarium regionis alpinae Olympi bith. latere S. E. invenitur. Floret Augusto decedente vel Septembre.

0bs. Hieracium pannosum Borss. Diagn. 4. p. 32 adnotante cl. Fl. rumel. Auctore, a nostro nisi varietatis lege distinguendum.

\section{Hieracium Pilosella L.}

Hab. In Olympi bith. reg. alpin. inferiori. 


\section{CARDUACEAE.}

\section{Calendela arvensis pygmaea Clem.}

Ilab. In arvis atheniensibus prope Piraeum haec $C$. arvensis forma singularis crescit monocaulis, monocephala, uncialis vel seminncialis, foliis lanceolato-linearibus, integerrimis, anthodiis minimis pulchellis. Floret vere.

\section{Echinops microcephalus $S_{м}$. Fl. rum. p. 229.}

llah. Legi Septembre in collinis locis steriliorihus prope Byzantium. 0bs. Stirps tomento et colore foliorum variabilis, ut ex observationibus D'Urvillei et Grisebachn l. c. nec non ex diagnosi DC. Prodr. VI. 523 manifestum est. Folia in speciminibus nostris supra obscure viridia subglabrescentia, subtus arachnoideo-tomentosa, albescentia observantur. Involucri squamae interiores pilis sex octoties longiores sunt, dorsoque glabrae, lucido-cyanescentes, nec villosae, ut ab Auctoribus supracitatis notatur.

\section{Echinops bitirnicus Boiss.}

Hab. In ditionis brussianae collibus Demerdesch, Augusto vertente, unicum tantum specimen reperi.

Obs. Stirps admodum singularis, quam primo obtutu, ob pilos papillaeformes mbescentes, rigidissimos, quibus caules foliaque niveo-canescentia vestiuntur, vel coniomycete quodam parasitico prorsus omnem olrutam, vel morbo quodam laborantem diceres!

\section{Echinops almidus Boiss.}

Hab. Mense Septembri legi in monte Hymetto ath.

Capituli cito decidui, in anthesi folia summa tantum viridia, cetera arefacta. Radix lignosia et robusta.

Echinors graeces Milt.

Hab. In Athenarum planitie crescit pulcherrimus et a congeneribus omnibus insigniter diversus!

Ritho Tenufolius DC.

Hab. Legi specimina prope Phanaraki ultra Scutarim asiaticum, 
quae folis polius piunatis quam pinnatifidis, laciniis margine valde revolutis praedita sunt. Floret Julio mense.

\section{CirsicM LECCOPSIS DC.}

liab. Crescit laeteque viget in glareosis circa aquas fluentes in Olympi bith. regione alpina media. Floret Augnsto.

obs. In speciminibus a me collectis squamae involucrorum spinula simplici, nec inucrone spinuloso instructae sunt; in reliquis ad unguem congrumnt cum diagnosi a Fl. rumelica (2. 252 .) hujnsce speciei allata.

\section{Cirsicy lanceolatem Srop.}

llab. Legi ad pedem Hymetti prope Kiessariany.

0bs. A stirpe italica foliis brevioribus, laciniis nulto minus biseriatodivaricatis, anthodiis majoribus, squamis in anthesi parum patentibus quidquam diversum.

\section{Carduus tenuiflorus Curt.}

llab. In agro byzantino.

\section{Chamaepeuce stellata DC.}

Hab. Legi specimina in insula Corcyra. Floret aestate incipiente.

0ls. Anthodii squamae praelongae, lineari-subulatae, pungentes. Folia linearia, falcata, subtns nivea, spinis stipulaeformibus acicularibus basi spinula minima praeditis.

Chamaepeuce mutica DC.

Hab. In montis Hymetti convalle, Fauce dicta, legi aestate.

Folia linearia rigiditatem, colorem et faciem foliorum coniferarum aemulantur.

\section{Silybum marinnum Gaertn.}

Ilab. In collibus constantinopolitanis interdum occurrit. Floret aestate decedente.

Onopordon virens DC. Fl. fr. et Prodr. VI. p. 48. - O. viscosum HorN.!

Hab. Crescit ad vias locisque sterilibus suburbanis circa Byzantinn. Floret aestate. 
Optime a Cannolleo $O$. viscosum Honnemansi ut synonymon hujusce speciei habetur.

\section{ONOPORDON ILLIRICIM L.}

Ilab. Legi Augusto in insulae Corcyrae monte Pandolratora.

A stirpe dalmatica non differt nisi statura majori et lana magis densa et candidiore.

\section{Carlina lanata W.}

Ilab. Crescit in collibus ad Demerdesch nec non ad vias in planitie circa Brussam. Tota aestate floret.

0lss. A $C$. lanata anctorum differt: squamis involucri medii linearilanceolatis, subulatis, viridescentibus, margine tantum scariosis et dorso lanatis, nec nuticis! scariosis ut in Fl. rumel. perhibitur.

Plantae statura summe varia, 1-2 spithamea, subinde vix sesquipollicaris et tunc anthodia minima. Folia omnia, in plaota florente, semper exsiccatione detrita.

\section{Carlina corymesa L.} aestate.

llab. In planitie atheniensi prope Acropolim vulgatissima reperitur

\section{Atractylis gumifera W.}

Hab. Legi aestate in planitie atheniensi superiori.

Cynarocephalarum stirps mirabilis, anthodio giganteo acauli.

\section{Atractilis cancellata $L$.}

Hab. Frequenter reperi in monte Hymetto.

\section{Jurinea consanguinea DC.}

Ilab. Species formosa, Julio florens, in convalle quadam alpina Olympi bith. Eurum versus, mihi tantum occurrit.

0ls. Cum autenticis speciminibus herbarii Webbiani nostra omnino similis. Involucı i foliola potius lineari-lanceolata, subulata, quam lanceolato-acuminata dicenda. Achenia squamulosa subpilosa pappo coroniformi exiguo lobulato-dentato instructa. Folia inferiora plerumque pinnatopartita, sed huc et illuc etiam integra et obverse lanceolata; superiora interdun squaniformia, saepins linearia. 
Kentrophylum dentatum DC. fide specimin. in herb. Webb.

Hab. Legi in collibus ad Demerdesch ditione brussianae ubi vulgatissimum. - Floret Augusto.

0bs. Capitula in unoquoque ramo solitaria. Involucri foliola exteriora bracteaeformia e basi ovata, coriacea, concava sensim angustata, basi 5 -nervia, reliqua parte 3 -nervia, ceterum foliis proprie dictis similia; intermedia coriaceo-scariosa, tenuissime nervosa, oblonga, ad apicem appendice ovato-acuminata ciliato-serrata instructa: quae sequuntur sensim angustata, intima lineari-lanceolata subulato-spinescentia, integra. Tota planta sub lente puberula et insuper lana arachnoidea sparsa, plus minusve copiose vestita.

Foliola involucri interiora vere a nonnullis auctoribus praetervisae sunt. Ceterum specimina mea is quae in herb. Webbiano nomine praeinisso asservantur exacte respondent.

Picnomon Acarna Cass.

Ilab. Circa Athenas.

\section{Scolymus hispanices L.}

Ilab. In Attica.

\section{Cevtaurea drabaefolia Su.}

Hab. Legi in regionis alpinae Olympi bith. declivitatibus calcareis. Floret Augusto.

0bs. Spccies ex cl. DC. jampridem a Siвthorpio el Auchero in Olympo bithyn. lecta, et a Grisebachio in Flora rumel. horum auctorum fide recepta. Quae ipse legi specimina, descriptioni Florae rumel. non ex integro respondentia, hisce notis se praebent

Radix monocaulis vel ramos binos, terve edens, quorum unicus tantum florigerus. Folia lanceolata irregulariter dentata, integerrimave, mucronulato-acuta, inferiora in petiolım attenuata. Involucri squamae ad spinarum ortum lanigerae. Anthodii magni conici cum corollis anrei. Spinae involucri basi utrinque 2-4-spinulosae. Pappus superne avellanaceus achenio glabro triplo longior. Planta elegans, caule pollicari spithameo foliisque niveo-tomentosis.

\section{Centaurea crupina Pers.}

Hab. Legi autumno incipiente prope pagum Spartilla in Corcyra. 
0bs. Planta corcyrensis faciem gracillimam pracbet; caulibus ramisque fere filiformibus rigidis; foliis radicalibus spathulato-obovatis, integerrimis, ceteris pinnatis, laciniis minutissimis, remote serratis, pilis glanduliferis ciliatis; squamis calycinis praelongis, post finctificationem margine admodum scariosis.

\section{Centaurea diffesa Lanck.}

llab. Abunde crescit prope Byzantium lócis sterilibus collinis et aestate decedente floret.

0bs. Specimina quae ipse legi ob ramos creberrimos patulos invicem implexos fere inextricatilia. Tota piloso-scabra, glandulisque sessilibus adspersa. Foliorum laciniae omnes lineares, lanceolatove-lineares, subfalcatae, mucronulatae. Capitula minuta, solitaria, ovata, lutescentia. Involucrorum minute furfuraceo-glandulosorum squanae superne palmatopectinatoque spinosae, spinulis arcnato-patentibus; achenio subsericeo, pappo nullo.

\section{Centaurea cana Sibth.}

Hab. Crescit hand frequens in saxosis prope nives perpetuas Olympi bith. Floret Augusto.

Obs. Species pulcherrima accedens ad $C$. montanam pygmaeam, sed magis tomentosa et nivea. Folia ei sunt brevia et lata, polymorpha. Anthodii, prae planta magni, squamae palmatifido-dentatae, dorso virides margine nigricantes, dentibus elongato-subulatis cartilagineo-albis, ciliatae.

\section{Centaurea paniculata L. ?}

Ilab. Ad radices Olympi bith.

0bs. Characteribus fere omnibus cum C.paniculata Emropae mediae congruit; differt vero flosculis lutescentibus, anthodii squamis ad apicem subulato-ciliatis, subcinnamomeis. An species distingnenda?

\section{Centalera alea $L$.}

Hab. In Corcyrae insula aestate decedente.

obs. Folia caulina basi edentata, laciniis earundem lineari-falcatis, mucronatis. 
Cextacrea Pinardi Boiss.

Cextaurea Hellenica Borss.

Hab. Circa Athenas; posterior speciatim in fissuris rupium Areopagi non frequens, et ab omnibus facile distinctissima caule subnullo, capitulis magnis.

\section{RADIATAE.}

Bellis anNu $\beta$. dentata DC.

Hab. Abunde crescit in pratis humentibus prope Piraeum athen. aliisque locis uliginosis Phalereum versus, ubi locum speciei tenet. Floret vere.

\section{Eupatorium Cannabincm L.}

Hab. In Attica; ad Kiephyssum.

\section{Firigeron alpinus L.}

ß. uniflorus Fl. rumel. et bith.

llab. Plurimis locis alpinis Olympi bith. huc et illuc haud frequens occurrit. Floret Augusto.

\section{Solidago Virgatré L}

Hab. In Olympi bith. reg. Fagi.

\section{Coniza candida L.}

ß. verbascifolia $\mathrm{W}$.

1lab. $\alpha$. in Corcyra insula, $\beta$. in Hymetto athen.

Asteriscus aquaticus Less. Syn.

Hab. Circa Athenas.

\section{Phagnalum Rupestre DC.}

Hab. Legi in ruderatis Parthenonis ramosissimum, candidissimum, ramis elongatissimis et quamvis attenuatis tamen vigore et tenacitate insigni donatis. Floret aestate.

\section{Evax pyguaea Pers.}

Hab. Exemplaria constantinopolitana staturam perpusillam, formam acaulem simplicissimam saepissime induunt. Floret locis collinis. 
60

INUla itscosa L.

INCLA ENSIFOLIA L.

llab. Utramque legi in insula Corcyra; prior etiam communis in planitiebus Atticae. Aestate.

Ingla graveolens Desf.

Hab. Ad vias Megaridis.

Pulicaria odora Reichb.

Ilab. Crescit in sylvulis saxosis circa Ciamlicia ultra Scutarim asiaticum. Legi autumno.

0bs. A specie in Liguria obvia vix differt. Folia caulina, etiam in planta juniori, obsoleta. Squamae anthodiales angustissimae, lineari-subulatae, nec lanceolato-lineares longe acuminatae.

Circa Byzantiun legi specimina omnibus partibus magis evoluta.

\section{Pulicaria vulgaris Gaertin.}

Hab. In collibus byzantinis crescit pusilla, plerumque statura unciali vel sesquipollicari.

Pulicaria dysenterica Gaertn.

Ilab. In agro atheniensi ad Kiephyssum flumen phurimisque aliis locis, antumno.

0bs. A planta in Italiae superioris planitiebus vulgatissima, nostra recedit: caulibus dense striatis, ramisque virgatis strictis, foliis lanceolato-angustatis.

\section{Omalotieca supina Cass.}

Ilab. In fossis humentibus alpinis Olympi bith. Augusto decedente et ineunte Septembri legi.

0bs. A Gnaphalio supino alpium italicarum olympica planta deflectit: caulibus basi ramosis, radicantibus, nec simplicibus, anthodii foliolis evidenter inaequalibus, nec subaequalibus.

Filago Jussiei Cosson et Germ. in Ann. Scienc. naturell. Sér. II. XX. p. 284. tab. 13.

Ilab. In monte Pentilico atheniensi legi Octobre. 
Filigo gallica L.

Ilab. In collibus byzantinis.

Helichrysen axatolucis Bolss.! Diagu. 4. p. 11. - H. arenarium anatolicum Fl. rumel. et bith. 2. p. 197.

Ilab. In herbidis petrosis regionis alpinae Olympi bith. legi Augusto.

obs. Ab H. arenario praeeunte cl. Grisebachio, nisi capitulis paullo majoribus, foliis spathulato-lanceolatis, corymbis contractis subrotundis differre videtur.

Axthenis moxtixa L. ex Fl. rum. 2. p. 208.

* glabrescens: caule foliisque glabrescentibus.

Hab. Promiscue crescunt et florent Augusti mense in Olympi bith. regione alpina.

Obs. Varietas insuper recedit a specie, praeter glabritiem, caulium foliorumque tenuitate. Caulis in utraque basi sublignosus, radicans.

Antilemis cirrsocephala Boiss. ! et Gris.

Ilab. In collibus byzantinis apricis legi Julio mense.

Obs. Planta constantinopolitana ad $A$. ponticam W. nonnullis characteribus accedit.

Radix est lignosa, robusta. Caules a basi ramosi; ramis aliis floriferis, simplicibus, divisisve, superne aphyllis, nervoso-sulcatis, pilosocanescentibus, monocephalis; aliis stoloniformibus, brevibus, foliis numerosioribus incano-argenteis praeditis. Folia bipinnatisecta, segmentis linearibus acutiusculis. Anthodii discoidei rotundato-conoidei squamae dorso pilosae, margine scariosae, longe sparseque ciliatae; exteriores acuminato-acutae, interiores obtusae. Receptaculum conicum, paleis oblanceolatis mucronatis. Achenia subtetragono-obconoidea.

ANTHEMIS ARVENSIS L.

Hab. In aggeribns prope Byzantium.

Antuemis Sismondeana mihi.

A. annua? villoso subcanescens; caulibus ramosis adscendentibus; foliis bipinnatisectis, segmentis lineari-lanceolatis, hinc dentiferis acutis mucronatis; pedunculis laeviter incrassatis, striatis; involucri squamis carina angusta viridibus, piloso-villosis, margine scarioso, lato, obtuso, 
subciliato-lacero; receptaculo conico, paleis obverse lanceolatis, acuminato-mucronatis, superne sublaceris; ligulis albis magnitudine variis, fertilibus sterilibusque ovato-oblongis; acheniis disci centralibus obconoideo-incurvis, nervoso-sulcatis, margine irregulari subnullo; excentricis subprismatico-quadrangulis, faciebus profunde sulcatis, margine lobulato (auriculato) inflexo; radii compresso-subtrigonis, nervoso-sulcatis, omnibus sub lente rugulosis.

Corollae disci basi admodum ventricosae persistentes; capituli magnitudine varii, in anthesi minimi, odore intenso $\boldsymbol{M}$. Chamomillae praediti.

Ilab. Floret Junio, Julio in collibus sterilibus byzantinis a loco le acque dolci nuncupato non longe.

0bs. A celeberrimo Grisebachio (Fl. rum. 2. p. 206. 208.) Anthemidem Chamomillam Brunneri ad $A$. montanam, speciatim ad varietatem ejus thracicam ducitur. Terum tum nomen cum patria speciei Brunnerianae suspicionem inferunt hanc potius cum nostra quam cum var. thracica Ant. montanae comparandam esse.

Planta nostra autem differt ab $A$. arvensi, quae etiam in solo byzantino reperitur, praecipue receptaculo exacte conico, nec conico-cylindrico; paleis obverse lanceolatis, nec lanceolatis; et tandem acheniis, quae formas supracitatas praebent.

Ludit statura et rigiditate caulium, sed parvitate anthodiorum ligularumque in anthesi, et odore $M$. Chamomillae facile distinguitur.

Anth. litorali W. in Liguria crescenti etiam affinis.

Anthems Chia W.

Ilab. Locis compluribus circa Athenas et Byzantium.

\section{Anthenis Tinctoria L.}

IIab. In Corcyra.

\section{Cota Triunfetti Gay !}

«. radiata.

ß. discoidea.

Hab. Utraque varietas abunde et promiscue crescit in collibus prope Byzantium ultra il Gran Campo di Pera et aestate floret.

0bs. In forma radiata folia ampliora adnotantur, eorundem rachides laciniaeque latiores, ligulae albae, ovato-oblongae, involucri foliola plus 
duplo superantes. Tota planta prae discoidea, magis evoluta et perfecta, reapse ut typus speciei habenda est. Discoidea omnibus partibus gracilior, capitulis omnibus ligulis destitutis, flosculis luteis, promiscue cum var. $\alpha$. crescit, nec ab ea nullimode, nisi varietatis lege separari potest.

Matricaria trichophylla Boiss.! Diagn. 6. p. 89 .

Hab. Mihi occurrit Augusto in regione Fagi Olympi bith. circa aquas stagnantes.

0bs. Specimina nostra receptaculum plane hemisphericum, achenia compresso-oblonga, incurva, ad basim angustata tricarinata, apice calloso-marginata umbilicataque exhibet.

Planta etiam orgyalis, caulibus ramosissimis interdum simplicissimis praedita.

\section{Matricaria Chamomilla L.}

llab. In Attica.

\section{Pyrethrum Parthenium Sm.}

Hal. In Olympi bith. reg. Fagi.

\section{Chrisanthemum Segetum L.}

Hab. In satis circa Byzantium, vere.

0bs. Quae ipse 1. c. observavi a descriptione Fl. rum. abludunt: foliis tum mediis cum inferioribus oblongo-cuneatis, vel e basi cuneata oblongoangustatis, apicem versus inaequaliter serrato-incisis, non vero lanceolatis, nec inaequaliter serratis; acheniis disci perfectis obtusissime nec argute 10-costatis, radialium costis marginalibus argutis, reliquis obtusis sed eximie prominentibus, neutiquam filiformibus obsoletisque.

Senecio vernalis W. K. nigro-punctatus Clem. S. pendelicus Boiss.

Hab. Legi in monte Pentilico atheniensi, primo vere.

Differt a specie anthodii squamis exterioribus constanter nigro-punctatis.

Senecio olympicus Borss. Diagn. 4. p. 13.

Hab. In regione alpina inferiori Olympi bith. haud frequens et sparse occurrit Aug. mense. 
SexeClo castaxeaxis DC.

Ilab. Crescit rarus in castanetis prope Ciamlicia ultra Scutarim astaticum. Legi aestate.

Folia nonnulla longissime petiolata. Totius plantae facies gracilis.

\section{A II P I N U L A C E A E.}

JASONE SUPINA SiвTh.

llab. Floret Aug. in pinetis unbrosis inferiorib. Olympi bith.

Obs. Spccies ludibunda ad $J$. montanam transitum faciens. Folia inferiora spathulata, media oblanceolata, superiora plus minusve linearia, omnia mutabilia, haud raro crispula. Cilia irregularia, plerumque a petiolo usque ad basim laminae tantum reperiuntur. Bracteae supra medium acutissime dentiferae. Caules nunc glabri, nunc piliferi, plus minusve prostrato-adscendentes, abbreviati, nani, vel etiam elati ad $J$. montanae staturam accedentes et forte ut in ea annui.

Phyteuma Sibthorpiandy $R$. et S.

Hab. Legi ineunte Augusto in herbidis alpinis Olympi bith. orientem. versus.

0bs. Cl. Bosssiero duce hanc plantam ad Ph. Sibthorpianum refero. Phyteumatis vero haec species a $P h$. elliptico Sмrтнr, quo cum a Grisebacho in Fl. rumelica (2. p. 291) conjungitur et forte non immerito, caule teretiusculo non angulato, foliis oblongo ellipticis crenatis, minime vero crenato-serratis, tantum differre videtur. Phyteuma campanuloides Biebersteinu huic quoque valde affine, secundum specimina in herb. Webbiano extantia. Vereor characteribus laevioris momenti hasce species superstructas esse.

\section{Phytecma limonifolium Sm.}

Ilab. In Corcyra, ad litora.

Phytecma Repandum Sibtr. et Sm. ad specimina herb. Webbiani. Horet.

Hab. In declivitatibus herbosis alpinis Olympi bith. Augusto mense

Obs. Planta statura, foliorum forma, florumque dispositione admodum mutabilis; si quae varietatis lege distingui meretur, est forma quaedam, floribus spicato-capitatis a reliquis recedens. 
Splcllaria pentagona $\alpha$. DC.

llab. Circa Byzantium.

Campanlla spathulata Sibth, et Su, a. DC. Prodr. VII. 2. p. 481.

Hab. In Olympo bith. solitaria.

0ls. Specinina a me collecta variant caulibus unifloris vel bi-trifloris, floribus secundis, vel in caulis apice congestis.

Campaxcla Billarderi $\propto$. DC. Prodr. VII. 2. p. 474.

llab. In Olympo bithynico haud frequens.

Obs. Species caulibus caespitosis, foliis cordatis, 3-5-lobis vel acute dentatis, radicalibus petiolo longo insidentibus, ramis floriferis superne subpaniculatis, floribus parvis. Insignis !

\section{A C C I N I E A E.}

\section{VaCCinila Mirtilles L.}

Ilab. In Olympo bith. sicuti et aliae stirpes alpinae nostrales aegre crescit. Forte limes australis areae hujus quoque speciei.

\section{E R I C I N E A .}

Erica verticillata Forsk.

Hab. In lapidosis colliam et planitiei superioris Athenarum vulgatissima. Floret aestate decedente et autumno.

0bs. Variat insigniter statura, nec non florum magnitudine. Caules vel erecti semiorgyales, vel adscendentes palmares caespitosi.

Brickenthalia spiculifolia Reiche. Fl. excurs. p. 414.

Hab. Crescit in regione media Olympi bith. ubi legi Augusto.

Ericinea foliis floribusque coccineis gracillimis.

\section{Arbitus Andrachne Lam.}

Hab. In monte Pentilico haud longe ab Athenis. Arbuscula elegans, cortice lucido in squamas papyraceas tenues secedente, more Platani.

\section{Arbutus Unedo L.}

Hab. Eodem in loco ac praecedens. 


\section{P Y R O L A G E E.}

Pyrola Secunda $\mathbf{L}$.

Hab. Aegre crescit in Olympi bith. regione alp. Floret Julio.

\section{J A S II I N E A E.}

\section{Jasminum Fruticans L.}

Hab. Ipse legi ad sepes circa Brussam asiaticam. Ad radices Olympi bith. in convalle del Paradiso nuncupata ab ornatissima Domina Josephina Fossatı una cum $J$. officinali inventum est, speciminaque utriusque speciei ab Ea comiter accepi.

\section{A S C L E P I A D E A E.}

\section{Cynanchum erectum L.}

Cynaxchum acutum $\mathbf{L}$.

Hab. Circa Brussam utrasque species legi, Jul. Aug. Prior etiam in Graecia mihi se obtulit.

0ls. In speciminibus brussianis $C$. erecti folia forma varia, subinde oblonga; insuper statura elatiori caulibusque debilioribus ab hellenicis differunt.

In $C$. acuto folia interdum cordato-truncata observantur.

\section{G E N T I A N E A E.}

\section{Chlora perfoliata $\mathbf{L}$.}

Hab. In Corcyra.

Erythraea ramosissima Pers.

Hab. In Attica, ad Kiephyssum.

Gentiana lutea L.

Hab. Mihi occurrit perrara in regione alpina Olympi bith. qui limina forte australiorae areae hujusce speciei sistit.

Gentiana verna L.

Hab. Eodem loco ac praecedens. 
A JOSEPHO CLEMENTI

Gentiana aestiva R. et S. - G. verna angulosa Fl. rum. 2. p. 63. llab. In collibus byzantinis, aestate.

\section{S E S A II E A E.}

Sesamum ORIENTALE L.

Hah. In Attica, ad Kiephyssum flumen.

\section{C $O$ N V O L V U L A C E A E.}

Convolveles textissimes $\mathrm{S}_{\mathrm{y}}$.

Hab. In Attica, ad Kiephyssum.

\section{Coxwolvulus Dorycxiem L.}

Ilab. Legi aestate circa Pnix atheniens. Frutex ramis numerosis intricatis nec non facie singulari praeditus, et a congeneribus admodum distinctus.

\section{B O R A G I N E AE.}

\section{Heliothropium Villosum Desf.}

Ilab. Copiose provenit circa Acropolim atheniensem.

\section{Helothropium europaeum $\mathbf{L}$.}

Hab. Promiscue crescit cum praecedenti specie, ab ea vere distinctum. Tota aestate et autumno florent.

\section{Cynoglossum pictum Ait.}

Ilab. Circa Byzantium.

\section{Oxosma pallidur Borss. ! Diagn. - Ipso teste !}

Ilab. Legi in sylvulis petrosis prope Ciamlicia ultra Scutarim asiaticum.

0bs. Pili stellati! sed antherae toto apice evidenter exsertae! quo charactere a sectione Prodr. Candolleani Onosmata pilis basi stellulatis distincta complectente, species haec exulatur.

Accedit nonnullis characteribus ad $O$. montanum ab Aucherio ex Asia occidentali advectum, secundum specimina herb. Mus. Parisiens. quibuscun meum comparavi. 
Ovosma erectum Sibth.

Hab. Legi aestate in monte Hymetto athen.

Cennthe purplrea Fl. dalmat.

llab. In insulae Corcyrae monte Pandoliratora, et in Olympo bith. legi specimina quae a stirpe dalmatica differunt bracteis minus obtusis, sepalis parce inaequalibus, corolla .........?

Num ad $C$. minorem referenda?

Echum arenarium Guss. Fl. sic. Syn. 1. p. 232.

Ilab. Legi in sabuletis Phalerei atheniensis, ubi floret primo vere.

0bs. Celeberr. GAY auctoritate ductus hanc planlam ad Echium arenarium refero, etiamsi notis nonnullis, per quan videre est in speciminibus fructu maturo adluc carentibus, ad $E$. calycinum accedat. Quomodocumque sit en quae in millenis a me rimatis speciminibus adnotanda veniunt :

Radix tenuis, longa, fibrosa, multicaulis. Caules erecto-adscendentes, pilis longis erecto-patulis hispidi vel tuberculato-hispidi, pollicares vel semipollicares. Folia inferiora obverse lanceolata, in petioluns attenuata, obtusa, vel rarius brevissime subacuminato-apiculata; superiora angustiora vel lanceolato-linearia, semper obtusiuscula. Foliorum inferiorum verrucae magnae pilique adpressi, discreti; superiorum conferti, e verrucis inconspicuis. Racemi terminales densi, contracti. Calycis segmenta constanter lineari-angustata obtusiuscula. Corolla extus pilosa calyce tertia parte vel duplo longior, limbo semper coeruleo, stamina inclusa.

\section{Echium plantagineum L.}

Hab. Vere et aestate haud frequens occurrit in collibus argillosis prope Byzantium ultra il Gran Campo di Pera.

0bs. Corolla magna, colore violaceo-azureo amoena. Stamina vix exserta vel corollam aequantia. Folia radicalia petiolata, ovata, lata, nervis in pagina prona valde extantibus.

Alkanna tinctoria Tausch.

Hab. Ad radices Pentilici ath.

Lithospermuy SibThorpianum Griseb.

Hab. Crescit et floret primo vere in sabuletis prope Phalereum atheniensem. 
Obs. Planta nunc simplicissima semiuncialis in arena subsepulta, num ramis pluribus pollicaribus vel sesquipollicaribus e basi suffulta. Flores azurei, arefactione pallescenti-luteoli, semper minimi.

\section{LITHOSPERMLM TENUIFLORCM $\mathrm{L}$.}

llab. A vere ad aestatem in arvis athen. haud rara, sed difficile visu.

obs. Planta polymorpha; simplex 1-2-pollicaris, vel inferne ramosa subspithamea. Forma nucularum et facie $L$. arvensi proxima.

Ad radices montis Pentilici, locis sterilioribus, legi specimina semiuncialia, strigoso-sericea, foliis radicalibus petiolatis, obverse ellipticis vel spathulatis; dum in speciminibus planitiei, etiam spithameis, folia radicalia semper angustato-oblonga observavi.

Myosotis olympica Boıss.! Diagn. 4. p. $9^{\circ}$

Ilab. Legi in summi cacuminis Olympi bith. declivitate septentrionali.

0bs. Myosotidi alpestri affinis, a qua magnitudine florum dense confertorum, prae plantae pumilae statura insigni, nuculis oblongo-ovoideis, foliis imis spathulatis, radice, ut videtur, perenni, facieque propria differt.

Myosotis pusilla Lois. albiflora Clem.

IIab. In sabuletis prope Phalereum Atheniensium, primo vere.

0bs. Differt a specie caulibus magis abbreviatis, caespitulis densioribus, floribus albis nec coeruleis.

Myosotis litoralis Stev. - Griseb. Fl. rumel. 2. p. ioo?

Ilab. Circa Stadium prope Athenas, vere.

0bs. Facies praecedentis, sed statim ab ea distinguitur racemis haud bracteatis. Nuculae ovatae laeves, nitidae, saltem ex speciminibus frnctu perfecto carentibus. Caeterum mihi adhuc dubia ob specimina nondum satis evoluta.

\section{Asperugo procumbens L.}

Hab. In Attica.

Mumbia cephalotes Boiss.! var. breviflora mihi. - Arnebia cephalotes Alph. DC. var.

Hab. Legi una vice in convalle lata quidem, sed fere inaccessa regionis alpinae Olympi bith. latere N. E. Floret Julio decedente. 
0ils. Stirps singularis et eximia, onosmadis habitu valde affinis. Specimina a me lecta characteres sequentes genericos exlibent:

Calyx 5-partitus. Corolla hypocrateriformis, fauce nuda, limbo 5-lobo. Stamina 5 inclusa, filamentis brevissimis, antheris liberis, loculis basi breviter solutis. Ovarium 4-lobum, stigma incrassatum, emarginatum. Nuculae 4 vel abortu 1 exanulatae, toro insertae.

Differt a specie: calyce longiore, tubum corollinum aequante vel subaequante, nec quarta vel tertia parte breviore; antheris brevibus, oblongo-ellipticis, nec oblongo-linearibus, verticillatim, nec biseriatim insertis.

An Munbya loco Mumbiae ex cl. Munby genus scribendum?

\section{S O L A N A G E A E.}

\section{Datura Stranonium L.}

Hab. In Attica, ad Kiephyssum.

\section{L.yCium europaeum $L$.}

Hal. In Corcyra.

\section{Solandm humle Bernh.}

Hab. In planitie atheniensi, autumno.

Statura 2-3-pedali et nltra occurrit!

SOLANUM NigRUM $\mathrm{L}$.

Hab. In Attica, cum praecedente.

\section{PER S O N A T AE.}

\section{Verbascum sinuatum L.?}

Hab. In agro byzantino et circa Scutarim.

0bs. Verbasco sinuato Europae australioris omnino simile et pariter ac illud summopere ludibundum forma, magnitudine, sinubus, incisuris foliorum, quae subinde integra. In speciminibus, quae hic memorantur, folia omnia semidecurrentia vidi. Corollae segmenta elongata, linguaeformia.

$V$. sinuatum Macedoniam, Thraciam, Calcidem, Pontum Euxinum et Bosphorum prope Scutarim quoque incolit, teste cl. Grisebachio. . 


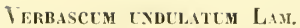

Ilab. Legi aestate in planitie atheniensi prope Acropoliu, quo loco folia insigniter lanuginosa, caulesque, etsi tantum bispithamei, lignosi et robusti evadunt.

Scrophelaria Scopoli Hoppe! Bertol. Fl. ital. VI. 386 - non Persoon Synops. 2. p. $160-$ ad specimina autentica herb. Webbiani!

Hab. Legi in Olympi bith. regione alpina, socia Potentilla Buccoana mihi. Floret Augusto.

Livaria triphylla Desf.

Livaria micrantha Steud.

Hab. In arvis atheniensibus promiscue reperiuntur vere.

0bs. Ambae statura et ramificatione summopere variant; characteribus uniuscujusque tamen immutatis.

LiNaria SPURia Mill.

Hab. In insula Corcyra, et in arvis prope Katikioi ultra Scutarim asiaticum.

\section{Linaria genistifolia Mill.}

Hab. In sylvulis collinis viisque reconditis prope Bosphorum.

Linari. Pelisseriana Mill. ?

Hab. Cum praecedente eodemque tempore florens, licet vere et aestate.

0bs. Foliis stolonum plerumque oppositis rarissime quaternis, segmentis calycis capsulam immaturam aequantibus, eademque matura superantibus, nec segmentis duplo longioribus.

Veronica caespitosa Bolss.! Diagn. 4. p. 79. - Griseb. Flor. rumel. 2. p. 5 is.

$\beta$. caulescens $\mathrm{C}_{\text {LEM. }}$ : caespitulis laxiusculis, ramulis elongatis 2-pollicaribus, foliis remotiusculis tenuioribus linearibus.

Hab. Legi speciem et varietatem in calcareis regionis alpinae Olympi bitlı, ubi frequens Junio, Julio.

0bs. Specimina ferme innumera varietatis $\alpha_{0}$, sive speciei a we in loco adducto collecta, caules undique exhibent foliosos. Folia ei insuper 
sunt linearia, margine admodum revoluta, apice conoideo-falcata nec lineari-spathulata; pedunculi bractea obverse lanceolata quadruplo breviores nequaquam vere bracteas aequantes.

Veronica gentianoldes Sy.

Ial. Stirps in Olympi bith. pascuis alpinis frigidioribus minus frequens. Floret Junio, Julio.

Teronica glacca Sibth. et Sil.

Veronica Beccarunga L.

llab. In arvis atheniensibus abunde crescunt. Legi etiam ambas ad radices montis Pentilici ubi prior crescit simplicissima, filiformis, pollicaris; secunda foliis admodum tenuibus crebrisque vestitur.

Veronica acisifolia L.

Veronica agrestis L.

Veronica caypestris L.

Veronica arvensis L.

Veronica cymbalaria Bertol.

llab. Omnes, ab italicis non dissimiles, in agro byzantino abunde proveniunt et florent vere et aestate.

Pedicclaris Sibthorpil Boiss.! Diagn.

Ilab. Haud frequens in summi cacuminis Olympi bith. declivitatibus calcareis. Floret Augusto. Pediculari comosae proxima.

Pedicularis olympica Boiss.! Diagn.

Hal. Praecedente magis rara et praecocior; crescit iisdem locis.

Foliis angustissimis et facie a congeneribus abunde diversa.

\section{Euphrasia latifolia L.}

Ilab. In cultis collinis prope Byzantium haud frequens occurrit primo vere, interdum perpusilla, caule filiformi.

Opontrtes ixones Boiss.! Diagn.

Hab. Crescit solitaria in regione abietis Olympi bith. et floret Augusto mense.

Obs. Stirps ab Euphrasia Odontide optime distincta.

Omnes plantulae partes et praesertim prima arefactione viscosissimae. 


\section{A B I A T A E.}

Lavandla Cariensis Boiss.! Diagn. 5. p. 3.

llab. In collibus apricis prope Bosphorum. Floret Junio, Julio.

01/s. Lavandulae pedunculatae habitu non absimilis; differt vero, adnotante cl. Botssiero, indumento in ramis floriferis tenuiore, bracteis exquisite nervosis, denticulatis, calycis valde nervosi appendiculo sessili, spicis densioribus, crassioribusque, caeterisque.

\section{MeNTHA tomentosa D'Úrvill.}

llab. In planitie locisque collinis atheniensibus copiose crescit et floret tota aestaie.

0ls. Foliorum canliumque magnitudine, florum numero in unoquoque verticillo nec non tomento facieque admodum varia.

\section{Mextha aQvatica L.}

Mentua Pulegicy L.

Hab. Cum praecedente vulgatissimae.

\section{Salvia Fonstilli L.}

a. Bjzantina: foliis oblongatis, basi plus minusve hastato-lyratis, corollae tubo calyce sesquilongiore.

3. Brussiana: foliis exacte cordato-ovatis, petiolis nudis, corollae tubo calyce duplo longiore.

Hab. $\alpha$. crescit in sylvulis byzantinis prope Maslak. - $\beta$. in brussianis prope Demerdesch, aestate.

0bs. Varietates hujusce speciei a cl. Grisebachio, Fl. rumel. 2. p. ioo, adhibitae, bifida nempe et bithynica, formae foliorum rotundatorum aut elongatorum, figurae tubi corollae rectiusculi aut recurvato-adscendentis, staminumque proportione superstructi, admitti nequennt. Hi enim characteres in permultis saltem speciminibus a me observatis, inferioris notae, nec constantes, me judice, ullo pacto hanc speciem in duas inter se distinctas, it vellet cl. Grisebach, separari sinunt. In tanta speciei versatilitate, characteribus a foliorum figura et corollarum longitudine desumptis unice attendendum est.

Pili in utraque varietatum memoratarum inaequaliter sparsi, nitiduli, in facie foliorum copiosiores. Stamina in utraque exserta. 
Silvia verrevaca L.

IIab. In pascuis collinis prope Byzantimu ubi $S$. pratensis locum tenere videtur. Floret tota aestate.

In herbidis suburbanis tiam varietatem clandestinam BENTH. reperi, nec non in aggeribus prope Athenas.

\section{SALViI Vertichlata L.}

Hab. In agro scntariano nltra Katikioi (Chalcedoniam). Aestate.

\section{Originem hirtum Benth.}

Ilab. Abunde provenit in collibus insul. Corcyrae, ubi $O$. nostri $n u l-$ garis locum tenet. Floret tota aestate.

Origancm virens Lk. - Griseb. Fl. rmm. 2. p. i 5.

Ilab. In Olympi bitl. regione subalpina, haud frequens.

0bs. Ab anctoribus nonuullis et ab ipso celeb. C. Savio (Osserv. Origan. 1840) ut varietas $O$. vulgaris habetur; ipse vero propriis innixus observationibus, cum cll. Link, Gussone, Grisebach, aliisque a vulgati sedulo distinguendun esse censeo. Ab illo revera, facie propria, caule brachiato-ramoso, foliis bracteisque pallide virentibus, bracteis eglandnlosis calyce glandulifero conspicue longioribus, spicis ab]reviatis facile distinguitur.

Folia caulina in nostro ovato-subacuta, integra vel plerumque remote, obsolete serrata, ciliataque, ramea minora.

\section{Micromeria graeca Auct.}

Hal. Legi in insula Corcyra.

0bs. In eadem insula cum $M$. graeca, M. Julianam Bistr. legi. Practerea substrati conditionibus paulisper mutatis in iisclem locis alia innumera specimiua Micromeriae huc et illuc observavi, quae characteres M. Julianae et graecae vicissim et promiscue exhibent. Folia vel figura vel situ ex internodiorum longitudine varia, indumentum plus vel minus densum, statura, caulinm divisio, facies denique, omnia uno verbo summopere mutabilia, sed omues hujusmodi variationes singillatim eumnerare supervacaneum puto. Animadvertendum autem existimo nomulla specimina bracteolas calyces subaequantes et fances nudas ut in $M$. Juliana praebere, corymbis autem paucifloris, irregulariter et parce fastigiatis 
ut in 11. graeca vestiri. E contra in nonnullis aliis bracteolas abbrevialas, fances barbatas ut in $\boldsymbol{M}$. graeca et corymbos densifloros exacte fastigiatos ut in M. Juliana observavi. Et sic aliorum characterum differentialium M. Julianae et $M$. graecae lusum frequentissimum illis in locis adnotavi. Quid plura? In ipso eodemque specimine, ramulus alter characteres et faciem $M$. Julianae, alter $M$. graecae, ni fallor, praebet!

Hisce perpensis, nec non is quae de Micromeriae graecae lusibus fere innumeris relebert. Bertoloni, Gussone, Bentham aliique protulernnt, $M$. Julianam et $M$. graecam varietates tantum insignes ejnsdem typi sistere contendo.

Thymbra capitata Griseb. Fl. rumel. 2. p. 127.

llab. Legi in insula Corcyra, ubi capituli minores quam in stirpe dalnatica observantur.

\section{T'UYMB:A SPICATA L.}

llab. Admodum prosperat in collibus ad Demerdesch ditione brussiana, uli caespites 1 -2-pedales, densissimos efformat. Floret antumno incipiente vel antea.

\section{Satureda Thymba $L$.}

Hab. Vulgatissima in planitie superiori atheniensi. Floret vere et aestate.

Calamintha incana Boiss. el Heldr.

Hab. In planitie atheniensi.

0bs. In Corcyra insula legi specimina minus incana, foliis amplioribus facieque a stirpe graeca divergentia.

Thymus Zygis L.

Hab. In monte Hymetto atheniense.

\section{'ThymUS SERPyLLu $L$.}

Ilah. Cum praecedente, nec non in collibus byzantinis.

Lamium Manganottianum mihi. - L. veronicaefolium, reniforme, bithynicum Вемтн. - L. striatum Sівтн. - Dracocephalum lamiifolium Desf.

L. perenne; caulibus erecto-adscendentibus, fistulosis, crassis, interdum filiformibus subfarctis; foliis cordato-ovatis plus minusve abbreviatis 
reniformibusve, crenatis vel crenato-incisis lobatisve, inlerioribus longissime petiolatis, omnibus glabris; verticillastris 2-8-floris; calycinis dentibus lanceolato-acuminatis plus minusve divaricato-patentibus; corollae calyce 3-4-plo longioris tubo subrecto in faucem abrupte dilatato; galea bifida utrinque bidentata.

llat. In Olympo bith. locis compluribus. Floret Augusto mense.

olss. In lapidosis alpinis reconditis montis citati $L$. veronicaefolium BENTH. crescit et floret mense citato. Iisdem localitatibus eodemque tempore L. bithynicum Bеnтн. et L. striatum Sивт. promiscue creseunt evidentissimeque ab uno in alterum transitum facimnt. Nunc planta ex saxis gracillima extrahitur et foliis parvis, rotundato-reniformibus, floribusque maxinis restitm ( $L$. veroniçaefolium, vel $L$. reniforme Bемтн.). Nunc e contra magis evolvitur, caules grandiores et crassiores mittit, foliisque minus rotundatis et magis cordatis vestitur ( $L$. bithynicum BENTH.). Tandem omnibus regetationis partibus, solo aliisque conditionibus faventibus maximain perfectamque evolutionem attigit ( $L$. striatum Sввтн. - Dracocephalum lamifolium DEsf.); et hac ultima forma ad L. garganicum vergit.

Formas superins unemoratas cum speciminibus autenticis Mus. Paris. comparavi, nec ullum de earum identitate mihi dubium superest. Alias formas porro innumeras locis citatis observavi, quae satis superque ostendunt species omnes et synorima huc comparata unicam mutabilissimamque constituere stirpem.

\section{LAMIUM AMPLENICAVLE L.}

Hab. In Attica.

\section{Staciys italica Jan.}

Hab. In collibus constantinopolitanis raro occurrit aestate, a nostra mullimode diversa.

\section{Sideritis TAURica W.}

llah. In regione alpina Olympi bith. in latere austro-orientali, decedente Augusto et Septembre.

0ls. Folia oblanceolata vel obovata, nec lanceolata; bracteae rombeocordatae acuminatae, nec tantum cordato-acuminatae. 
Ballota acetabulosa Benth.

Ballota Nigra L.

Ilab. In Attica; prior in planitie, altera ad radices Pentilicı.

Marrubium velgare var. apulum Ten.

Ilab. In planitiei atheniensis locis siccioribus aestate legi.

Lana densissima candidissima; rerticilli 40-6o-flori, fructiferi valile compacti.

Phloms ferruginea Ten.

Hab. Legi in collibus prope Demerdesch ditione brussiana. Augusto.

obs. Pili omnes stipitato-stellati, stipitulo tuberculo insidente, in caule laxiores, in facie foliorum robustiores rariores, in dorso minutissimi et crebri. Folia inferiora profunde cordata ovato-abbreviata, summa lanceolato-subcordata. Subulae calycinae longitudine variae.

\section{Phloms fruticosi L.}

Hab. In sterilibus Atticae tantum observavi, nec ullam reperi in agro constantinopolitano.

Scctellaria orientalis $\beta$. pinnatifida Benth. in DC. Prod. r 2. p. 413. - $S$. orientalis L. Aucr. in herb. Mus. Paris.

S. caule fruticuloso, ramoso, prostrato; ramulis adscendentibus foliisque pilosulis, parvis, cordato-oblongis, petiolatis, oppositis, pectinatopinnatifidis; laciniis lineari-obtusiusculis, subtus nervosis, facie ad nervos sulcis profundis impressis; superioribus bracteiformibus, pilosioribus, ovato-oblongis ellipticisve, obtusis acuminatisve, inferioribus dentatis superioribus integerrimis; floribus axillaribus, breviter pedunculatis, adproximatis, spicam terminalem capituliformem mentientibus; calycibus minimis obsolete bilabiatis corollisque flavis pilosis.

Ilab. Abunde provenit in saxosis alpinis Olympi bith. caurum spectantibus. Floret Augusto mense.

Corollae labium superius rotundato-obtusum; inferioris trilobi lobi laterales parvi, medius elongatus, carinato-rostratus, truncatus. Folia etiam glandulis raris notata.

$S$. orientalis vulgaris differt a nostra praesertim foliis ovato-oblongis, pinnatifido-dentatis, subtus incano-tomentosis, bracteis subintegerrimis. 
l'raeterea planta nostra magis contracta, ob ramos primarios lignescentes iterum divisos tortuoso-repentes.

Scetellaria peregrina L.

Hab. In insula Corcyra.

\section{Ajega Laxmand Benth.}

Calyx 5-fidus, nec 5-dentatus vel 5-lobus ut in Ajuga; nec 5-dentatus aut bilobus ut in Teucrio. Corolla cum stylo marcescens, nec cum illo decidua ut in Teucrio. Labii superioris loco fissura utroque latere dentata, nec labium superius brevissimum bifidum ut in Ajuga. Labium inferius 3-lobum, labello bifido (licet labium inferius 4-fidum), nec 5-lobum ut in Teucrio. An genus distinguendum?

Ut melius stirpis nostrae morphosis botanicis pateat, descriptionem sequentem addendam puto.

Perennis; pilis longis articulatis villoso-scabra. Caules basi ramosi, rotundato-angulati. Folia venoso-subtrinervia, elliptica vel oblongo-elliptica, obtusa; inferiora minora, basi angustata caulinaque media antice remote et obtuse dentata, interdum emarginata; superiora integerrima bracteantia floribusque spicato-axillaribus longiora. Calycis 5-fidis dentes oblongi, obtusiusculi, subaequales. Corollae luteolae labii superioris loco fissura utroque latere dente lineari barbato praedita. Labium inferius trilobum, lobo medio elongato-bilobo, lobulis crenulatis. Tubum supra basim villis densis annulatum. Nuculae dorso convexae, punctato-foveolatae.

Hab. Crescit in dumetis alpinis inferioribus Olympi bith., ubi specimina herb. exsiccati legi Augusto mense. Floret Julio.

\section{AJga orientalis L.}

Hab. In sylvulis abietinis Olympi bith. solitaria crescit, et floret Junio, Julio.

Folia valde elongata, obverse lanceolata, nec tantum orata, ut in plurasi Linneana stirps olympica exhibet.

\section{Ajcga Chamaepitys Schreb.}

Hab. Ad radices Pentilici atheniensis, 
Tecchicm Flavem L.

Teucricy Policy L.

llab. In insula Corcyra frequenter occurrunt ad radices montis Pandokratora.

TeCCricm SCORDIOIDES Schreb.

Hab. In monte Pentilico atheniensi.

Vitex Agnus L.

Hab. In Corcyra et in Attica.

\section{E N T 1 B UL A R I E AE.}

\section{Pinglicula alpina L.}

Hah. Milii occurrit rarissima ad rivulos alpinos Olympi bith. Floret Junio, Julio.

Cum speciminibus in alpibus italicis lectis exacte congruit.

\section{P R I M U L A G E A E.}

Avagallis phoenicea Lam.

Anagallis coerulea Schreb.

Hab. In Attica, ad Kiephyssum.

\section{Lysimacila atropurenea L.}

Hab. Uno loco in declivitatibus glareosis ad Bosphorum, Maslak pagum versus, sponte crescentem reperi aestate.

Stirps pro inflorescentia speciosa.

Androsace olympica Borss.! Diagn. 4. p. 37 - A. villosa Sıвт. - Griseb. Fl. rum. p. 5i 2.

Hab. In cacuminibus alpinis minoribus Olympi bith. reperi Augusto; eodem loco ubi cl. Sıвтн. suam Androsacem villosam collegit.

obs. Plantae statura, indumento, facieque summopere versatilis characteres potiores ex speciminibus innumeris a me collectis depromptos exhibeo.

A. perennis, caespitosa: in anthesi nana, pilis simplicibus articulatis, in scapo longioribus, laxiusculis, canescens; fructifera elongata, glabriuscula 


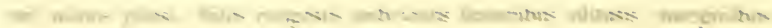

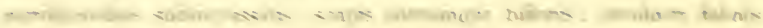

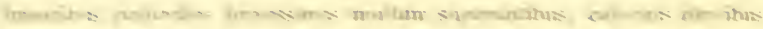

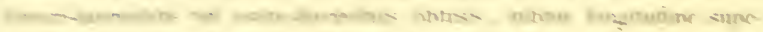

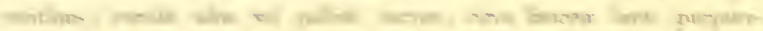

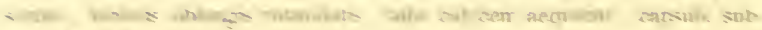

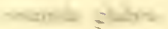

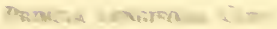

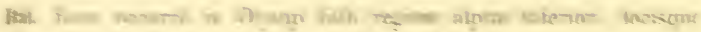

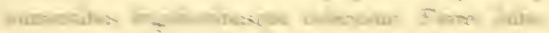

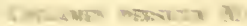

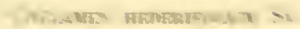

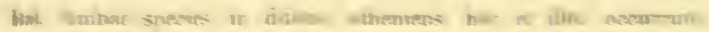

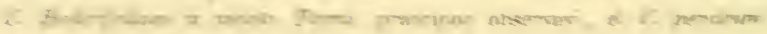

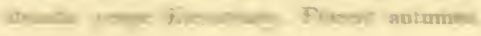

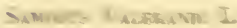

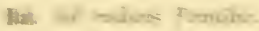

\section{- I J B A I I I A E}

S-mat moveraus I

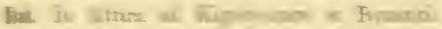

\section{I I I I \& D IE \& E}

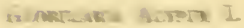

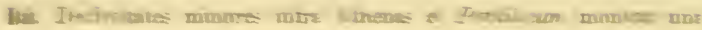

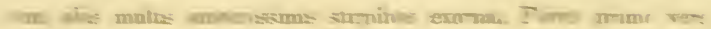

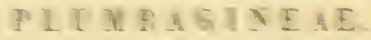

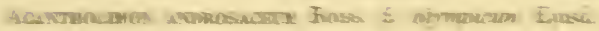

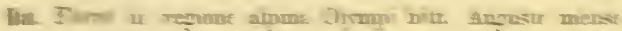

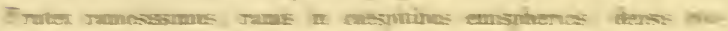

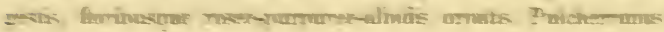


Statice graeca $\beta$. microphylla Borss. in DC. Prodr. Corinthi.

Hab. Abunde prorenit in litore prope Kalamaki ultra isthmum

Statura perquam raıiabilis.

Plumbago elropaea L.

Hab. Ad rias in proximitatibus atheniensibus aestate.

\section{PLA I T I INEAE.}

Plastago gevtunoides Sir. - $P$. gentianoides $x$. Griseb. Fl. rumel. 2. p. 363 .

Hab. Crescit in aquis lente Aluentibus frigidisque Olympi bith. regionis alpinae inferioris. Legi Ingusto.

Ubs. Tota glabra: radice incrassata: scapis adscendentibus substriatis; foliis ellipticis rel elliptico-lanceolatis, 3-nerriis, in petiolum attenuatodecurrentibus, sparse et irregulariter dentatis, lucidis; spica linearicylindrica, fructifera subiuterrupta ; bracteis oratis obtusinsculis, atropurpureis, involucello brevioribus; involucelli segmentis oboratis, dorso atropurpureis, margine cartilagineo-rubescenti; calycis campanulati purpurascentis lobis oblongis apice rotundatis; antheris luteo-albis, ellipticis, basi solntis, apice mucronatis; capsulis oblongis superne attenuatis styli basi persistente mucronatis, atropurpureis, calycem duplo superantibus, dispermis; seminibus oblongo-ellipticis, complanatis, rugulosis. atropurpureis.

Species a congeneribus omnibus scapigeris distinctissima.

Plantago laxceolata gossypina Clem.

P. scapis gracillimis, I-3 pollicaribus, foliis angustatis, linearibusve. tomento candidissimo restitis, spicis rotundato-oratis. bracteis ovato-acuminato-subulatis.

Hab. Crescit in collibus sterilibns circa Byzantium et Scntarin. Floret aestate.

0bs. Forma, foliorum tomento plus minusre denso, bracteisque oratoacuminatis, subulatis, spectabilis.

Prostat in herbario W'ebbiano ex Asia minore sub nomine $P$. lanceolatae. 
Plaxtago maritima alpina Clem.

Hab. In alpinis Olympi bith. vulgatissima. Species polymorpha.

Plantago Bellarid Alf.

llab. In agri byzantini locis collinis. Plerumque pusilla hirsutissima.

\section{Plantago Psillicm L.}

Hab. In planitie circa Athenas.

Statura varia, subinde semiuncialis, caule simplicissimo, capitulis paucifloris.

\section{H E NOPO D I E A E.}

\section{Polycnemuin arvense L.}

Ilab. In collibus byzantinis haec etiam stirps summopere ludit statura, quae saepissime vix mnciam adaequat. Floret aestate.

SALICORNiA FRUTICOSA L.

Schoberia fruticosa C. A. M.

Hab. In litore prope Kalamaki ad Corinthum.

Atriplex roseum $\mathbf{L}$.

Atriplex portulacoides L.

Hab. Ad litora prope Kalamaki.

Atriplex litorale L.

Hab. In Corcyra insula.

\section{Atriplex hortensis $L$.}

Ilab. In palustribus locis prope Phalereum athen. sponte crescit, sed olim forte culta.

\section{Atriplex Halymus L.}

Ilab. In Attica.

\section{Chenopodium album $\mathbf{L}$.}

Hab. Ad litora prope Kalamaki corinthiacum. 
Chexopodicy Veluaria L.

Ilab. Ad pedes montis Pentilici et Hymetti.

Obs. Hoc ultimo loco planta foliis omnibus minutissimis restitur.

Sal.sola Kali L.

Hah. In Corcyra.

Salsola Tragus L.

llab. Circa Athenas.

\section{POL Y G O E AE.}

Rigex alpines L.

Rumex digrves L.

Ilab. In sylvaticis alpinis Olympi bith.

\section{Rumex Acetosella L.}

llab. In proximitatibus byzantinis haud frequens.

RUMEX BUCEPHALOPHORUS $L$.

Hab. In collibus byzantinis nec non in tota Graecia vulgatissimum et admodum mutabilem observavi.

\section{Polygonum Maritimum L.}

Hab. In litore prope Kalamaki vulgatissimum.

\section{Polygonum alpinuy var, olympicum Clem.}

$P$. radice oblonga, incrassata, fere tuberiforme; caulibus ad ochreas parce pilosis; foliis lanceolatis acutis, facie dorsoque glabratis, minutissime ciliolatis; perigonii laciniis oblongis obtusis; stylis tribus statim deciduis; nuculis nitidis acutissimis trigonis, faciebus canaliculatis perigonio sesquilongioribus. mense.

llab. Legi in dirutis calcareis regionis alpinae Olympi bitl. Augusto

Polygonum Venantianum mihi.

P. glabrum, ramosum, subglaucescens; caule, vel ramo centrali erecto, ceteris prostratis vel prostrato-adscendentibus; foliis lineari-lanceolatis, 
utrincue augustatis; vaginis setaceo-laceris; floribus 5-andris axillaribus, fasciculatis, pediolatis; pediolis perigonium subaequantibus; fasciculis 2-multifloris, distantibus, racemum gracilem elongatum interruptum mentientibus; perigonii laciniis obovatis, antice rotundatis, patentibus, laetissime roseis, imo dorso virentibus; stylis tribus abbreviatis; nucula faciebus concavis, superne attenuata, a basi styli persistente rostrata, rugulosa, sparse furfuracea.

llab. Abunde provenit in arvis argillosis Maslak pagum versus, in ditione byzantina.

0bs. P. arenario W. K. affinis; sed stipulis setaceo-laceris scariosis, nec membranaceis acutiusculis, racemis gracillimis admodum elongatis interruptisque nee terminalibus, floribus pentandris.nec octandris, et tandem habitu peculiari diversus.

Polygonum aviculare L.

Ilab. In Attica et Byzantii.

Polygonum conolyeles L.

Hab. Byzantii.

\section{T H Y H E L E A E.}

\section{Passeriva hirsuta L.}

llab. In planitie atheniensi superiori vulgatissima. Flores etiam monoici et dioici observantur. Fere toto anno floret.

Clamidantulus Tartonreira C. A. M.

llab. Copiose reperitur ad radices montis Pentilici atheniensis, ubi floret primo vere.

0bs. Frutex argenteo colore splendens, ramosissimus, superne dense foliosus. In speciminibus nostris ramuli potius villoso-sericei quam pubescentes et flores luteoli nec albidi adnotantur.

Daphe Jisminifolia Si. ex Griseb. Fl. rum. 2. 320. - D. glandulosa Bertol. - D. oleoides Boiss. Voyag. espagn. ex Griseb.

D. ramosissima, semiorgyalis, dense caespitosa; ramulis, in sicco, profinde sulcato-angulatis rubentibus, plerumque parce pilosis; foliis carnoso-coriaceis obovatis spathulatisve obtusis, rarius elliptico-oblanceolatis 
obtusiusculis, glabris rarinsve sparsim pilosulis, supra laete virentilus subtus pallidioribus; floribus fasciculatis terminalibus, subquaternis, brevissime pediolatis; perigonio albido inodoro, extus adpresse pilososericeo, lobis lineari-lanceolatis, obtusiusculis, tubi longitudinem aequantibus; drupa juniori olslonga, perigonio inclusa, exsucca; matura libera. rotundata, succosa, rubra.

Ilab. Copiose provenit in pratis alpinis inferioribus Olympi bith. et floret Augusto mense.

0bs. Cortex caulis fuscescens, rimulosus. Folia, in sicco, laeviter nargine incrassata, facie sub lente acriori levissime impresso-punctata, dorso vero plus vel minus conspicue puuctis creberrimis expallentibus notata.

Nomen a celeberrimo Bertolon (Amoenit. ital. p. 356) huic speciei inditum, ni fallimur, ineptum est: revera glandulae, sic dictae, in pagina foliorum inferiorum obviae, in speciminibus saltem quae ad manus habemus nil aliud, microscopii ope, esse videntur, nisi stomata, quorum. margo supra epidermidem plus minusve prominet!!

Caeterum species nonnihil varia videtur, foliis oblongo-obovatis, obovatis, spathulatisve, apice acutiusculis vel brevissime mucronulatis, statura a spithama ad orgyam dimidiam et ultra.

\section{A U R I N E AE.}

LAURUS NOBILIS $\mathrm{L}$.

Hab. In monte Parnis atheniens.

\section{S A N T A L A C E A .}

Osyris alba L.

Hab. In Corcyra et Hymetto atheniens.

\section{E U P H O R B I A C E AE.}

\section{Euphorbia chanaesice L. var. canescens.}

Hab. In locis incultis et in areis pagorum atheniens. aestate.

0bs. Ad aggeres prope Phanaraki ultra Scutarim specimina magis evoluta, caulibus adscendentibus, foliis 4-6-plo longioribus et latioribus minusque pilosis legi. 
Euphorbia exigua L.

Ilab. In herbidis collinis circa Byzantium rara. Statura pusilla, omnibus partibus vere exiguis, sed semper multicaulis.

\section{Euphorbia Peplis L.}

Ilab. Legi in insula Corcyra; nec non in litore prope Kalamaki ultra isthmum Corinthi, ubi foliis admodum pruinoso-canescentibus vestitur. Floret Julio et Augusto.

Euphorbia Peploides Gouan! - E. rotundifolia Loist. Not. tab. VI. fig. I, rudis.

Hab. Crescit et floret vere in dumetis ad ripam Bosphori europaeam.

Obs. In innumeris a me collectis speciminibus, caulis e basi simplici, erecta vel prostrata, fere corymbose ramosus, ramis adsurgentibus. Folia tenuiter membranacea, tenuiterque venosa, obovato-cuneata, subrombea, non semper orbiculata, plerumque obsolete emarginata, inferiora dorso rubentia. Folia, umbellam parvam, vulgo 3-radiatam, involucrantia, ellipticosubrotunda, involucellorum vero cordato-ovata, tenuiter apiculata. Semina subhexagona, faciebus binis contiguis foveola longitudinali exaratis, caeteris 3-4-5-foveolatis variis, foveolis fundo obscure rubentibus. Radix fibrosa, fibris tennissimis comantibus. In reliquis convenit cum descriptione Fl. rumel. (1. p. 138), clarissimoque Grisebacho qui ab E. Peplo distinctam esse declarat libentissime assentior.

\section{Euphorbia heloscopia L.}

llab. Ad vias circa Byzantium.

Euphonbia pumli Sibth. Fl. graec. tab. 460.

Hab. Crescit in Olympi bith. regione alpina cum Astrag. Sibthorpiano promiscue. Legi Augusto.

0bs. Collata cum descriptione Fl. runelic. 1. 14 nostra recedere videtur caulibns ramosis, spithameis longioribusque, omnino glabris, nec simplicibus digitalibus puberulis; seminibus juxta raphem linea purpurea (canaliculo) notatis, nec bisulcatis.

In Fl. rumelica planta Sibthorpiana ejusdem montis incola asseritur.

Euphorda Apios L.

Hab. Species in insula Creta primum reperta, ad radices montis 
Pentilici atheniensis in solo calcareo et aprico nec alibi adnotavi. Floret primo vere.

0bs. Folia omnia lanceolata vel anguste obovato-elliptica obtusa, nec in ramis floriferis subrotundo-ovata (PERS. Synops.) observavi.

Euphorbia pilosa L.

Euphorbia falcata L.

Euphorbia Characias L.

Hab. In arvis et pascuis circa Athenas abunde crescunt.

\section{Euphorbia Mrrsinites L.}

llab. In monte Parnis atheniense.

Crozophora verbascifolia Juss. Croton villosum Siвth.

Hab. Prope Acropolim atheniensem frequenter occurrit.

Obs. Quamplurimum variat statura, sed semper tomento denso candidissimoque obvolvitur.

Crozophora tinctoria Adr. Juss.

Hab. Ad Kiephyssum flumen in planitie atheniensi.

\section{U R T I C E A E.}

\section{Urtica pilulifera Pers.}

IIab. In umbrosis Atticae locis haud frequens. Floret a vere ad aestatem.

\section{Parietaria diffusa Koch.}

llab. Legi in ruderatis Parthenonis, ubi ramosissima et sublignosa crescit. Floret aestate.

Parietaria officinalis elatior Clem. : Bi-tripedalis, a solo adscendens vel erecta; foliis ellipticis grandibus nervosis, longe petiolatis, acuminatis; glomerulis axillaribus cum ramulo intermedio, nunc abortiente et glomerulis duobus lateralibus 4-6-floris centrali faemineo, nunc elongato florifero glomeribus omnibus paucifloris. scutariana.

Hab. Legi ad litora maris intra sepes prope Phanaraki, ditione 


\section{O N I F E R A E.}

Epiledra fragilis Dese.

Hab. In montis Hymetti convalle, fauce dicta, valde prosperat, ef floret aestate decedente.

0bs. Statura etiam biorgyalis et ultra; ramis longissimis ex arboribus, supra quas planta scandit, dependentibus; baccis subcaesio-rubris.

JeNileres NANA W.

Hab. In summitatibus Olympi bith. aegre crescit.

JUNIPERUS OXYCEDRUS L.

Hab. In monte Parnis atheniens. legi. Baccae rubrae.

JUNIPERUS PHOENICEA L. crescit.

Hab. In monte Hymetto et ad litora prope isthmum Corinthi abunde

Abies Apollinis LK.

Hab. In monte Parnis atheniens.

Pinus halepensis Ait.

Hab. In Hymetto meridionali.

\section{A M E N T A C E AE.}

Quercus Aegrlops L.

Hab. Ad pedes Pentilici atheniens.

QUERCUS COCCIFERA L.

Hab. In Corcyra vulgatissimum.

Platants orientalis L.

Hab. Sponte in Attica prope Kiephyssum flum.

\section{A R 0 I D E AE.}

\section{Arum tenUifolium $\mathbf{L}$.}

Hab. In monte Parnis atheniens. 


\section{R I D E AE.}

IRIS PIMILA L.

Hab. Ad radices montis Pentilici una vice legi. Flores pallide lutescentes primo vere aperiuntur.

Croces Sprunneri Boiss. et Heudr.!

Obs. Species pulcherrima, quae montem Parnis aliaque loca complura collium atheniensium incolit. Perigonii variant colore albo-azureo-purpurascente. Bulborum tunicae, in anthesi, fenestrato-reticulatae, fructu maturescente minus reticulatae, demum in fibris tenuioribus quasi parallelis solutae. Scapi processu fructificationis magis magisque abbreviati. Legi autumno.

Romclea Colunnae Seb. el Main.

llab. In solo duriori atheniensis planitiei frequenter occurrit humillima et pulchella. Floret a vere ad aestatem.

\section{Romllea Livarezi Parlat.}

Hab. Praecedentis minus frequens, ad pedes Pentilici locis umbrosis primo vere reperitur.

\section{A S P A R A G E A E.}

\section{Asparagus aphyllus $\mathbf{L}$.}

Hab. Legi prope Athenas ad Kiephyssum flumen.

0bs. A. aphyllus in Sicilia proveniens a cl. Bertolonio (Oss. it. 4. p. 153 ) in caulis parte superiore ramisque hirtus declaratur; specimina vero omnia quae ipse l. c. legi omnino glabra observantur.

SMilax aspera L.

Smilax mauritanica Guss.

Hab. Promiscue crescunt et valde mutabiles in planitie collibusque atheniensibus. Tota aestate florent.

\section{A M A R Y L L I D E A.}

Sternbergia lutea Ker.

Hab. In Hymetto meridionali. 


\section{I L I A E A E.}

Asphodeline Morisiana mihi.

A. canle densissime folioso ; foliis lanceolato-subulato-triquetris, erectis; racemo spicaeformi, cylindrico, densifloro, subsimplici, bracteis oblongis vel ovato-acutis obtusisque scarioso-argenteo.

Ilab. Reperi infra saxa mobilia una localitate sed abunde prope nives perpetuas Olympi bith. latere N. O. Floret Augusto mense.

Radix ..... Caulis cylindricus, farctus, durus, cum spica circiter bispithameus. Folia crebra, rigida, abbreviata licet m. o, o4 ad o, os longa, basi latiuscula, sensim angustata, lanceolato-subulato-triquetra, striata, supra canaliculata, pallide viridia, margine tenuissime cartilagineoserrulata, intus subfarcta. Vaginae arctae amplexicaules in folium ovatae, pellncido-membranaceae, demum scariosae. Racemus subspithameus simplex, spicaeformis, cylindricus, densissimus, bracteis magnis, scariosis, ovato-acutis vel ovato-oblongis, vel obtusis argenteo-fulgens. Racemuli subsessiles biflori, flosculo altero longius pedicellato abortienti. Perigonium prae racemo parvum, inferum, corollinum, sexpartitum! patens; phyllis subaequalibus lineari-spathulatis, nervo fusco diremtis. Stamina sex basi perigonio inserta: 3 perfecta in anthesi perigonium aequantia: 3 sterilescentia prioribus multo minora. Staminum fertilium filamenta e basi plana, filiformia, glabra, antheris duplo longiora. Antherae oblongolineares dorso adsiscae, loculis basi discretis. Staminum sterilium filamenta apicem versus (in sicco) subclavulata fuscescentia. Antherae minutae, cordato-ovatae antheris perfectis quadruplo saltem minores, subinde una alterave deficiens. Stylus filiformis perigonium fere aequans, in anthesi declinatus (?) Stigma distincte trilobum!! Capsula ovalis utrinque obtusa, coriacea, basi ad suturas parietales calloso-cartilaginea, loculicido-trivalvis, loculis dispermis. Semina acnte triquetra, faciebus elliptico-lanceolatis, canaliculatis, testa fusco nigroque variegata, sub lente minutissime muriculata; hilo lineari angustissimo.

0bs. Ab Asphodelo luteo differt foliis inferne latioribus, brevioribus, erectis ; racemo exacte cylindrico, densissimo; bracteis conspicue scariosis maximis, plerumque non acuminatis; perigoniis minoribus, nec non forma antherarum et stigmatis; tandem facie propria ab illo omnino diversa. 
Asphoblus fistulosis L.

Hab. Circa Athenas.

\section{Ornithogaluy exscapum Ten.}

Hab. Legi ad aggeres prope Bosphorum vere et aestate.

ols. Scapi non desunt, sed semper brevissimi, circiter semipollicares adnotantur.

Gigei spithacea Srhult. Syst. VII. p. 54 1? Griseb. FI. rumel. 2. p. 383 !

llab. Legi mense Aprilis in herbidis collinis summitatis Ciamliciae ultra Seutarim asiaticum.

0bs. Specimina omnia a me collecta glabra, uniflora, caule foliis 2 , 3 , alternis bracteacformibus instructo, omnino ut in diagnosi Fl. rumelicae. Aliter vero haec species se prodit, in Europa centrali, ex auctorum germanicorum descriptionibus, folio florali nempe spathaceo ab umbella longe pedunculata $2-5$-flora remoto. Planta nostra statura vix 7 centim. exredit, perigonii foliola glabra, oblonga, obtusa 7 millim. longitudinis.

Gagea ARIensis Schult. Syst. 7. p. 547 .

Hab. In umbrosis humentibus Atticae.

Obs. Folia radicalia 2-3 glabra vel puberula e basi attenuata, in sicco filiformia, florem excedentia, arcuata: caulis glaber, in nostro uniflorus, pedunculo villoso: folia floralia 2 opposita, e basi dilatata, lanceolatosubulata, longitudine inaequalia. Perigonii foliola 3 acuta, 3 obtusiuscula.

\section{Scilla AUtumalis L.}

Hab. Legi specimina in Attica prope Kiessariany, nec non in insulae Corcyrae locis apricis.

\section{SCILla MaRitima L.}

Hal. In Corcyra insula vulgatissima, a maris litoribus ad montes etiam altiores adscendit.

Aluun WeBrH mihi.

A. bulbo rotundato-ovato, vaginis superne laceris albis demum nigrescentibus vestito; scapo tereti striato plerumque spithameo, ad medium usque vaginato-foliato, vaginis striatis, inferioribus scabris; foliis duobus tribus linearibus, canaliculatis, laevibus, scapum subaequantibus; spathae 
hivalvis persistentis phyllis lanceolato-subulatis, inferiore unbella breviore, superiore longiore; umbella multiflora; pediolis longitudine variis divaricato-patulis; perigonii suburceolati lntei plyllis oblongis obusiuscnlis; filamentis imo perigonio inscrtis, compresso-linearihus, cuspidatis phyllorum longitudinem dimidio superantibus, parte exserta jurpurco-violaceis; antheris peltatis; stylo stamina superante; capsulis obcordato-triquetris, exsiccatione reticulatis, perigonium vis superantibus; seminibus membranaceis semiovatis nigris.

Species perigonii et filamentorun: colore pulcherrima.

Ilab. Crescit in lapidosis alpinis Olympi bith. latere N. E. ubi legi die 14 Aug. 1850.

Alinu ofympicum Bosss. ! Diagn. Pl. Orient. V. p. 58.

liab. In Olympi bith. regione abietis crescit et floret Augusto.

0bs. Species $A$. montano Siвтн. affinis. Tota planta gracillima. Bulbi parvi. Folia et spatha livalvis longissima linearia. Pedioli longitudine varii. Perigonii foliola exteriora laete purpurascentia, interiora albidoscariosa.

\section{Alliey MaRgaritaceum SibTh.}

Ilab. Floret Augusto mense in collibus brussianis ad Demerdesch, nec non in regione subalpina Olympi bith.

0bs. Planta quam colligimus bulbos parvos tunicis argenteo-scariosis vestitos praebet. Folia extant duo vel tria linearia culıno elato breviora. Umbella ovoideo-globosa; pedunculi subaequales, centrales sursum elati densi, exteriores laxiusculi. Flores parvi, phyllis lineari-oblongis, obtusiusculis, scarioso-argenteis, carina vix viridescenti. Filamenta profunde bificla, laciniis lateralibus capillaceis, crispulis, intermedia breviori plus minusve latiori, decidue antherifera. Stylus linearis capsula oblongata acnte-triquetra perigonium aequante triplo brevior.

Planta solitaria, splendore argenteo fulgens quasi luxurians.

\section{O L C H I C A C E A E.}

\section{Colchicum variegatum $\mathbf{L}$.}

llab. Legi speciem performosam in summa regione montis Parnis. Floret aestate decedente et autumno. 
Perigonium maximum campanulatum, variegato-reticulatum, colore purpureo-roseo laeto praeditum.

Colchicey yontaxcy L.

hab. Cum praecedente.

\section{Merendera attica Boiss.!}

Hab. Ad radices montis Cabeti prope Athenas, ipso in loco in quo a cl. Boissierio primum detecta, hanc pulcherrimam plantam legi vere.

\section{J U N G E A E.}

Juncus Capitatus Weigl. - Косн. Syn. ed. 2. p. 841.

Hab. Speciem perpusillam locis humentibus collinis prope Byzantium una vice legi aestate.

Juncus striatus Griseb. Fl. rum. 2. p. 407 an Schousb. ?

Hab. In Olympo bith.

0bs. Synonimon Flor. rumelicae mihi vix dubium, sed planta Olympi collata cum descriptione $J$. striati in Schuctesu Systemate 7. p. 205 notis nonnullis discrepat; nempe foliis non adproximatis, vaginis culmum ex integro non vestientibus; involucro capitulo saepius longiore.

Junces glauces ErhN.

Hab. In Attica ad Kiephyssum flumen.

Luzula canpestris Desv.

Hab. Circa Byzantium.

\section{Y P E R A C E AE.}

Carex glauca Scop.

Hab. In Olympo bith.

Crperus badius Desf.

Ciperus flavescens L.

Cyperus fuscus $\mathrm{L}$.

Hab. Promiscue crescunt in udis planitiei superior. .atheniens. 
Scippus setaceus $L$.

Hab. In Olympo bith. ad rivulos subalpinos lente fluentes.

Scirpus palustris L.

Scikpus HoLOSCHOENUS L.

Hab. In agro byzantino.

Schoenus Nigricans $L$.

Hab. In Attica.

\section{G R A II N A C E A E.}

\section{Saccharum Ravennae L.}

Hab. In planitie humidiori atheniense, aestate.

0bs. Insigniter glaucnm; caeterum a specie nulla nota diversum.

Andropogon pubescens Vis. Pl. rar. dalm. p. 3.

Hab. Augusti mense specimina corcyrensia, vere atheniensia legi.

0bs. Specimina in saxosis agri atheniensis lecta cum stirpe dalmatica apprime quadrant; caespites tamen majores et magis contractos pruinososque sistunt. E contra specimina quae in Corcyra legi, sunt minus caespitosa minusque pruinosa; spicae magis pubescentes cum tota planta grandiores.

\section{Andropogon Grillus L.}

Hab. Circa Byzantium.

\section{Phalaris canariensis $L$.}

Hab. Legi aestate ad vias circa Scutarim asiaticum ubi sponte crescere videtur.

\section{Polypogon Monspeliensis Desf.}

Hab. Circa Byzantium.

Lagurus ovatus L.

Hab. In Hymetto merid.

Alopecurus vaginatus Pall. ex Kunth Agrostogr. 1. p. 25 . $-A$. angustifolius Sy. 
Ilab. Crescit in regione alpina Olympi hith., ibique limites regetationis $A$. lanati exacte signat. Legi Aug. mense.

0bs. Folia caulina abbreviato-linguiformia convoluto-subulata, potius quam linearia (Fl. runel.) in nostris speciminibus adnotantur. Vaginae admodum inflatae et elongatae sunt. Mucrones glumarum haud breves et paleae inclusae ut in $A$. lanato. Spica villosissima sed minus canescens quam in illo.

Alopecuncs laxatus S.r. Kunth. Agrost. I. p. 25.

Hab. Crescit in declivitatibus calcareis cacuminis Olympi bith. ad stationem usque praecedentis speciei descendens, sed non infra. Floret Angusto.

0bs. Graminacearum stirps insignis; foliis more compositarum nonnullarum constanterque niveo-lanatis!

\section{Alopecunds agrestis L.}

Hab. Circa Scutarim asiaticum.

\section{Pilleum arenarium L.}

Hab. In monte Hymetto atheniense crescit, statura minima, foliisque tenuibus. Legi aestate.

\section{Pilleum tenue Schreb.}

Hab. In agro byzantino observavi.

Calamagrostis olympica Boiss. Diagn. 5. p. 70. - Griseb. Fl. rumel. 2. P. 459 .

Hab. In pascuis editioribus Olympi bithynici.

Valvulae subaequales, uninerves, laete purpurascentes, punctato-pellucidae. Palea inferior tenuiter membranacea, superiore vix longior, apice 4-dentata, 5-nervis!; nervo medio supra basim in aristam flosculo longiorem exeunte; caeteris, quorum exteriores validiores! ultra dentes apicis paleae ipsius productis, et inde palea subsimplici lente 2-aristulata.

Caetera ut in diagnosi clarissimi Borssier species insignis !

Agrostis velgaris Wither.

Hab. Circa Byzantium. 
Agrostis verticillata Vill.

Ilab. Ad pedes Pentilici atheniens.

Aelocarpus litoralis Parlat.

Hab. Circa Kalamati ad isthmum Corinthi.

Digitaria sanguivalis Pers.

Hab. In Attica ad Kiephyssum.

Cynodon Dactylon Rich.

Hab. In Attica et circa Scutarim.

Panicum Crus Galli L.

Hab. In Attica ad Kiephyssum.

\section{Milium Lendigerum L.}

IIab. In collibus byzantinis crescit aestate, et tantum caulibus paniculisque brevioribus a planta italica divergit.

\section{Miljum coerulescens Desf.}

Milium nultiflorum $C_{\text {av. }}$.

Ilab. Reperi primum hand frequens in monte Hymetto; alterum abunde crescit prope Kiessariany aliisque locis atheniensis planitiei. Florent aestate.

\section{Holcus lanatus $L$.}

llab. In agro byzantitio floret vere et aestate.

\section{Holcus haLepensis L.}

Hab. In Attica ad Kiephyssum.

\section{Briza maxima L.}

BRIZA MEDIA L.

llab. In Olympo bithynico ambae reperiuntur europeaeis omnino similes, sed statura paullo minores.

\section{Catabrosa variegata Boiss.}

llab. Legi in pascuis sterilibus alpinis Olympi bith. Augusto.

0bs. Gramen humile, panicula pauciflora, pedunculis patentibus vel reflexis, glumis purpureo-sanguineis. 
Catamosa minuta Trix.

Hab. In editioribus Olympi bithynici! Augusto.

0bs. Collata cum speciminibus Catabrosae minutae ex Europa australiori et Africa boreali, nulla nota differre videtur. Species a Sигтню circa Byzantium, a Buxbaumo in Thracia ex Fl. rumelica jam nunc observata, sed a recentioribus ut videtur practervisa.

\section{Poa alpiNa L.}

Ilab. In Olympi bith. pratis editioribus.

0bs. Variat flosculis basi undique piloso-sericeis, paniculae ramis non semper geminatis; stipulis omnibus longinsculis; foliis latis abbreviatis.

\section{Poa nemoralis L.}

Hab. In eodem monte, sed locis humilioribus.

PoA Rigida L.

Poa bulbosa L.

POA ANNA pumila.

Hab. Omnes reperiuntur in agro Byzantino.

Glyceria maritima Mert. et Косн.

Hab. Legi aestate vertente in collibus constantinopolitanis.

obs. Suberecta, vix glaucescens, paniculae rami erectiuscnli haud patuli; palea inferiori tenuiter 5-nervia.

Dactilis hispanica Roth.

Hab. In collibus sterilibus circa Byzantium crescit, ubi nonnullae aliae hispanicae stirpes, forma quidquam mutata, occurrunt. Legi aestate.

\section{Cryostrus ecinnatus L.}

Criosercs elegans Desf.

Hab. Utramque speciem in Hymetto meridionali, Julio vertente, legi.

Festuca pungens R. et S.

Ilab. Legi in regione alpina Olympi bith. locis sterilioribus.

ols. Planta Olympica foliis rigidissimis crassissimis junceis caeterisque Festucae pungentis gaudet, et a $F$. glauca Scrran. distinguendam esse existimo. Qui vero Festucam glaucam, duriusculam, cum F. ovina LinNaeI conjungunt profecto errant. 
VULPIA Myurus $\mathrm{L}_{K}$.

Vulpia cillata $\mathrm{L}_{K}$.

Hab. In pascuis collinis siccioribus circa Byzantium.

STIPA tortilis Desf.

Hab. In Hymetto meridionali.

Aristella bromoides Bertol. Fl. ital. I. p. 69o. - Stipa aristella L. - Alr. Auct. tab. 2. fig. 4.

llab. In monte Parnis atheniensi legi autumno.

0bs. Collecta cum speciminibus siculis et ligusticis nulla nota essentiali differt! Genns Aristella a cl. Bertolonto in Fl. ital. conditum pro hac a reliquis Stiparum speciebus tum habitu, cum characteribus desciscente, libenter amplectendum esse concedimus.

\section{Brachyodum ramosum Roem. et Schult.}

Hab. Legi in monte Hymetto ab thenis non longe.

0bs. A reliquis generis speciebus, culmis repetite ramosis, ramisque adpressis subfastigiatis, foliomm convolutorum distiche patentium tenuitate et rigiditate distinctum. Folia superiori pagina sub vitro dense hispidula. Locustae in speciminibus nostris 6-7-floris, flosculis adproximatis ; palea inferior arista brevissima rigidula mucronata.

Braciypodum pinnatum $\gamma$. coespitosum Косн. Syn. p. 944.

Hab. In collibus byzantinis.

Huc forte ducendum Brachypodium ramosum Fl. rumelicae.

Bromus intermedius Guss.

llab. In inonte Hymetto atheniensi legi aestate. Iariat racemo siripliciusculo paucifloro, foliis et culınis minus pilosis.

\section{Bromus erectus L.}

Hab. In Olympo bithyrico. Spicae compressae et magis laxae quam in stirpe italica.

Gaudinia fragilis P. B.

Hab. Crescit in pascuis siccis constantinopolitanis, cui loco et cl. Grisebach refert. 
Spicae articulationes multo minus fragiles quam in stirpe italica observantur. Floret aestate.

T'riticum glaucum Desf.

Triticun Repens L.

Hah. In aggeribus sterilioribus ad Bosphorum frequenter occurrunt aestate.

\section{Elymus crinitus Schrb.}

Hab. Legi in collibus byzantinis vere decedente et in m. Hymetto.

0bs. In speciminibus byzantinis a me observatis, characteres speciei paullo aliter se praebent quam in planta a cl. Grisebachio descripta; folia nempe lineari-setacea, convoluta, facie glabrata! Spicae retrorsum valde scabrae. Species aliunde pro loco maxime variabilis, et revera in monte Hymetto atheniensi ipsius speciei complura exemplaria inveni, quae fructu maturescente spicas omnino glabras et folia multo latiora praebent.

\section{HoRdeug Distichum L.}

Hab. Prope Katikioi (Chalcedonia) ad agrorum margines aestate.

Statura plus quam orgyalis; spica abbreviata; radix minus quam in sequenti specie bulbosa.

\section{Hordeum bulbosum $L$.}

Hab. In cultis locisque apricis byzantinis.

\section{Secale villosa L.}

Hab. Ultra Scutarim.

LOLIUM PERENNe L. varietas.

Hab. Legi in siccioribus locis collinis circa Byzantium.

obs. Haec ubique pervariabilis species, illa regione formam contractam, caules adscendenti-tortuosos, duros, spicas abbreviatas offert.

Aegilops Nótanisı mihi.

AE. Spica oblonga, valvulis spicularum inferiorum fertilium bifidis, segmento antico dentiformi, postico in aristam valvulis ipsis plus duplo longiorem producto; valvulis spiculae terminalis sterilis integris, angustis, subulato-aristatis, spicam longitndine superantibus; palea inferiore acute. bicuspidata, 
IIab. Crescit rara in sylvulis collinis circa Ciamlicia ultra Scutarim asiaticum. Legi die 25 Junio $\mathbf{8 5 0 .}$

Planta caespitosa. Radix fibrosa, annua? Culni geniculati, striatosulcati, geniculis badiis. Vaginae laeviter inflatae merithallos ultra medium amplectentes. Folia linearia subinvoluta, vaginis dimidio breviora, pilis rigidulis patulis adspersa, superiora nuda; omnia ad vaginarum fancem utrinque auriculata, auriculis nervosis, inflexis, albidis; ligulae abbreviatae, truncato-lacerae. Rachidis haud fragilis articuli inferiores 2, 3, abbreviati steriles. Spiculae plerumque 3: inferiores adpressae ventricosae 3-4-florae, flore supremo abortiente: terminalis sterilis. Valvulae nervosae bifidae, segmento antico ovato, ovatove-lanceolato, postico angustiore, in aristam 2-3-nerviarn scaberrimam rigidam attenuato. Valvulae spiculae terminalis tabescentis integrae, e basi lanceolata sensim subulatoaristatae spica longiores. Paleae subchartaceae, harum inferior 5-nervis ex apice contracto longe bidentatae. Caryopsis cymbiformis carina bicostata, superne marginato-coronata, barbataque.

0ls. Facies Aegilopsis caudatae L. (Ae. cylindrica Host. Gram. austr. 2. tab. 7.), sed palearum inferiorum forma ab illa prae ceteris diversa.

\section{Aegilops tricncialis L. - Kuntu Agrost. i. p. 458.} state floret.

llab. Abunde crescit in herbidis collinis prope Byzantium. Tota ae-

0bs. Formam caespitosam et staturam humilem praebet. Arista intermedia longitudine summe variat; quandoque, etian in glumis inferioribus, laterales aequat, rarissime deest; quo charactere a specie Linneana divergit.

Avena fatua L.

Hab. Circa Scutarim.

Psiluncs Nardoides $T_{\text {rin. }}$

Hab. In declivitatibus collinis sterilioribus prope Byzantium haud frequens reperitur. Legi quoque, sed perpusillum, in monte Hymetto atheniense.

Rotrboella incurvata $L$. fil.

Hab. In sterilibus constantinopolitanis crescit aestate. 
Naridus aristata $L$.

Hab. In pascuis editioribus Olympi bith. crescit, sed minus frequens quam in nostris regionibus. Floret tota aestate.

Schismus marginatus P. Brauv.

Hab. In collibus atheniensibus, circa Philopappi monumentum legi.

\section{F I L I C E S.}

Cheilanthes odora Swartz.

llab. Inter saxa montis Hymetti atheniensis haud raram et minus furfuraceam quam planta dalmatica reperi.

Nothoclaena lanuginosa Desv.

Hab. Filix perelegans et rupium fissuras prope Piraeum athen. rarissime incola. Legi Martio mense fructificatione adhuc carente.

Ceterac officinarum $W$.

Hab. In monte Parnis atheniens.

Asplenium Trichomanes L.

Adiantum capillos L.

Hab. In monte Pentilico ath. ad rupium fissuras humentes. 


\section{ICONUM EXPLANATIO}

\section{TAB. I. - Ranunculus Canozzianus.}

a. Torus et carpophorus, staminibus duobus et carpella praediti, cum sequentibus multoties aucti ; $b$. carpella; $c$. syncarpus; $d$. petalum; $e$. calyx quinquesepalus.

\section{TAB. II. - Dianthus Cibrarius.}

a. Ramulus e caespite decerptus; $b$. caulis fistulosi sectio, cum sequentibus multoties aucta; $c$. folii inferioris summitas; $d$. calyx bracteis circumdatus; $e$. bracteae calycinae magis auctae; $f$. stamina cum pistillo et petalo.

\section{TAB. III. Fig. 1. - Asphodeline Morisiana.}

a. Flos duplo auctus, bracteatus, perigonio sexpartito, stigmate trilobo; $b$. anthera fertilis cum sequente quadruplo aucta; $c$. anthera sterilis; $d$. capsulae pars plus quam duplo aucta; $e$. semen quadruplo auctum.

\section{Fig. 2. - Polygonum Venantunum.}

$f$. Flos triplo auctus et sectus ut stamina quinque pateant; $g$. semen triplo auctum, tricostatum, costis rolundato-obtusis.

\section{TAB. IV. Fig. 1. - Lamium Manganottianum.}

a. Forma L. reniformis Bentr., licet foliis reniformibus, caule gracillimo, farcto; b. forma ad L. bilhymicum BeNTH. vergens, foliis minus reniformibus, caule fistuloso; c. forma ad L. strialum Sıвтн. vergens, foliis magis magisque cordato-oblongis, omnibus partibus magis evolutis.

\section{Fig. 2. - Cheinanthus Jacomellit.}

$d$ Siliquae pars superior cum stylo et stigmate duplo aucra; $e$. pilus bifurcatus fere in tota planta sparsus, octuplo auctus; $f$. semen duplo auctum, cotyledonibus accumbentibus; $g$. seminis sectio transversalis.

\section{TAB. V. Fig. 1. - Egilops Notanisiz.}

a Valvula sesquidiametro aucta; $b$. palea inferior sesquidiametro aucta; $c$. Palea superior sesquidiametro aucta; $d$. cariopsis e dorso visa et duplo aucta ; e. cariopsis e facie visa.

\section{Fig. 2. - Tunica Orfanidesiana.}

f. Bractea ex interioribus, cum sequentibus sesquidiametro aucta; $g$. bractea ex exterioribus; $h$. calyx quinquefidus; $I$. petalum; $m$. valva; $n$. valva extrema maturitate apice truncata. 
TAB. VI. Fig. 1. - Сichorium Byzintinum.

a. Capitulum duplo auclum, ligulis anthodium vix superantibus; $b$, achenium triplo auctum et a dorso glabro visum; $c$. achenium a facie costata transverse rugulosa visum.

Fig. 2. - Anthems Sismondaeana.

(Clar. $^{\text {mo }}$ Eugenio Sismonda Hist. Nat. Prof. et Palaeontolog. cullori dicata).

d. Receptaculum sectum cum sequentibus duplo auctum; e. paleae; $f$. achenium radii ; $g$. achenium disci excentricum; $h$. achenium disci centrale.

TAB. ViI. Fig. 1. - Trifolium Meneghinianum.

a. Flos, ex sicco, magnitudine triplo auctus; $b$. calyx magnitudine sextuplo auctus.

Fig. 2. - Trifolium Petrisavil.

c. Flos, ex sicco, magnitudine quadruplo auctus; $d$. calyx magnitudine sextuplo auctus; $e$. semen magnitudine quintuplo auctus.

\section{TAB. VIIL. Fig. 1. - Allium Webil.}

a. Flos duplo auctus; $b$. perigonii phyllum cum stamine tripla magnitudine auctum; $c$. capsula dupla magnitudine aucta; $a$. semen dupla magnitudine auctum.

Fig. 2. - Potentilla Buccoana.

e. Receptaculum columnare! dupla magnitudine auctum. 


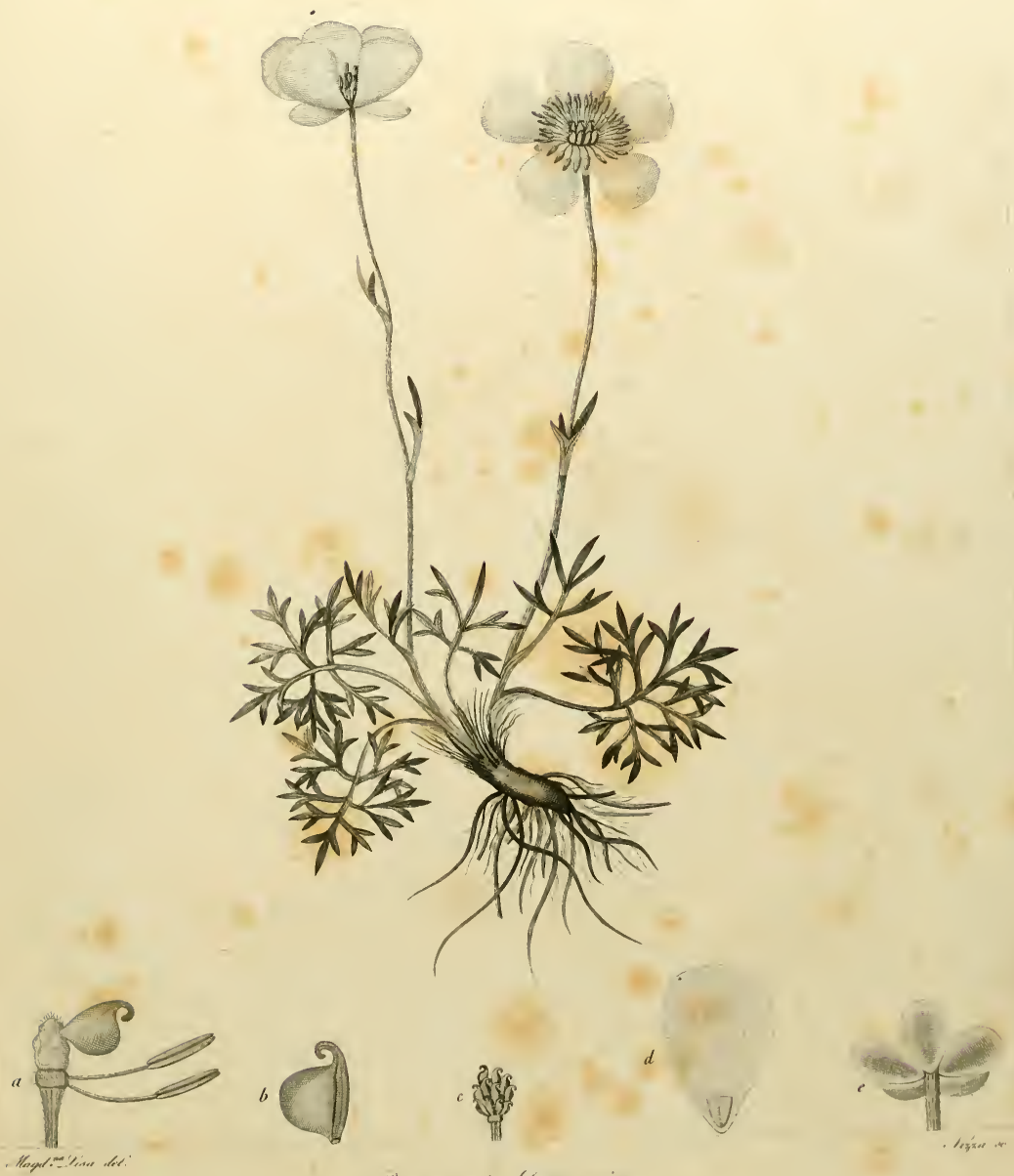

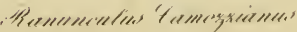




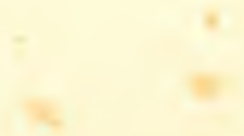

(n)

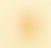

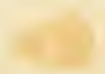

$\sqrt{2}+x^{2}$ 


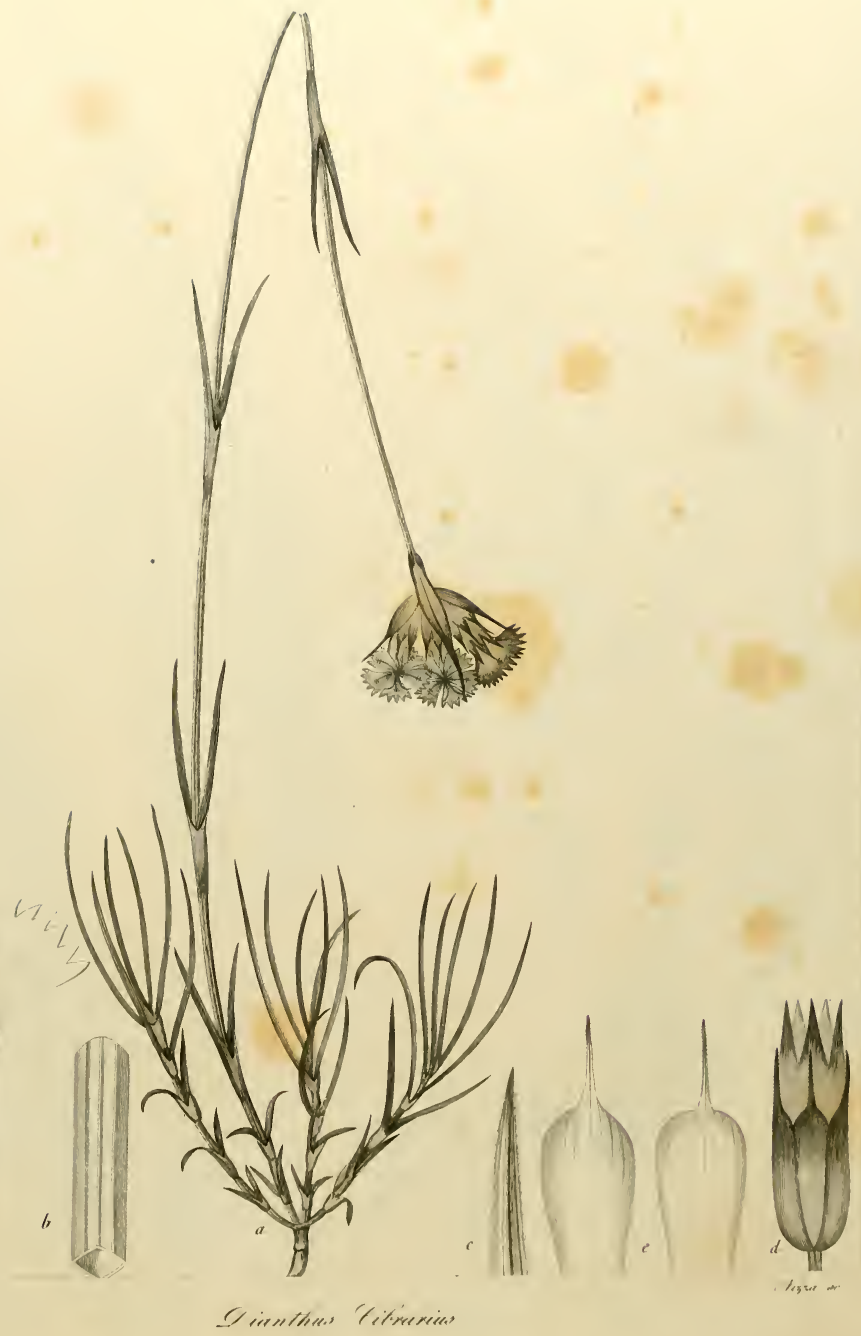





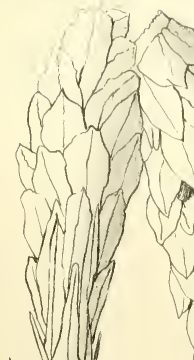

$1 \sqrt{ }$

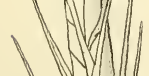

NyNa $1 / N$
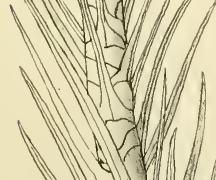

14

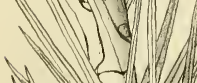

1

1. $1.1-1$

(1)

$$
12
$$

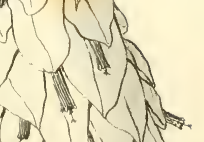

(1) ?

WN $\sqrt{ }$

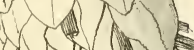

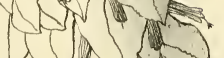
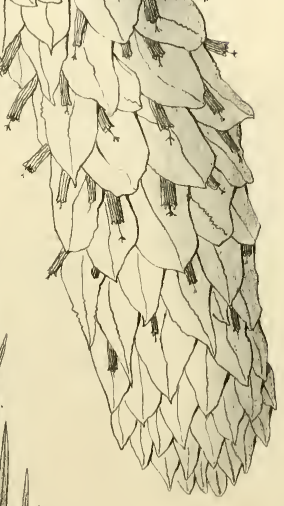

Fig.1.

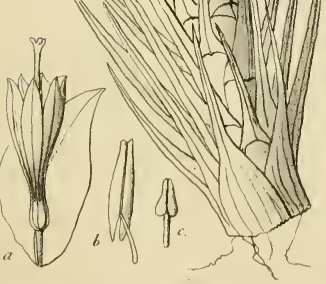

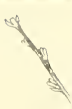

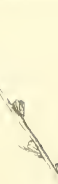

औ

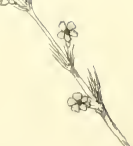

क्यै कै
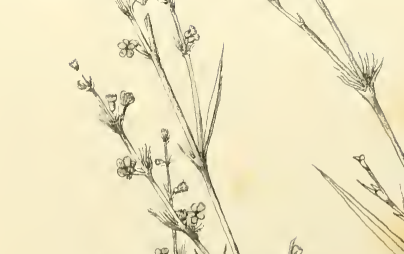

\&.
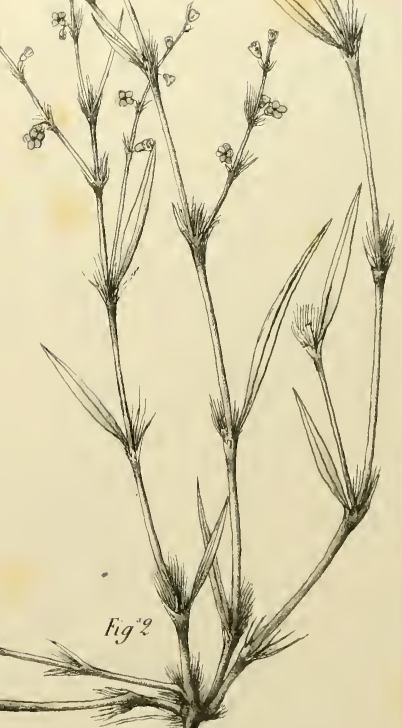

(10). P. P 1

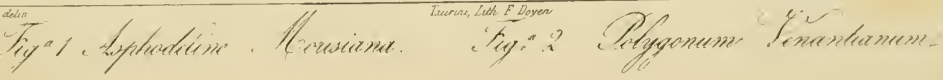





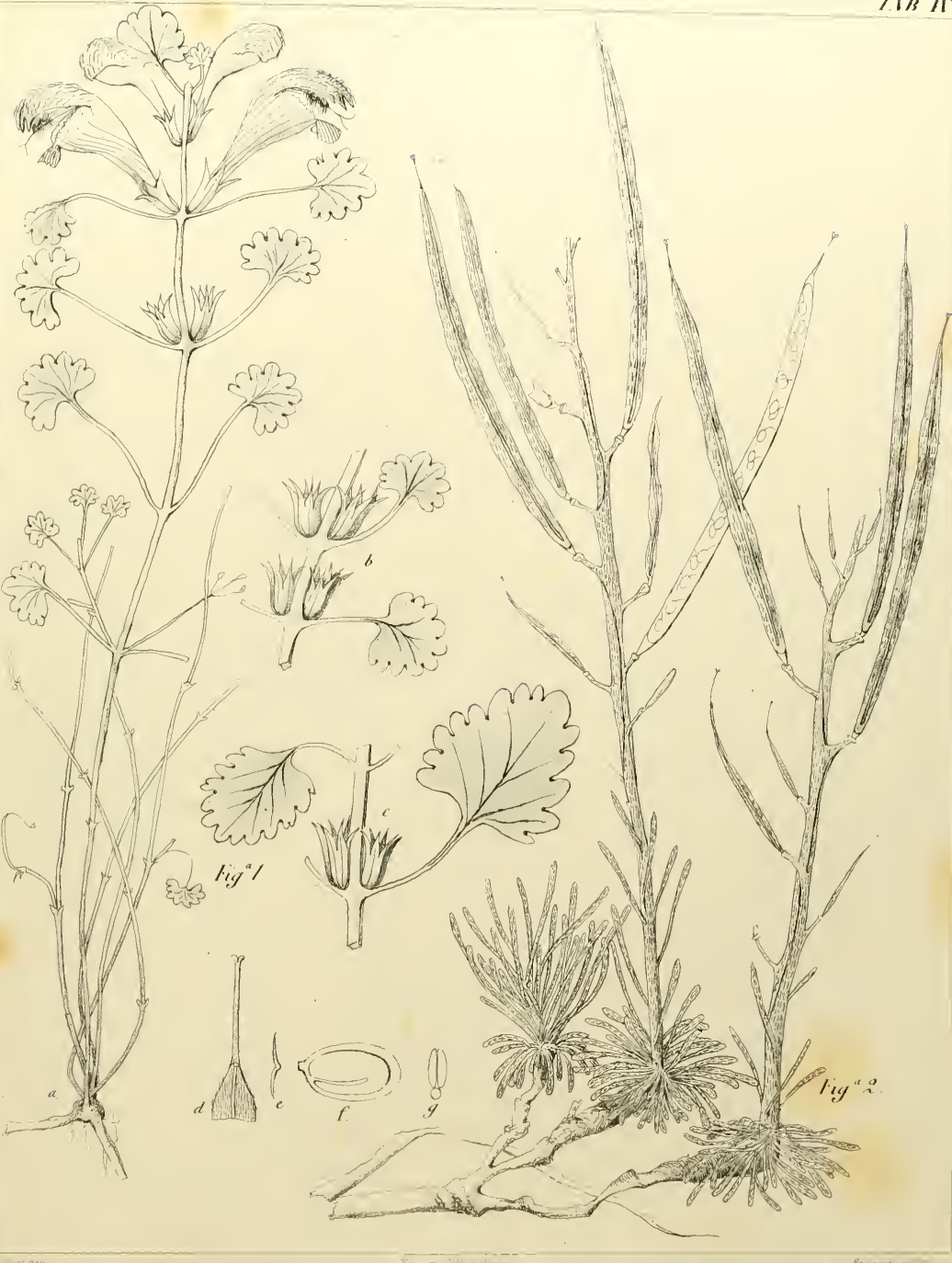

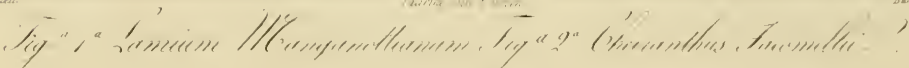



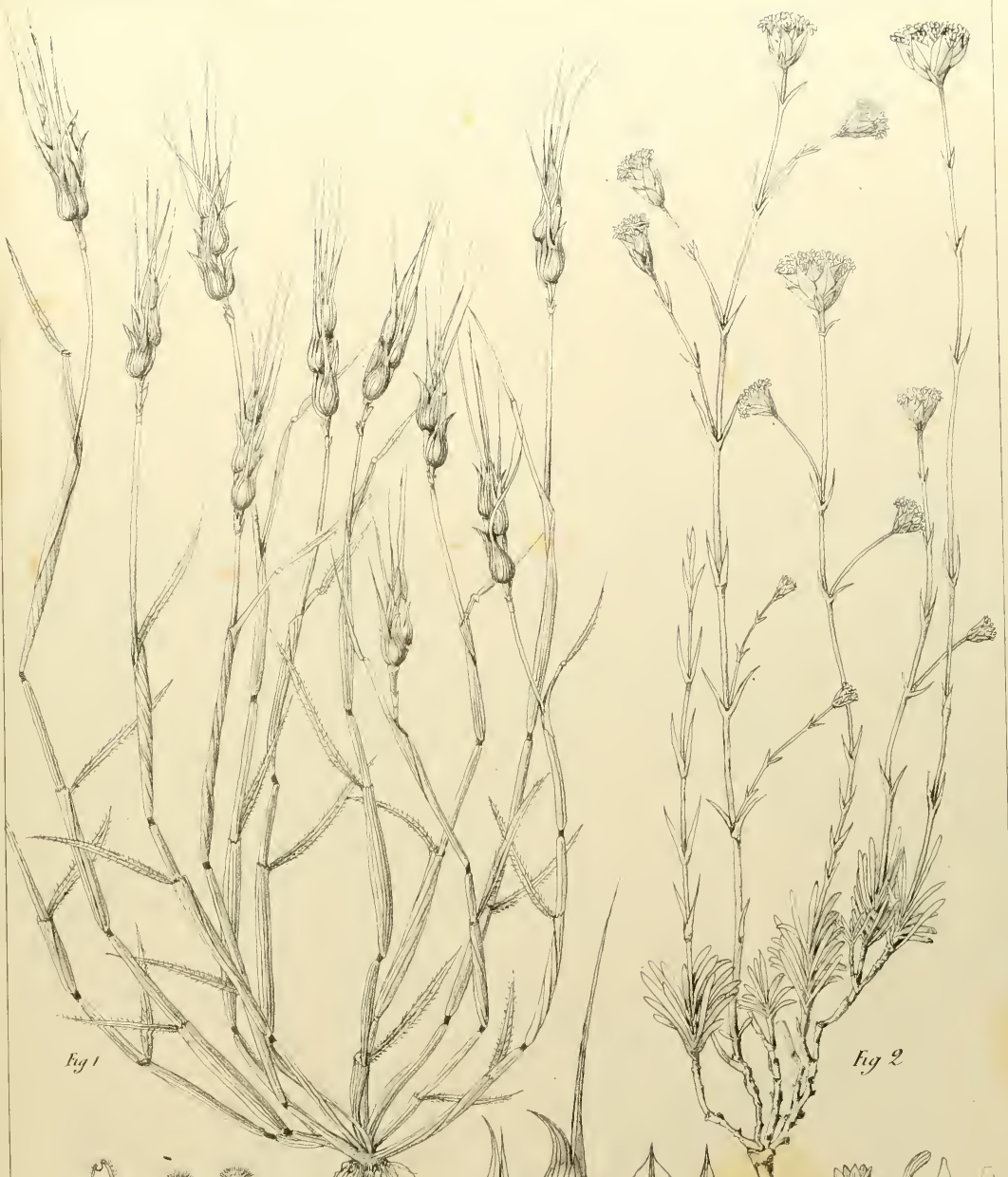



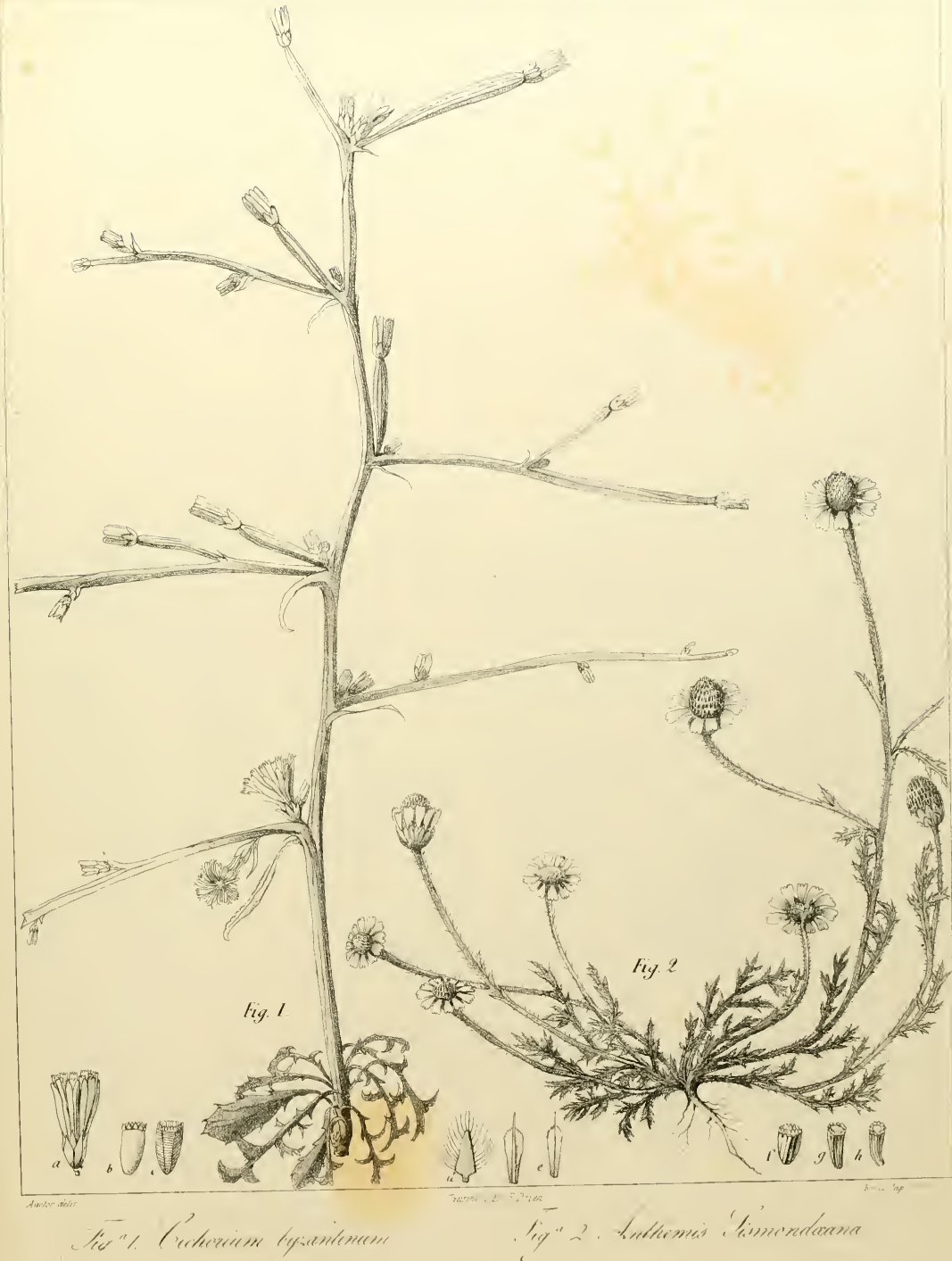




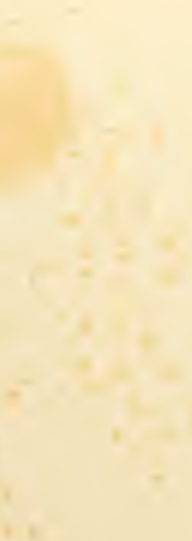





\section{.}



